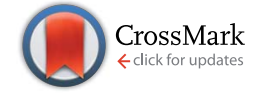

Cite this: Energy Environ. Sci., 2014, 7, 3192

\title{
Hierarchical electrospun nanofibers for energy harvesting, production and environmental remediation
}

\author{
Palaniswamy Suresh Kumar, $\uparrow^{\star a b}$ Jayaraman Sundaramurthy,,$^{\star a b}$ \\ Subramanian Sundarrajan, $\uparrow^{c}$ Veluru Jagadeesh Babu, $\uparrow^{d}$ Gurdev Singh, ${ }^{\text {b }}$ \\ Suleyman I. Allakhverdiev ${ }^{\text {ef }}$ and Seeram Ramakrishna*ac
}

As the demand for energy is rapidly growing worldwide ahead of energy supply, there is an impulse need to develop alternative energy-harvesting technologies to sustain economic growth. Due to their unique optical and electrical properties, one-dimensional (1D) electrospun nanostructured materials are attractive for the construction of active energy harvesting devices such as photovoltaics, photocatalysts, hydrogen energy generators, and fuel cells. 1D nanostructures produced from electrospinning possess high chemical reactivity, high surface area, low density, as well as improved light absorption and dye adsorption compared to their bulk counterparts. So, research has been focused on the synthesis of 1D nanostructured fibers made from metal oxides, composites, dopants and surface modification. Furthermore, fine tuning these NFs has facilitated fast charge transfer and efficient charge separation for improved light absorption in photocatalytic and photovoltaic properties. The recent trend in exploring these electrospun nanostructures has been promising in-terms of reducing costs and enhancing the efficiency compared to conventional materials. This review article presents the synthesis of 1D nanostructured fibers made via electrospinning and their applications in photovoltaics, photocatalysis, hydrogen energy harvesting and fuel cells. The current challenges and future perspectives for electrospun nanomaterials are also reviewed.

Received 21st February 2014

Accepted 23rd June 2014

DOI: $10.1039 / c 4 e e 00612 g$

www.rsc.org/ees

\section{Broader context}

In recent years, the world has been facing enormous challenges such as increasing energy demands, depleting power sources, and environmental pollution. In order to overcome these challenges, much attention has been focused on creating new hierarchical nanostructured materials and technologies for the adoption of cleaner solutions and renewable sources of energy. Although, various methods such as precipitation, hydrothermal and sol-gel have been adapted to synthesis novel nanostructures, electrospinning is one of the simplest and most effective technologies with scale-up potential for a wide range of nanomaterials aimed at industrial production. This review highlights recent developments in the fabrication of one dimensional nanostructured fibers from metals, metal oxides, carbon nanofibers, nanocomposite materials and so on, using electrospinning techniques. These electrospun nanomaterials exhibited enhancement in performance compared to conventional materials. In this review, we attempt to provide a detailed overview of such nanostructured materials in specific applications such as photovoltaics, photocatalysis, hydrogen generation and fuel cells. We believe that this review will provide sufficient background information and knowledge about electrospinning and pave the way for new innovations in electrospun nanomaterials for energy and environmental applications.

${ }^{a}$ Center for Nanofibers and Nanotechnology, National University of Singapore, 117576, Singapore.E-mail: seeram@nus.edu.sg; sureshinphy@yahoo.com; sundaram1304@ gmail.com; sundarnus1@gmail.com; vjbabu2002@gmail.com

${ }^{b}$ Environmental \& Water Technology, Centre of Innovation, Ngee Ann Polytechnic, Singapore

${ }^{c}$ Department of Mechanical Engineering, National University of Singapore, 117576, Singapore

${ }^{d}$ UNAM-National Nanotechnology Research Center, Bilkent University, Ankara-06800, Turkey

${ }^{e}$ Institute of Plant Physiology, Russian Academy of Sciences, Botanicheskaya Street 35, Moscow 127276, Russia

${ }^{f}$ Institute of Basic Biological Problems, Russian Academy of Sciences, Pushchino, Moscow Region 142290, Russia

$\dagger$ These authors have contributed equally.

\section{Introduction}

In recent years, the world has been facing enormous challenges in energy demands, depleting power sources, and environmental pollution. The demand for energy is rapidly increasing. The total primary energy production of the world was $1.02 \times 10^{5}$ TW h in 1990 and $1.49 \times 10^{5}$ TW h in 2010 and extrapolated statistics indicate these figures will be around $1.81 \times 10^{5} \mathrm{TW} \mathrm{h}$ in $2020,2.11 \times 10^{5}$ TW h in 2030 and $2.25 \times 10^{5}$ TW h in 2035, with an average annual percentage change of $1.6 \%{ }^{1-4}$ In last few decades, there has been increasing concern about global warming due to the emission of greenhouse gases, which has received attention from governments across the globe and 
resulted in the alteration of energy policies and strategies. Hence, it is important to reduce our dependence on fossil fuels by augmenting them with supplies from cleaner, renewable sources of energy. In order to overcome these challenges, researchers have worked to create new functional nanomaterials and technologies. Although these emerging energy technologies are significantly important for meeting existing energy demands, new breakthroughs are needed to improve their performance. Nanostructure materials possessing high surface areas, which are significantly larger than that of the bulk materials have received extensive attention in recent years. Their nanosize improves the behaviour of the electrons being transported in nanostructures, in view of limiting the electron mean free path due to the quantum confinement effect. ${ }^{5-7}$ Hierarchical nanostructured materials have unique functional properties and have found fascinating applications in photonics devices (light emitting diodes, UV detectors), dye-

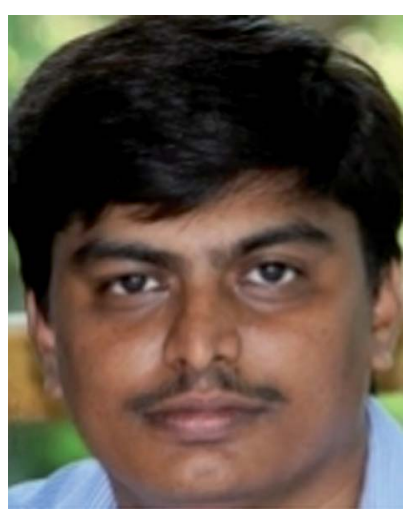

Dr Palaniswamy Suresh Kumar is currently working as a Research \& Development Scientist in the Environmental and Water Technology Centre of Innovation (EWT COI) at Ngee Ann Polytechnic, Singapore. Previously, he worked as a Research Fellow at the School of Materials Science and Engineering/Energy Research Institute@NTU (ERI@N), Nanyang Technological University and NUSCNN, National University of Singapore, Singapore (20102013). His main research interests include the synthesis and fabrication of $1 D$ nanorods, nanostructured thin film materials for smart coatings, as well as electrospun nanofibers for energy and the environment.

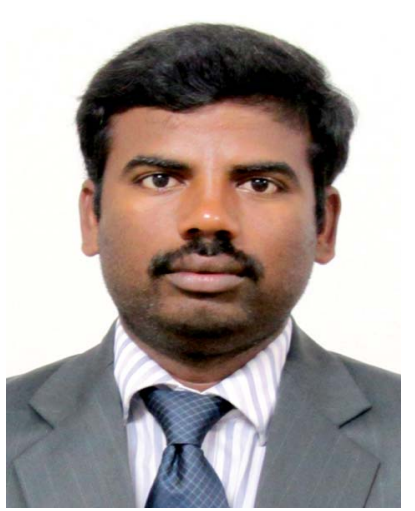

Dr Jayaraman Sundaramurthy is currently working as a Research \& Development Scientist in the Environmental and Water Technology Centre of Innovation (EWT COI) at Ngee Ann Polytechnic, Singapore. He completed his Master of Technology in Chemical Engineering at IIT Roorkee, India, and his Doctorate at the Department of Chemical \& Biomolecular Engineering, National University of Singapore. Previously, he worked as a post-doctoral fellow at NUS and NTU for 2 years. His research interests include molecular self assembly and thin films, supercritical fluids, fabrication of nanomaterials and organic-inorganic hybrid nanostructures, and applications related to energy and the environment. sensitized solar cells (DSSCs), batteries, fuel cells, water-splitting, ${ }^{8-11}$ as well as environmental (coatings, photocatalysis, air and water filtration) $)^{\mathbf{1 2 - 1 5}}$ and biological domains (drug delivery, tissue engineering). ${ }^{16,17}$ So far, various methods such as precipitation, ${ }^{18}$ solution, ${ }^{19}$ hydrothermal, ${ }^{20}$ template synthesis, ${ }^{21}$ sol-gel, ${ }^{22}$ successive ionic layer adsorption and reaction processes $^{23}$ have been adopted to synthesis different forms of nanostructure such as nanorods, nanotubes, nanowires, nanoflowers, etc. ${ }^{24-26}$ Among these methods, electrospinning is one of the simplest and most effective technologies for scaling-up a wide range of nanomaterials for industrial production. In recent years, great progress has been made in electrospinning with the controlled growth of novel electrospun NFs which have shown great potential in different fields such as energy storage $^{27}{ }^{2}$ sensors, ${ }^{28}$ water filtration ${ }^{29}$ and biomedicine/tissue engineering. ${ }^{30}$ Notwithstanding the economic recession, the value of the global nanofiber (NF) market increased from \$43.2

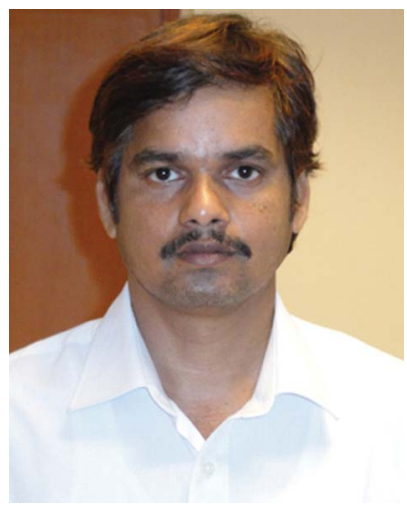

Dr. Subramanian Sundarrajan graduated with M.Sc. in Inorganic Chemistry from the University of Madras, India in 1996. Later, he joined in a research project at Indian Institute of Science, India till 1999. He was awarded one of the prestigious fellowships of India 'Senior Research Fellowship' by CSIR and received PhD degree from the University of Madras in 2003. He joined the National University of Singapore in 2003 where he is working on synthesis of polymers, electrospinning of nanofibers and nanoparticles for air, water, tissue engineering and fuel cell applications.

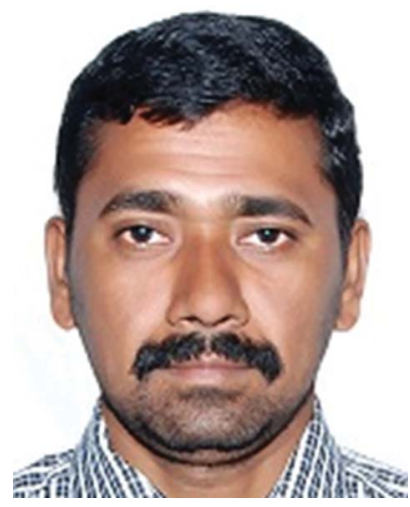

Dr V. Jagadeesh Babu is a visiting scientist fellow at the UNAM-National Nanotechnology Research Centre, Bilkent University, Ankara, Turkey. He completed his PhD from the department of physics, IIT Madras, India and subsequently become a research assistant till receive his $P h D$ degree (2009). He worked as a post-doc fellow at GIST, Gwangju, South Korea for about 6 months. Then he joined as research fellow at NUSCNN, National University of Singapore, Singapore. His research interests include the fabrication of nanostructured materials via electrospinning and their use in photocatalytic hydrogen generation by watersplitting and probing electrical charge transport in conducting polymers. 


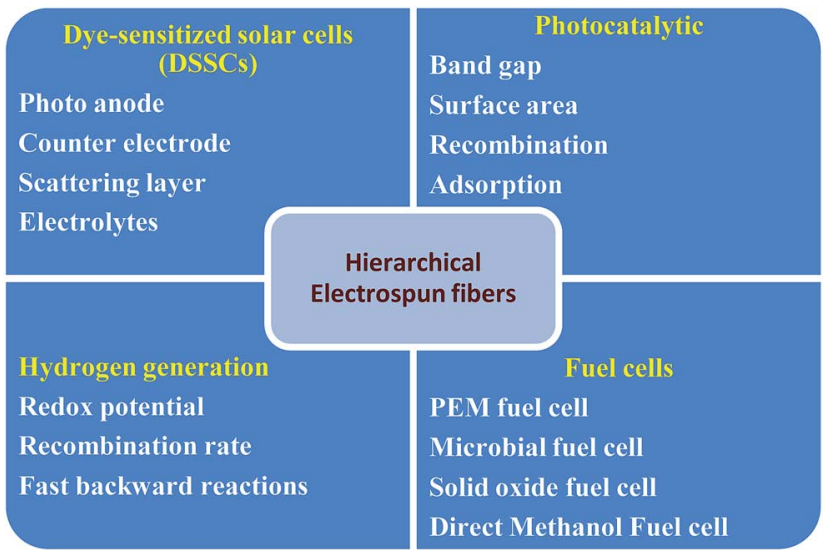

Fig. 1 Overview and simplified illustration showing the future and ongoing research works on hierarchical electrospun fibers for energy applications and environmental remediation.

million in 2006 to $\$ 101$ million in 2010 , and is projected to reach $\$ 2.2$ billion by $2020 .^{31,32}$ The categorization shown in Fig. 1 is a simplified illustration of future and ongoing research works on hierarchical electrospun fibers for energy applications and environmental remediation. This review combines this knowledge to stimulate further developments in electrospinning, demonstrate the potential of NFs with improved functionality and versatile hierarchical surface morphologies for energy harvesting, energy production and environmental applications and, finally, provide perspectives on the future of electrospun fibers.

\section{Electrospinning}

Electrospinning is an effective and simple method to fabricate nanomaterials with diameters ranging from tens of nanometers up to micrometers. The electrospinning technique was first developed in1934 for the synthesis of 1D materials and it has been demonstrated that a rich variety of materials can be electrospun to form uniform 1D materials, including polymers, inorganic and hybrid (organic-inorganic) composites. Ceramic NFs can be synthesized from electrospun organometallic NFs by heating in an oxidizing atmosphere. Metal NFs or nanowires can be produced by heating NFs that contain metal atoms in a reducing atmosphere. Hydrocarbon NFs such as polyacrylonitrile NFs can be converted to carbon NFs by low temperature oxidation followed by heating in an inert atmosphere.

Electrospinning generates ultrathin fibers from a few $\mathrm{nm}$ to few $\mu \mathrm{m}$ in diameter using a wide variety of materials that include metal oxides/ceramics ${ }^{33-36}$ such as $\mathrm{CuO}, \mathrm{Fe}_{2} \mathrm{O}_{3}, \mathrm{TiO}_{2}$ and NiO, mixed metal oxides such as $\mathrm{NiFe}_{2} \mathrm{O}_{4}, \mathrm{TiNb}_{2} \mathrm{O}_{7}$, and $\mathrm{LiMn}_{2} \mathrm{O}_{4},{ }^{37-39}$ composites $^{40-42}$ such as PVA/TiO ${ }_{2}$, carbon/ $\mathrm{SnO}_{2}$, graphene/TiO ${ }_{2}$, Nylon-6/gelatin, collagen/hydroxyapatite, and polymers ${ }^{43,44}$ such as polyvinylalcohol (PVA), polyacrylonitrile (PAN), polyvinylidene fluoride (PVDF), polyvinylpyrrolidone (PVP), polyethylene glycol (PEG), polystyrene (PS) and carbon based materials. Electrospinning with controlled calcination can provide a simple route to produce hierarchical nanostructures that are difficult to fabricate using other methods.

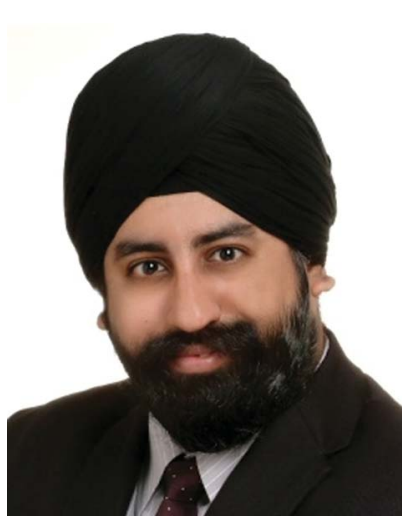

Dr Gurdev Singh is the Deputy Director of the Environmental and Water Technology Centre of Innovation at Ngee Ann Polytechnic, a nationally funded Centre that provides research, consultancy and technical services to the Industry. He concurrently also heads the Sustainable Development Technology Cluster at Ngee Ann Polytechnic, which comprises the School of Engineering, School of Life Science \& Chemical Technology, School of Design \& Environment and School of Information \& Communication Technology. He holds a PhD degree in Civil Engineering from the National University of Singapore and completed his post-doctoral training in Chemical Engineering at the Department of Chemical and Biomolecular Engineering, University of Ottawa, in Canada. His research interests are in energy, environment and water.

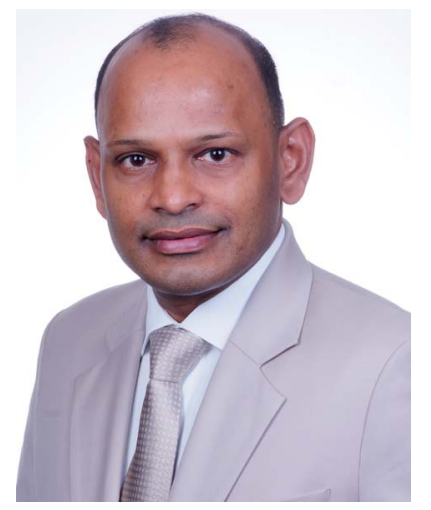

Prof $\mathrm{Dr}$ PE Seeram Ramakrishna, FREng, is the Director of Center for Nanofibers \& Nanotechnology at the National University of Singapore. He has authored 6 books and $\sim 600$ ISI listed journal papers, which have attracted $\sim 35000$ citations and has an $\mathrm{H}$-index of 86. He has been the recipient of the ASEAN Outstanding Engineering Award, NUS Outstanding University Researcher Award, Singapore Lee Kuan Yew Fellowship, India Cambridge Nehru Scholarship, Chandra P. Sharma Award, and Changjiang Professor \& High End Foreign Expert of China. He is a UNESCO expert on nanotechnologies. He is an elected international fellow of the Royal Academy of Engineering, UK; National Academy of Engineering, India; Institution of Engineers Singapore; ASEAN Academy of Engineering \& Technology; American Association of the Advancement of Science; ASM International; American Society for Mechanical Engineers; American Institute for Medical \& Biological Engineering; Institution of Mechanical Engineers, UK; and Institute of Materials, Minerals \& Mining, UK. 


\subsection{Basic principles of electrospinning}

The electrospinning technique is a unique approach using electrostatic forces to produce fine fibers from polymer solutions or melts and the fibers produced have thinner diameters (from the nanometer to micrometer scale) with larger surface areas than those obtained from conventional spinning processes. Various techniques such as electrostatic precipitation and pesticide spraying work in a similar fashion to the electrospinning process, which is mainly based on the principle that strong mutual electrical repulsive forces can overcome the weaker forces of surface tension in the charged polymer liquid. Basically, an electrospinning system consists of three major components: a high voltage power supply, a spinneret and a grounded collecting plate (usually a metal screen, plate, or rotating mandrel). It utilizes a high voltage source in order to inject a charge of a certain polarity into a polymer solution or melt, which is then accelerated towards a collector of opposite polarity. Typically, electrospinning techniques involve the use of a high voltage electrostatic potential $(\sim 5-30 \mathrm{kV})$ field to charge the surface of the polymer solution droplet and thus induce the ejection of a liquid jet through a spinneret (single, multi-spinneret or co-axial). ${ }^{32}$

In a typical process, an electrical potential is applied between a droplet of a polymer solution or melt, which is held at the end of a capillary tube, and a grounded target. When the applied electric field overcomes the surface tension of the droplet, a charged jet of polymer solution is ejected from the tip of the needle. The jet exhibits bending instabilities caused by repulsive forces between the carried charges. The jet extends through spiralling loops and the loops diameter increases as the jet grows longer and thinner and it then solidifies or collects on the target. These NFs have unique characteristics such as high surface-to-volume ratios and the ability to produce highly porous fibrous networks with excellent pore interconnectivity as well as having controllable fiber diameters, surface morphologies and fibrous structures..$^{\mathbf{4 3 4 5 , 4 6}}$ Electrospun NFs with a wide variety of morphologies including dense, ${ }^{47}$ hollow, ${ }^{48}$ and porous ${ }^{49}$ structures for specific applications have been obtained by changing the process parameters such as the electric potential, flow rate, polymer concentration, distance between the capillary and collection screen and ambient parameters. ${ }^{50}$ Fig. 2(a) shows a typical electrospinning set-up for random/ aligned NF synthesis.

\subsection{Coaxial electrospinning}

An important breakthrough in electrospinning was coaxial electrospinning in which a spinneret consisting of two coaxial capillaries is used with two viscous fluids (or a non-viscous liquid as a core and viscous fluid as a shell) form a core-shell compound jet in an electric field, which then solidifies to form core-shell fibers. Compared with other methods, it is an attractive, simple and effective top-down way to prepare coreshell ultrathin fibers with lengths of up to several centimeters on a large scale. It has been reported that polymer, organic, inorganic, and hybrid core-shell and hollow materials have been fabricated using this facile method. Among all of the

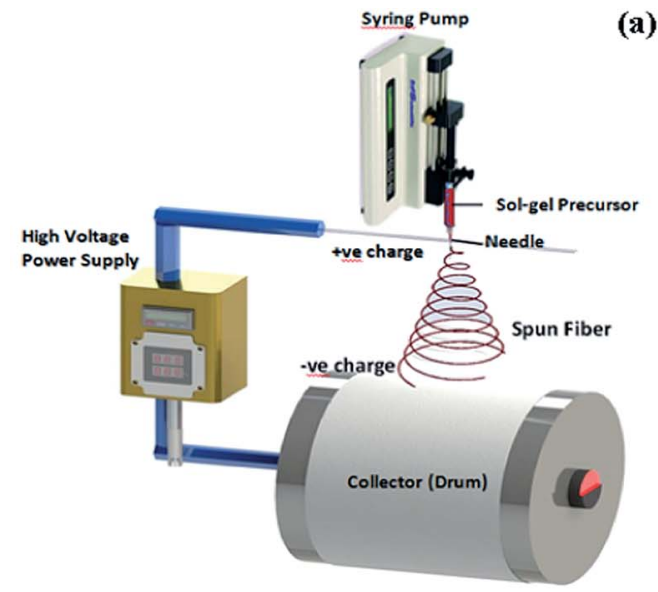

(a)

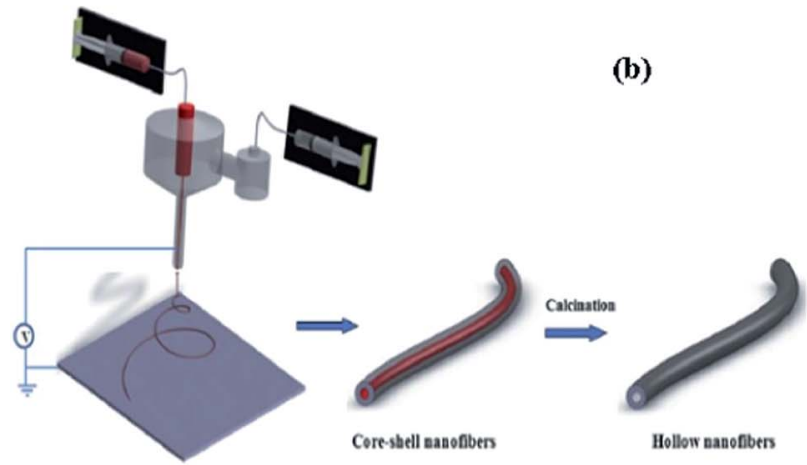

Fig. 2 Different types of electrospinning set-up for fiber production: (a) random/aligned fibers; (b) core-shell/hollow NFs. ${ }^{48}$

parameters, the immiscibility of the core and sheath liquids is most crucial to the formation of continuous and uniform hollow fibers. Hollow structures were observed after the polymers had been removed by solvent extraction or by calcination at an elevated temperature, although the core liquid was sufficiently viscous to be electrospun as fibers with diameters as thin as a few hundred nanometers. ${ }^{51}$ Fig. 2(b) shows the typical electrospinning set-up for core-shell NF synthesis.

The following parameters and processing variables affect the electrospinning process: (i) system parameters such as the molecular weight, molecular weight distribution and architecture of the polymers (like branched, linear, etc.), and polymer solution properties (such as the viscosity, conductivity, dielectric constant, surface tension, and charge carried by the spinning jet) and (ii) processing parameters such as the electric potential, flow rate, concentration, distance between the capillary and collection screen, ambient parameters (such as temperature, humidity and air velocity in the chamber) and, finally, motion of the target screen. For instance, the polymer solution must have a concentration high enough to cause polymer entanglements, yet not so high that the viscosity prevents polymer motion induced by the electric field. The solution must have a surface tension low enough with a charge density high enough and viscosity high enough to prevent the jet from collapsing into droplets before the solvent has 
evaporated. Morphological effects can occur upon decreasing the distance between the syringe needle and substrate. Increasing the distance or decreasing the electrical field decreases the bead density, regardless of the concentration of polymer in the solution. Moreover, applied fields can influence the morphology in periodic ways, creating a variety of new shapes on the surface. In addition to creating circular NFs, electrospinning of a polymer solution can produce thin fibers with a variety of cross-sectional shapes. ${ }^{52}$

\subsection{Influential parameters on the electrospinning process}

(a) Viscosity. The solution surface tension and viscosity play important roles in determining the range of concentrations from which continuous fibers can be obtained via electrospinning. Viscosity is a function of the concentration of the solution and the molecular weight of the polymer. When the viscosity of the solution is too low, electrospraying may occur and polymer particles are formed instead of fibers. At lower viscosity usually the number of polymer chain entanglements is lower, which leads to beaded fibers instead of smooth fibers. Therefore, factors that affect the viscosity of the solution will also affect the electrospinning process and the resultant fibers. Higher viscosity solutions can prove extremely difficult to force through the syringe needle, making the control of solution flow rate to the tip unstable.

(b) Applied electric field ( $\boldsymbol{V}$ ). The electric field can be varied over a range, however, when the point to collector distance is changed to $5 \mathrm{~cm}$, stable electrospinning only occurs at an electric field of $1-2 \mathrm{kV} \mathrm{cm}^{-1}$. During electrospinning, charge transport due to the applied voltage is mainly due to the flow of the solution jet towards the collector and the increase or decrease of current can be attributed to the mass flow of the solution from the spinneret tip. An increase in the applied voltage causes a change in the shape of the jet initiating point, which alters the structure and morphology of the fibers.

(c) Spinneret collector and feed rate. Different spinneret collectors such as foils, metals and rotating drums have been utilized by numerous researchers. The typical electrode that is most widely used is aluminium foil, due to its inexpensive price, availability, and its ease of changing for the analysis of many samples. The foil is connected to a grounded electrode in order to provide a path for the current to travel. Generally, rotating drums are used to produce NFs with uniform thickness and whenever reproducible results are the primary desire. The flow rate of the solution from the syringe is an important process parameter as it influences the jet velocity and the material transfer rate. With a lower solution feeding rate, smaller fibers with spindle-like beads are formed and vice versa.

\subsection{Advantages of electrospinning}

Electrospinning is a simple and elegant method to produce NFs from organic and inorganic materials. This technique has attracted significant attention since the 1990s, due to its versatility and economic competitiveness for laboratory scale
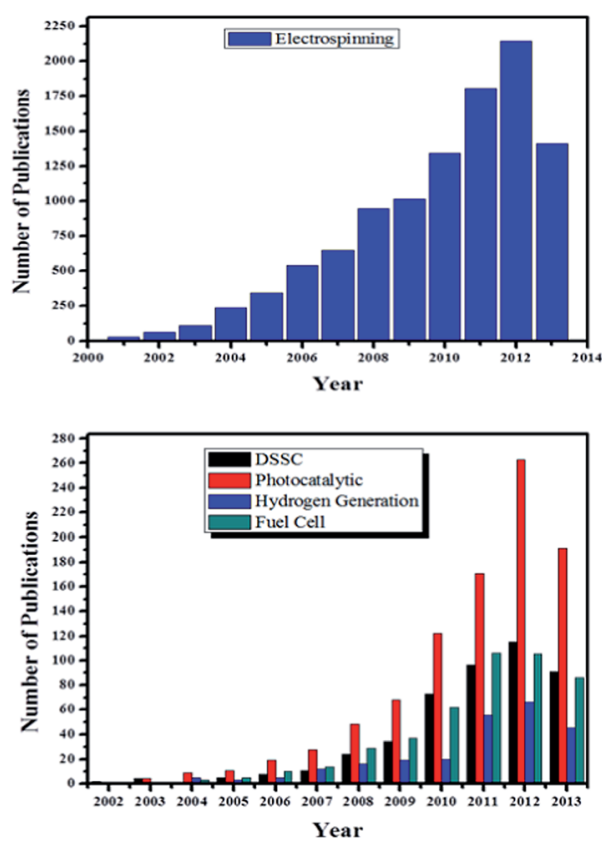

Fig. 3 Comparison of (a) the number of research publications produced within last fifteen years (2000 to 2013) using electrospinning and (b) research articles published using electrospun NFs in different energy domains (DSSCs, photocatalysis, hydrogen generation and fuel cells).

fiber production. It can be used to produce tuneable nanostructures and properties for a wide range of applications. ${ }^{43,53-57}$ The unique and fascinating properties of these electrospun nanostructured materials with well-defined geometrical shapes have triggered a tremendous research activity among scientists for a multitude of applications such as DSSCs, dye degradation, water-splitting and fuel cells. Fig. 3(a) illustrates the growth of research into electrospun materials annually and Fig. 3(b) shows the corresponding research articles published on the use of electrospun NFs in different energy domains (DSSCs, photocatalysis, hydrogen generation and fuel cells).

\section{Electrospun fiber based Dye- Sensitized Solar Cells (DSSCs)}

Solar energy is abundant as more sunlight strikes the Earth in a day than the total energy consumption of the world in a year. Despite its vast availability, the energy produced from solar radiation remains at only $0.01 \%$ of total energy demand. ${ }^{3,58,59}$ Over the past five years, solar PVs have averaged an annual growth rate of over $50 \%$ and the present trend of using photovoltaics for electricity generation is increasing rapidly from 1.5 GW in 2000 to $67 \mathrm{GW}$ at the end of 2011 across the world. ${ }^{4}$ Photovoltaic (PV) technology has advanced rapidly in terms of both materials technology and device architecture. DSSCs have been widely recognized as a promising alternative to conventional silicon cells since they were first reported by O'Regan and Grätzel in $1991 .^{60}$ DSSCs are sometimes included in the category 
of organic solar cells because of the organic nature of the sensitizer dye. However, third generation solar cells have a lot of attractive features that are superior to first and second generation solar cells, for example, their compatibility with flexible substrates and the low cost of their materials and manufacture. Of the many types of solar cells, the fabrication of DSSCs is the simplest and most economical. Until recently, the highest DSSCs power conversion efficiency that had been achieved was little more than $12 \%$, which is lower than that of bulk silicon solar cells. ${ }^{61}$ However, it has been difficult to predict the determining factors that enhance the efficiency, which is still a crucial issue and plenty of research has been carried out to improve the performance of DSSCs using various methods. ${ }^{\mathbf{6 2 , 6 3}}$

A typical DSSC device is structurally composed of a photoactive n-type semiconductor working electrode (photo anode), a counter electrode made up of either a metal or semiconductor (photocathode), and an electrolyte. DSSC cells consist of a mesoporous photo electrode layer of a suitable metal oxide (commonly, $\mathrm{TiO}_{2}$ ) on a conducting glass substrate (fluorinedoped tin oxide, $\mathrm{F}_{-} \mathrm{SnO}_{2}$ or FTO). The surface of the oxide layer is chemisorbed with a layer of an organic dye, which acts as a sensitizer. The cell is made complete by sealing the photo electrode with a counter electrode in the presence of an electrolyte that helps regenerate the dye. Upon shining light upon the cell, excited electrons from the dye are transferred to the conduction band (CB) of the oxide layer and are then transported out through an external circuit. ${ }^{63-66}$ A detailed schematic diagram of a electrospun based DSSC is shown in Fig. 4. Electrospun $\mathrm{NF}\left(\mathrm{TiO}_{2}, \mathrm{ZnO}, \mathrm{CuO}\right)$ based DSSCs have received considerable attention from the academic community and industry due to their ease of production, high efficiency and environmental-friendliness with abundant and inexpensive materials.

Highly ordered nanostructures of $\mathrm{TiO}_{2}$, and other wide band gap semiconductors are promising alternatives to the mesoporous NP thin films that are currently used for DSSCs. However, up to now, most successful DSSCs have been based on $\mathrm{TiO}_{2}$ nanostructured materials owing to their combined advantages of porosity, dye adsorption, charge transfer, and electron transport. ${ }^{68}$ Hierarchical electrospun $\mathrm{TiO}_{2}$ NFs with

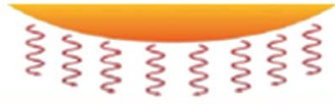

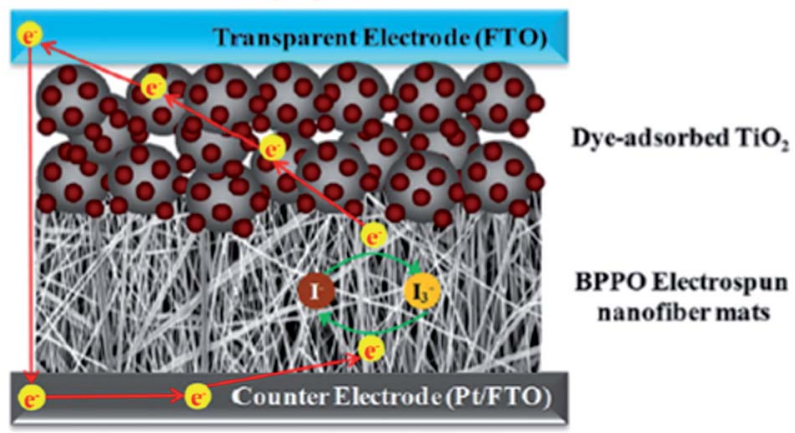

Fig. 4 Schematic diagram of an electrospun NF based DSSC. ${ }^{67}$ tuneable diameters are one available $1 \mathrm{D}$ material, which has great potential for use in the fabrication of DSSCs with several advantages over other methods; large-area applicability, environmental friendliness and room temperature processability. Lee et al. fabricated DSSCs with high energy conversion efficiencies using electrospun $\mathrm{TiO}_{2}$ nanorods. ${ }^{69}$ The electron diffusion coefficient of the post treated nanorods was $\sim 51 \%$ higher than that of an untreated ones, leading to a charge collection efficiency that was $19 \%$ higher at an incident photon flux of $8.1 \times 10^{16} \mathrm{~cm}^{-2} \mathrm{~s}^{-1}$. The efficiency of a nanorod-based DSSC with a device thickness of $14 \mu \mathrm{m}$ was found to be $9.52 \%$ with $V_{\mathrm{oc}}=761 \mathrm{mV}, J_{\mathrm{sc}}=17.6 \mathrm{~mA} \mathrm{~cm}^{-2}$, and fill factor $=70.0 \%$. Lin et al. have reported a series of $1 \mathrm{D}$ mesoporous anatase $\mathrm{TiO}_{2}$ NFs (TNF $x, x=0-3$ in wt\%) with $0-3 \mathrm{wt} \%$ of a room-temperature ionic liquid (RTIL) as the mesopore formation template. ${ }^{70}$ The DSSC fabricated with TNF1 demonstrated the largest improvement $(\sim 50.4 \%)$ in energy conversion efficiency $(5.64 \%)$ over that of TNF0, which was electrospun without RTIL (3.75\%). The enhancement of the energy conversion efficiency was mainly attributed to the more efficient light harvesting caused by the larger amount of dye adsorbed and faster electron transport in the TNF $x$-based $(x>0)$ photoanodes. Li et al. fabricated highly transparent nanocrystalline $\mathrm{TiO}_{2}$ films by electrospinning NFs based on a transmutation process. ${ }^{71}$ The electrospun NF films were shown to possess rich bulk oxygen vacancies (BOVs, PL band at 621-640 nm) when measured using photoluminescence (PL) spectroscopy. The resulting doublelayer cell yielded a high efficiency of $6.01 \%$, which was an increased of $14 \%$ compared to that obtained from a $10 \mathrm{~mm}$ thick P25 film. Song et al. developed single crystalline $\mathrm{TiO}_{2}$ nanorod electrodes made from electrospun fibers after calcination. ${ }^{72}$ This electrode provided efficient photocurrent

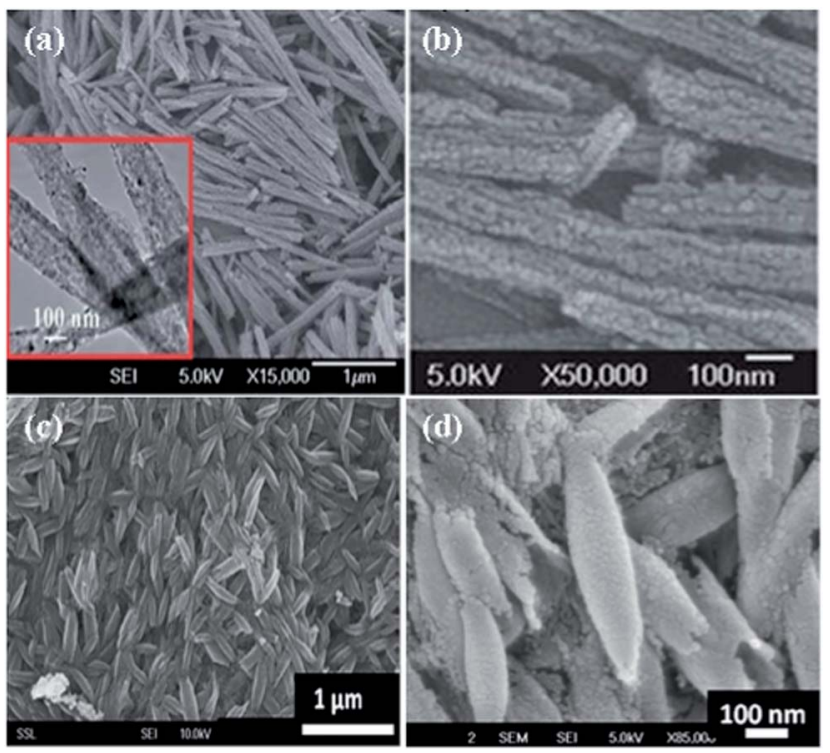

Fig. 5 (a and b) Low and high resolution FESEM images of electrospun porous $\mathrm{TiO}_{2}$ nanorods prepared at $500{ }^{\circ} \mathrm{C}$. The inset shows the corresponding TEM images. ${ }^{73}$ (c and d) $\mathrm{A}$ sintered $\mathrm{TiO}_{2}-\mathrm{CNT}$ nanocomposite and $\mathrm{TiO}_{2}-\mathrm{CNT}(0.2 \mathrm{wt} \%$ ) nanocomposite showing their rice grain-shaped morphology. ${ }^{74}$ 
generation in a quasi-solid-state dye-sensitized solar cell with an overall conversion efficiency of $6.2 \%$. Kumar et al. reported highly crystalline hierarchical $\mathrm{TiO}_{2}$ nanostructures with various morphologies ranging from one-dimensional regular fibers to hollow tubes, porous rods and spindles through electrospinning $\mathrm{TiO}_{2} /$ composite fibers. ${ }^{73}$ XRD analysis confirmed the phase transformation from anatase to rutile with a crystallite size variation from $11 \mathrm{~nm}$ to $36 \mathrm{~nm}$, which was observed upon changing the annealing temperature. At $500{ }^{\circ} \mathrm{C}$, the surface morphology exhibited a highly porous rod-like structure with an average particle length of $1.5 \mathrm{~mm}$ and a diameter of $150 \mathrm{~nm}$ as shown in Fig. 5(a and b). A higher conversion efficiency $(\eta)$ of $4.56 \%$ with a short circuit current $\left(J_{\mathrm{sc}}\right)$ of $8.61 \mathrm{~mA} \mathrm{~cm} \mathrm{~cm}^{-2}$ was observed for the ordered porous anatase $\mathrm{TiO}_{2}$ nanorods with higher surface area of $75.74 \mathrm{~m}^{2} \mathrm{~g}^{-1}$.

Anjusree et al. reported that the morphology control of electrospun $\mathrm{TiO}_{2}$ depends on the chemical interactions between the polymer and the $\mathrm{TiO}_{2}$ during the sintering process. ${ }^{75} \mathrm{~A}$ change in the polymer mixture from polyvinyl pyrrolidone (PVP) to polyvinyl acetate (PVAc) resulted in a variation of the morphology of $\mathrm{TiO}_{2}$ from a continuous fibre to rice-shaped and then to leaf-shaped with a device efficiency of $4.5 \%$ under 0.5 AM with current density of $5.7 \mathrm{~mA} \mathrm{~cm}^{-2}$, an open circuit voltage of $0.65 \mathrm{~V}$ and a fill factor of 59.4\%. Yang et al. reported an innovative bilayer $\mathrm{TiO}_{2} \mathrm{NF}$ photoanode which demonstrated significantly improved performance in DSSCs. ${ }^{76}$ In the case of bilayer photoanode DSSCs with a thickness $8.9 \mu \mathrm{m}$, they observed a significant increase in the photocurrent density and obtained a highest PCE of $8.40 \%$ with a corresponding $J_{\mathrm{sc}}$ of $22.5 \mathrm{~mA} \mathrm{~cm}^{-2}$. In contrast, the performance of a single-layer photoanode with approximately the same thickness $(9.2 \mu \mathrm{m})$ had a PCE of just $7.14 \%$ and a $J_{\text {sc }}$ value of $20.1 \mathrm{~mA} \mathrm{~cm}^{-2}$. The conversion efficiency of the bilayer photoanode DSSC device had improved by more than $20 \%$ compared with the single-layer photoanode device. Nair et al. reported a simple recipe for the fabrication of an electrospun $\mathrm{TiO}_{2}$ nanorod-based efficient dyesensitized solar cell using a Pechini-type sol. ${ }^{77}$ The Pechini-type sol of $\mathrm{TiO}_{2}$ NFs produced a highly porous and compact layer of $\mathrm{TiO}_{2}$ upon doctor-blading and sintering without the need for an adhesive, scattering layer or $\mathrm{TiCl}_{4}$ treatment. The best $\mathrm{NF}$ DSSCs, which had an area of $\sim 0.28 \mathrm{~cm}^{2}$ showed an efficiency of $\sim 4.2 \%$ and an incident photon-to-electron conversion efficiency (IPCE) of $\sim 50 \%$. Similarly, they also demonstrated a titanatederived high surface area $\mathrm{TiO}_{2}$ material that achieved a $\sim 50 \%$ higher efficiency than that of the fiber/rice grain-shaped anatase $\mathrm{TiO}_{2}$ (4.63\% and $4.49 \%$, respectively). ${ }^{78}$

Krysova et al. have also reported porous structured electrospun $\mathrm{TiO}_{2}$ NFs with diameters of 100-280 nm and surface areas of $9-100 \mathrm{~m}^{2} \mathrm{~g}^{-1}$ and the efficiency of the NFs was investigated by incorporating them into mesoporous $\mathrm{TiO}_{2}$ films. ${ }^{79}$ Incorporation of NFs into the mesoporous film resulted in a decrease in N719 dye adsorption, but at the same time increased the roughness factor. The preparation of thick mesoporous $\mathrm{TiO}_{2} \mathrm{NF}$ electrodes resulted in an improved solar efficiency of 5.51\%, which outperformed the pure mesoporous film efficiency (4.96\%). Peining et al. reported $\mathrm{TiO}_{2}-\mathrm{CNT}$ nanocomposites with a novel single crystalline rice grain-like nanostructure, which were synthesized using cost effective electrospinning followed by subsequent high temperature sintering. ${ }^{74}$ At very low CNT loading $\left(0.1-0.3 \mathrm{wt} \%\right.$ of $\left.\mathrm{TiO}_{2}\right)$ they observed that the rice grain shape remained unchanged, while at a higher CNT concentration (8 wt\%) the morphology became distorted with CNTs sticking out of the rice-grain shape (Fig. 5(c)). $0.2 \mathrm{wt} \%$ was the optimum concentration of the $\mathrm{CNTs}^{-\mathrm{TiO}_{2}}$ matrix (Fig. 5(d)) and showed the best performance in DSSCs with a $32 \%$ enhancement in energy conversion efficiency. Similarly, Peining et al. also fabricated an electrospun one-dimensional $\mathrm{TiO}_{2}$-graphene nanocomposite (TGC) with average dimensions of $\sim 450 \mathrm{~nm}$ in length and $\sim 150 \mathrm{~nm}$ in diameter. ${ }^{80}$ With the introduction of graphene into the $\mathrm{TiO}_{2}$ network, the $J_{\mathrm{sc}}$ was improved from 9.58 to $12.78 \mathrm{~mA} \mathrm{~cm}^{-2}$. The fill-factor remained at $\sim 62 \%$ with an enhancement in the overall energy conversion efficiency from 4.89 to $6.49 \%$. Li et al. adopted a novel polymer $\mathrm{NF} / \mathrm{TiO}_{2} \mathrm{NP}$ composite photoelectrode with a high bendability, synthesised using a spray-assisted electrospinning method. ${ }^{81}$ These composite photoelectrodes in flexible plastic DSSCs showed outstanding mechanical stability even after 1000 bending cycles because crack formation and propagation were effectively suppressed by the PVDF NFs and this level of stability was much greater than that of a conventional photoelectrode film consisting of only $\mathrm{TiO}_{2}$. Zhang et al. successfully synthesized hollow mesoporous $\mathrm{TiO}_{2}$ NFs via co-axial electrospinning of a titanium tetraisopropoxide (TTIP) solution with two immiscible polymers, poly(ethylene oxide) (PEO) and PVP, using a core-shell spinneret. ${ }^{82}$ The hollow mesoporous $\mathrm{TiO}_{2}$ NFs were found to have an average diameter of $130 \mathrm{~nm}$ with a high surface area of $118 \mathrm{~m}^{2} \mathrm{~g}^{-1}$. The solar-to-current conversion efficiency $(\eta)$ and short circuit current $\left(J_{\mathrm{sc}}\right)$ were measured to be $5.6 \%$ and $10.38 \mathrm{~mA} \mathrm{~cm}^{-2}$, respectively, which were higher than those of a DSSC made using regular $\mathrm{TiO}_{2}$ NFs under identical conditions $\left(\eta=4.2 \%, J_{\mathrm{sc}}=8.99 \mathrm{~mA} \mathrm{~cm} \mathrm{~cm}^{-2}\right)$. The improvements in the conversion efficiency were mainly attributed to the higher surface area and the mesoporous $\mathrm{TiO}_{2}$ nanostructure. Jin et al. developed electrospun $\mathrm{TiO}_{2}-\mathrm{ZrO}_{2}$ fiber composite electrodes using sol-gel and electrospinning techniques. ${ }^{83}$ Adding these $\mathrm{ZrO}_{2}$ fibers into $\mathrm{TiO}_{2}$ electrodes provided a good dye loading capability and effective electron pathway resulting in an increase of charge transfer across the $\mathrm{TiO}_{2} /$ electrolyte interface compared to a conventional $\mathrm{TiO}_{2}$ electrode. The energy conversion efficiency of DSSCs made with this composite electrode was $6.2 \%$, an increase of $26.5 \%$ over the pure $\mathrm{TiO}_{2}$ electrode $(4.9 \%)$. Du et al. reported a novel $\mathrm{TiO}_{2} / \mathrm{ZnO}$ core-sheath NF film fabricated through an extraordinary coaxial electrospinning technique as shown in Fig. 6 (middle). ${ }^{84}$ The surface morphology of the randomly oriented PVAc/TTIP/Zn( $\left(\mathrm{CH}_{3} \mathrm{COO}\right)_{2}$ composite fibers was smooth, while the diameters were around $200 \mathrm{~nm}$ and after calcination the diameter was reduced by $\sim 25 \%$ to $c a .150 \mathrm{~nm}$ due to the removal of DMF and PVAc (Fig. 6(a-d)). A photo-conversion efficiency of $5.17 \%$ was observed for the $\mathrm{TiO}_{2} / \mathrm{ZnO} \mathrm{NF}$ film based photoanode material and which was approximately $16 \%$ larger than a bare $\mathrm{TiO}_{2} \mathrm{NF}$ based DSSC. The increase in $J_{\mathrm{sc}}$ was ascribed to the improved light harvesting efficiency and electron collection efficiency. 


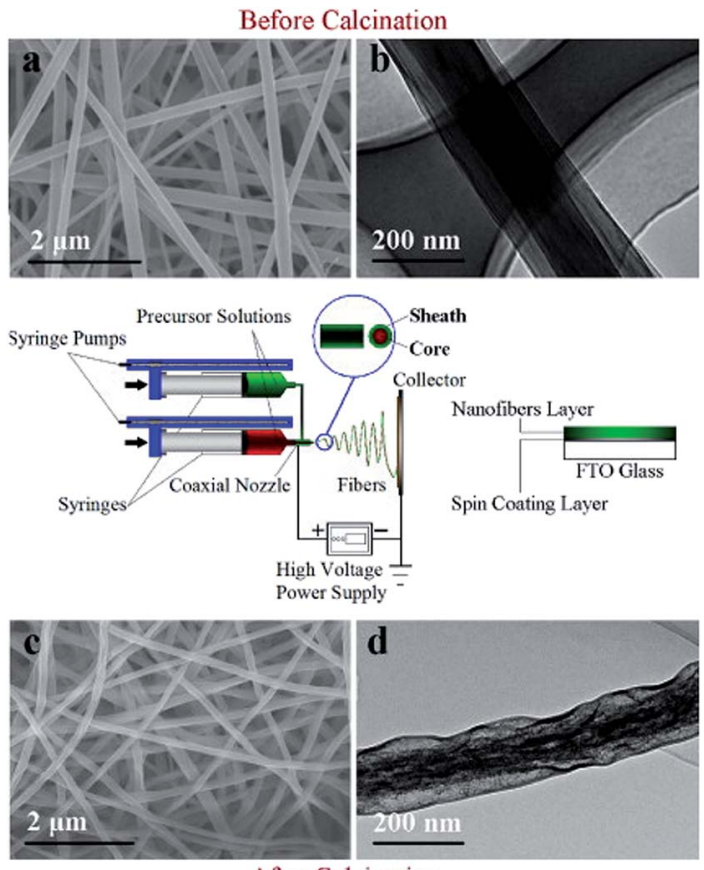

After Calcination

Fig. 6 FESEM/TEM images of the PVAc/TTIP/Zn $\left(\mathrm{CH}_{3} \mathrm{COO}\right)_{2}$ composite fibers ( $a$ and $b$ ) before and ( $c$ and d) after calcination and $a$ schematic diagram (middle) of the coaxial electrospinning process. ${ }^{84}$

However, the important drawback of DSSCs using liquid electrolyte is that they have lower long-term stability due to the volatility of the electrolyte which contains an organic solvent. For commercialization, durability is a crucial factor. Replacing the liquid electrolyte with a solid-state electrolyte (SSE) or polymer electrolyte (PE) has been considered as one of the crucial issues that needs to be addressed in order to fully capitalize on the merits of DSSCs, which has resulted in not only improvements in their mechanical stability and simplified their fabrication processes, but also eliminated the need for hermetic sealing. Hwang et al. demonstrated high-performance solidstate DSSCs using hierarchically structured $\mathrm{TiO}_{2} \mathrm{NF}$ electrodes and plastic crystal-based solid-state electrolytes. ${ }^{85}$ Fig. 7(a and b)
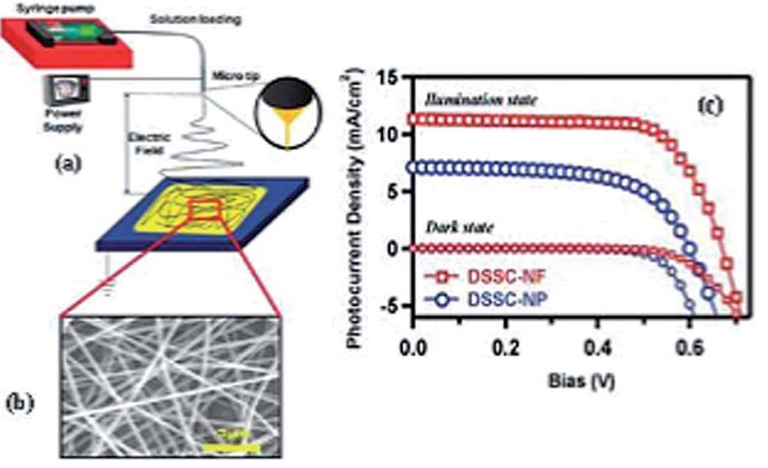

Fig. 7 (a) Schematic description of an electrospinning technique used to prepare HS-NFs, (b) SEM images of electrospun $\mathrm{TiO}_{2} /$ polymer composite NFs and (c) J-V curves measured under simulated AM 1.5G light one sun conditions. ${ }^{85}$ show the typical spinning setup used to obtain $\mathrm{TiO}_{2} /$ polymer composite NFs resulting in a high density of nanorods with an average length between 150-200 $\mu \mathrm{m}$. The solid-state DSSCs using NFs demonstrated improved power conversion efficiency (PCE) compared to conventional $\mathrm{TiO}_{2}$ NP based DSSCs. The optimized PCE of NF DSSCs using PC electrolytes were 6.54, 7.69 , and $7.93 \%$ at a light intensity of 100,50 , and $30 \mathrm{~mW} \mathrm{~cm}^{-2}$, respectively, with an increased charge collection efficiency (>40\%) (Fig. 7(c)).

Ahn et al. developed poly(vinylidene fluoride-co-hexafluoropropylene) (e-PVdF-co-HFP) based NFs as polymer gel electrolytes (PGE). ${ }^{86}$ Cells containing this electrospun e-PVdFco-HFP polymer gel electrolyte, with and without doping of the liquid crystal E7 and with a liquid electrolyte were fabricated. Owing to the high ionic conductivity $\left(2.9 \times 10^{-3}\right)$ of the E7 when embedded into e-PVdF-co-HFP-PGE, higher values of $J_{\mathrm{sc}}$ (14.62 $\mathrm{mA} \mathrm{cm}^{-2}$ ) and PCE (6.82\%) were achieved for the quasisolid-state DSSCs. The quasi-solid-state DSSC with e-PVdF-coHFP PGE was found to have a PCE of $\sim 6.35 \%$. Kim et al. prepared PVDF-HFP NFs by electrospinning and applied these to a polymer matrix in polymer electrolytes for use in DSSCs. ${ }^{87}$ The ionic conductivity and porosity of the electrospun PVDFHFP NF films were $4.53 \pm 1.3 \times 10^{-3} \mathrm{~S} \mathrm{~cm}^{-1}$ and $70 \pm 2.3 \%$, respectively, regardless of NF morphology. The best results of $V_{\mathrm{oc}}, J_{\mathrm{sc}}, \mathrm{FF}$ and $Z$ of the DSSC devices using the electrospun PVDF-HFP NF films were around $0.75 \mathrm{~V}, 12.3 \mathrm{~mA} \mathrm{~cm}{ }^{-2}, 0.57$, and $5.21 \%$, respectively. Sethupathy et al. reported electrospun fibrous membranes formed of hybrid composites of polyvinylidene fluoride (PVdF), polyacrylonitrile (PAN) and silicon dioxide $\left(\mathrm{SiO}_{2}\right)$ (PVdF-PAN-SiO $\left.{ }_{2}\right)$, which were prepared using different proportions of $\mathrm{SiO}_{2}(3,5$ and $7 \% \mathrm{w} / \mathrm{w}) .{ }^{88}$ In terms of their photovoltaic performance, the devices exhibited an open circuit voltage $\left(V_{\text {oc }}\right)$ of $0.79 \mathrm{~V}$ and a short circuit current $11.6 \mathrm{~mA}$ $\mathrm{cm}^{-2}$ with efficiency of 5.61\%. Dissanayake et al. reported NF membrane electrolytes for the fabrication of quasi-solid state (gel) DSSCs and the performance of these solar cells were compared with DSSCs fabricated with liquid electrolyte and conventional PAN-based gel electrolyte (PAN:KI:PC:I2). ${ }^{89}$ The DSSC with a NF membrane electrolyte of thickness $9.14 \mu \mathrm{m}$ exhibited a highest light-to-electricity conversion efficiency of $5.2 \%$, whereas an identical cell based on the corresponding liquid electrolyte showed an efficiency of 5.3\%.

The counter electrode (CE) is also an important and expensive component in DSSCs. CE is commonly made of a thin layer of a noble-metal catalyst deposited on a transparent conducting oxide (TCO) substrate, such as fluorine-doped tin oxide (FTO) or indium-doped tin oxide (ITO). Platinum (Pt) is most often used as a CE in DSSC for two main reasons: (a) it acts as a catalyst that helps in the regeneration of $\mathrm{I}^{-}$from $\mathrm{I}_{3}{ }^{-}$, and (b) it collects electrons from the external load and pass them onto the electrolyte. Even though Pt is an expensive noble metal, it is used often because its electrocatalytic activity allows for rapid reactions and it has excellent stability towards $\mathrm{I}^{-} / \mathrm{I}_{3}{ }^{-}$electrolytes. However, it also limits application in flexible DSSCs and so there is a need to explore Pt-free materials for the CE in DSSCs. In order to reduce the cost of DSSCs, conductive polymers and carbon materials, such as PANIs (polyanilines), polypyrrole 
(PPy), carbon nanotubes (CNTs) and graphene, have been widely utilized. However, cheap CEs with high catalytic performance and facile fabrication procedures are required for the commercial application of DSSCs. So far different nanostructured carbonaceous materials such as carbon black, CNTs, graphene, polymers and transition metal carbides have been synthesized and used as alternatives to Pt CEs for DSSCs. Among the various nanostructured CEs, cost effective electrospun NFs and composites have proven to be exciting alternative materials as CEs in DSSCs and can enhance the overall photovoltaic performance of DSSCs.

Joshi et al. synthesized a low-cost electrospun carbon NF (ECNs) CE alternative to Pt for use in DSSCs..$^{90}$ ECNs have been explored as an electrocatalyst and low-cost alternative to $\mathrm{Pt}$ for triiodide reduction in DSSCs. The ECN-based cells achieved an energy conversion efficiency $(\eta)$ of $5.5 \%$ under AM 1.5 illumination at $100 \mathrm{~mW} \mathrm{~cm}^{-2}$. The lower cell performance using the ECN electrode was due to its lower fill factor $(\mathrm{FF})$ compared to that of the Pt-based cells, probably caused by its high total series resistance $\left(R_{\text {Stot }}\right)$ at $\sim 15.5 \Omega \mathrm{cm}^{2}$, which was larger than the $\sim 4.8 \Omega \mathrm{cm}^{2}$ value for the Pt-based devices. Li et al. developed high catalytically active one-dimensional CuS/carbon NFs (CuS/EC), which were fabricated by combining an electrospinning technique with a hydrothermal process. ${ }^{91}$ The CuS/EC hetero-architectures demonstrated good performance as CEs for quantum dot-sensitized solar cells. Poudel et al. reported composite CEs made of ECNs and Pt NPs. ${ }^{92}$ The new ECN-Pt composite was demonstrated as a more efficient electrocatalyst with a lower charge transfer resistance $\left(R_{\mathrm{ct}}\right)$, larger surface area, and faster reaction rate for the reduction of $\mathrm{I}_{3}{ }^{-}$ions than those of conventional Pt CEs in DSSCs. The DSSCs using the ECN-Pt CE achieved a $\eta$ value of $\sim 8 \%$, which was higher than that of the conventional Pt cells. Peng et al. demonstrated a simple electrospinning method to directly deposit conductive 10-camphorsulfonic acid (CSA)-doped polyaniline (PANI) blended with poly(lactic acid) (PLA) composite films (PANI-CSA-PLA) onto rigid FTO and FTOcoated poly(ethylene naphthalate) (PEN) substrates as shown in Fig. 8(a). ${ }^{93}$ The rigid and flexible DSSCs demonstrated high photovoltaic efficiency, close to that of sputtered Pt-based DSSCs. The surface morphology showed that the PANI-CSA-PLA films were assembled from about $200 \mathrm{~nm}$ diameter NFs, with a
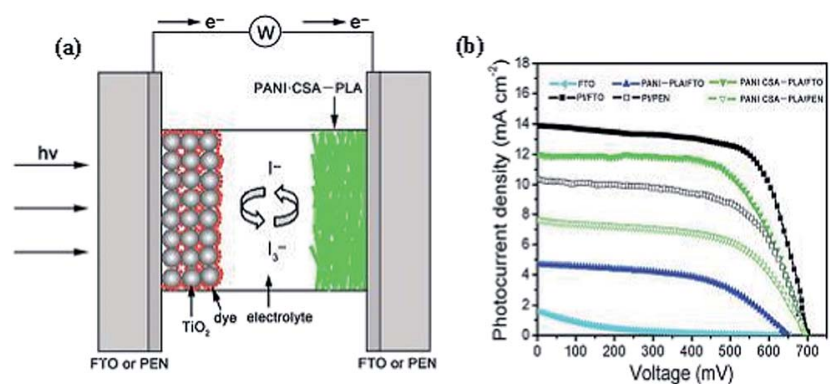

Fig. 8 (a) Schematic diagram of a DSSC with a PANI-CSA-PLA NF film on FTO or PEN substrate as the CE. (b) Photocurrent density-voltage $(J-V)$ curves of the DSSCs based on FTO glass, PANI-PLA/FTO, PANICSA-PLA/FTO, Pt/FTO, PANI-CSA-PLA/PEN, and Pt/PEN counter electrodes under 1 sun illumination of $100 \mathrm{~mW} \mathrm{~cm}^{-2}$ (AM 1.5). ${ }^{93}$ uniform thickness of about $2 \mu \mathrm{m}$. The photoelectric conversion efficiency of the DSSCs first based on such rigid and flexible PANI-CSA-PLA counter electrodes achieved values of $5.3 \%$ and $3.1 \%$, respectively, which was close to sputtered Pt-based DSSCs. In addition, the rigid PANI-CSA-PLA-based DSSC demonstrated good stability and its photocurrent density-voltage $(J-V)$ curves are shown in Fig. 8.

Park et al. prepared mesoporous multi-walled CNT (MWCNT)-embedded CNFs (MWCNT/meso-ACNF) through various steps of electrospinning, stabilization, carbonization, $\mathrm{SiO}_{2}$ template etching, and activation..$^{94}$ Its mesoporous structure provided a surface area of $562 \mathrm{~m}^{2} \mathrm{~g}^{-1}$ with an average mesopore diameter of $27.32 \mathrm{~nm}$ and its electrical conductivity was increased to $0.19 \mathrm{~S} \mathrm{~cm}^{-1}$. The overall conversion efficiency of a MWCNT/meso-ACNF DSSC increased to $6.35 \%$ which was slightly higher than for the Pt counter electrode because of its characteristics in promoting electron and ion transfer, decreasing the resistance of charge transfer and increasing the contact area between the liquid electrolyte and CNT/mesoACNF. Mali et al. successfully adopted highly crystalline kesterite $\mathrm{Cu}_{2} \mathrm{ZnSnS}_{4}$ (CZTS) NFs as counter electrodes for DSSCs. ${ }^{95}$ For CZTS NFs synthesised with PVP they observed single crystalline crystal structure, whereas NFs with cellulose acetate (CA) exhibited polycrystalline behaviour. The prepared PVP-CZTS and CA-CZTS counter electrode based DSSCs exhibited efficiencies of $3.10 \%$ and $3.90 \%$, respectively.

Kim et al. also reported a multifunctional crystalline platinum NF (PtNF) web with NF diameters of $40-70 \mathrm{~nm}$ for FTOfree DSSCs. ${ }^{96}$ These electrospun PtNFs were highly catalytic, transparent and conductive resulting in good free electron transport properties for acting as counter electrodes in DSSCs with an increased power efficiency of $6.0 \%$, reaching up to $83 \%$ of a conventional DSSC using Pt-coated FTO glass as a counter electrode. Park et al. reported hollow activated carbon NFs (H-ACNF) as catalystic CEs for DSSCs. ${ }^{97}$ H-ACNF exhibited a high surface area of $1037.5 \mathrm{~m}^{2} \mathrm{~g}^{-1}$ with an average mesoporous diameter of $17.4 \mathrm{~nm}$. The overall conversion efficiency of H-ACNF CEs were comparable to Pt CEs due to easier promotion of electron and ion transfer, decreasing the resistance of charge transfer, and increasing the contact area between the liquid electrolyte and H-ACNF.

Another challenge in improving DSSC conversion efficiency is the poor harvesting of solar light with wavelengths longer than $600 \mathrm{~nm}$, due to the transmission of incident light through the photoanode. However, inclusion of large particles with a size comparable to the wavelength of incident light encourages better light scattering in DSSCs, especially from the red part of the solar spectrum. Though this is technologically challenging, this light scattering layer approach is an effective and practical method to enhance efficiency in larger DSSCs. Electrospun 1D NFs provide direct pathways for electron diffusion, which can enhance light scattering properties and possibly enhance the conversion efficiency of DSSCs. Thus, additional scattering layers of large $\mathrm{TiO}_{2}$ particles, nanorods, and/or NFs have been incorporated into photoanodes to improve their light absorbance. Recently, $\mathrm{TiO}_{2}$ nanostructures with large diameters and high surface areas, such as mesoporous microspheres and 
hemispheres, have been used as scattering layers for both increasing the light harvesting efficiency as well as dye-loading. Zhu et al. fabricated nest-shaped $\mathrm{TiO}_{2}\left(\mathrm{NS}-\mathrm{TiO}_{2}\right)$ structures by electrospinning and used them as an effective scattering layer on the top of $\mathrm{TiO}_{2}$ nanoparticle electrodes in DSSCs. ${ }^{98}$ The $\mathrm{NS}^{-\mathrm{TiO}_{2}}$ scattering layer enhanced the photocurrent of the DSSCs due to enhanced light harvesting, which in turn improved the light scattering and lowered the electron transfer resistance under one sun illumination (AM 1.5G, $100 \mathrm{~mW} \mathrm{~cm}^{-2}$ ). A high efficiency of $8.02 \%$ was achieved for the cell with a $\mathrm{NS}-\mathrm{TiO}_{2}$ scattering layer, which had an increased efficiency of $7.1 \%$ compared to a cell without a scattering layer (7.49\%).

Similarly, Wang et al. fabricated double layered $\mathrm{SnO}_{2} \mathrm{NFs} /$ NPs DSSCs using an efficient light scattering layer and blocking layer. ${ }^{99}$ Photovoltaic performance of the DSSCs with a single layer of $\mathrm{SnO}_{2} \mathrm{NPs}(18.5 \mu \mathrm{m})$ and double layer of $\mathrm{SnO}_{2} \mathrm{NPs}(14.5$ $\mu \mathrm{m}) / \mathrm{NFs}(4.0 \mu \mathrm{m})$ demonstrated conversional efficiencies $(\eta)$ of $4.30 \%$ and $5.44 \%$, respectively. Furthermore, an additional $\mathrm{SnO}_{2}$ blocking layer in double layered photoanode DSSCs showed an increase in power conversion efficiency of $6.31 \%$ (with $J_{\mathrm{sc}}$ value of $16.78 \mathrm{~mA} \mathrm{~cm}{ }^{-2}, V_{\mathrm{oc}}$ of $711 \mathrm{mV}$ and $\mathrm{FF}$ of 0.53 ) which was mainly due to the faster electron transport rate and lower electron recombination rate between the FTO and the electrolyte. Chen et al. synthesized ultraporous anatase $\mathrm{TiO}_{2}$ nanorods as a photoanode with a composite structure of meso and macropores fabricated via a simple micro emulsion electrospinning approach. ${ }^{100}$ The porous $\mathrm{TiO}_{2}$ nanorod based DSSC showed a power conversion efficiency of $6.07 \%$ and, furthermore, a porous $\mathrm{TiO}_{2}$ nanorod based DSSC with a bilayer structure, which acted as a light scattering layer exhibited an improved efficiency of $8.53 \%$. Lee et al. reported electrospun $\mathrm{TiO}_{2}$ NFs could be used as scattering layers in double-layered $\mathrm{TiO}_{2} \mathrm{NP} / \mathrm{TiO}_{2} \mathrm{NF}$ structures in DSSCs. ${ }^{\mathbf{1 0 1}}$ The double-layered $\mathrm{TiO}_{2} \mathrm{NF}$ scattering layer played a major role in dye adsorption and light transmission, which improved the absorption of visible light due to its light scattering effect. The $12 \mathrm{~mm}$-thick photoanode comprised a $2 \mathrm{~mm}$-thick $\mathrm{TiO}_{2} \mathrm{NF}$ layer and $10 \mathrm{~mm}$ thick $\mathrm{TiO}_{2}$ NP layer gave a 33\% higher conversion efficiency than a DSSC with only a $\mathrm{TiO}_{2} \mathrm{NP}$ photoanode. Wu et al. demonstrated an enhancement in the light-harvesting efficiency of the photoanode of DSSCs by forming NFs into a nanofilm on top of a $\mathrm{ZnO}$ nanowire (NW) anode. ${ }^{102}$ A $74 \%$ enhancement of the efficiency of the resulting ZnO NW DSSCs was achieved via reflectance of unabsorbed photons back into the NW anode using the novel light-scattering layer of the nanofilm. Zhu et al. used the concept of a thin film of rice grain and NF-shaped $\mathrm{TiO}_{2}$ nanostructures made by electrospinning for an effective scattering layer on NP electrodes in DSSCs.$^{103}$ Fig. 9(a and b) shows the cross-sectional SEM images of the NP electrodes with rice grain and NF-shaped $\mathrm{TiO}_{2}$ as scattering layers where the average thickness of the $\mathrm{TiO}_{2} \mathrm{NP}$ electrodes was $\sim 10 \mu \mathrm{m}$ and that of the scattering layers was $\sim 2 \mu \mathrm{m}$. With the NFs as a scattering layer, the efficiency was increased from $6.44 \%$ to $7.06 \%$, while the current density increased from 13.6 $\mathrm{mA} \mathrm{cm}{ }^{-2}$ to $14.9 \mathrm{~mA} \mathrm{~cm}{ }^{-2}$. In the case of the rice grain structure, the efficiency was increased from $6.44 \%$ to $7.45 \%$, with the $J_{\mathrm{sc}}$ enhanced from $13.6 \mathrm{~mA} \mathrm{~cm}^{-2}$ to $15.7 \mathrm{~mA} \mathrm{~cm}^{-2}$. The rice

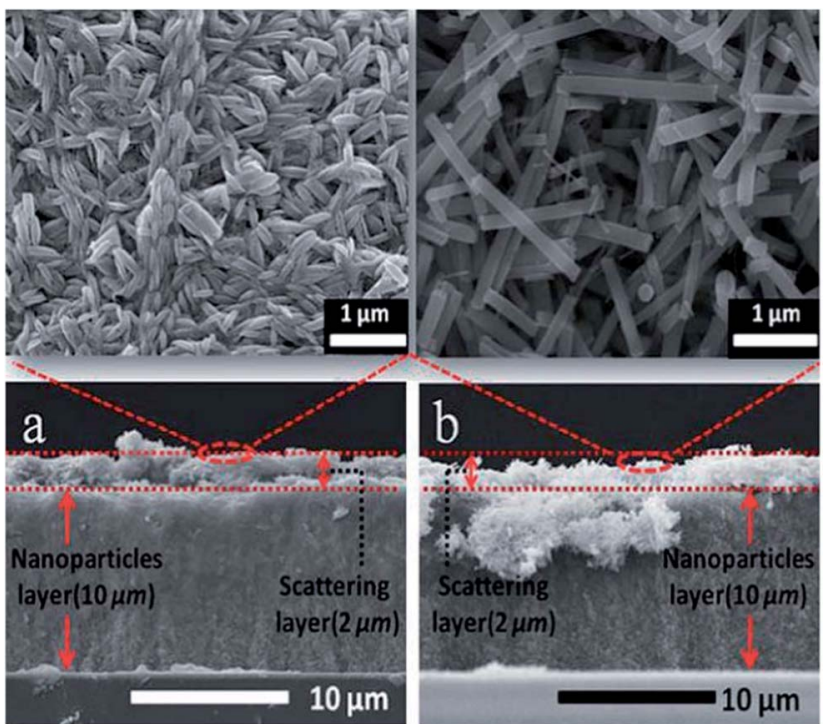

Fig. 9 Cross-sectional SEM images of (a) a $\mathrm{TiO}_{2} \mathrm{NP}$-rice grain nanostructure electrode, and (b) a $\mathrm{TiO}_{2} \mathrm{NP}-\mathrm{NF}$ electrode. Magnified images of the scattering layers are shown on top. ${ }^{103}$

grain-like nanostructures were found to be better at scattering light with a $15.7 \%$ enhancement in efficiency compared to $9.63 \%$ for NFs.

Joshi et al. reported that a composite photoanode made of electrospun $\mathrm{TiO}_{2} \mathrm{NFs}$ and $\mathrm{TiO}_{2} \mathrm{NPs}$ had noticeably improved light harvesting without substantially sacrificing the dye uptake in DSSCs. ${ }^{104}$ The increase in light harvesting was found to be very effective due to Mie scattering, resulting from the incorporation of the $\mathrm{TiO}_{2}$ NFs. The DSSC made using a composite with $15 \mathrm{wt} \%$ fibers achieved a $J_{\mathrm{sc}}$ of $16.8 \mathrm{~mA} \mathrm{~cm}^{-2}$ and $\eta$ of $8.8 \%$ when compared to $\mathrm{TiO}_{2}$ NPs alone, which had a $J_{\text {sc }}$ value and $\eta$ of $11.4 \mathrm{~mA} \mathrm{~cm} \mathrm{~cm}^{-2}$ and $6.1 \%$, respectively, for the same photoanode thickness $(\sim 7.5 \mathrm{~mm})$. Chen et al. reported electrospun NFs constructed of mesoporous nanocrystalline titania with fiber diameters ranging from 194 to $441 \mathrm{~nm}$ as light-scattering photoactive materials. ${ }^{\mathbf{1 0 5}}$ The photocurrent-voltage response of the NF sample with a scattering band that overlapped with the absorption band of titania exhibited a significant photocurrent increase as a function of the fiber deposition density. Yang et al. reported electrospun $\mathrm{TiO}_{2}$ microspheres $\left(\mathrm{M}-\mathrm{TiO}_{2}\right)$ as a scattering layer on top of a nanocrystalline $\mathrm{TiO}_{2}$ (P25) film for CdS QDSCs. ${ }^{106}$ A power conversion efficiency of $1.49 \%$ was achieved for the cell with an $\mathrm{M}^{-}-\mathrm{TiO}_{2}$ scattering layer, which was an increase of $28.4 \%$ compared to a cell without the scattering layer $(1.16 \%)$.

In order to further enhance DSSC efficiency, a very thin metal layer can be applied to form a passive layer and prevent injected dye electron recombination between the photoanode and electrolyte. Naphade et al. observed an enhancement in the performance of DSSCs using in situ 4-5 nm Au NP (Au NP) loaded $\mathrm{TiO}_{2}$ NFs (Au:TiO 2 NFs) as a light harvesting layer. ${ }^{107} \mathrm{~A}$ significant $25 \%$ enhancement in the efficiency was achieved with the $\mathrm{Au} \mathrm{NF}$ light harvesting layer, compared to $12 \%$ when using a NF layer without a light harvesting layer. Horie et al. 
reported Nb-doped electrospun $\mathrm{TiO}_{2}$ (TNO) NFs as a conductive agent in a mesoporous $\mathrm{TiO}_{2}$ layer. ${ }^{108}$ The coating of TNO NFs exhibited an efficiency $(\eta)$ increase from 4.8 to $5.8 \%$. This increase was mainly attributed to the increase in $J_{\mathrm{sc}}$ by $\sim 15 \%$ from 9.7 to $11.2 \mathrm{~mA} \mathrm{~cm}^{-2}$. Similarly, Horie et al. also reported electrospun NFs of $\mathrm{TiO}_{2}$ and $\mathrm{Nb}$-doped $\mathrm{TiO}_{2}$ (NTO) added to a $\mathrm{TiO}_{2}$ mesoporous layer in the photoelectrodes of DSSCs. ${ }^{109}$ The short-circuit current density, $J_{\mathrm{sc}}$, of the electrospun $\mathrm{NFs}$ of $\mathrm{TiO}_{2}$ and NTO, was around $6 \%$ and $8 \%$, respectively.

In the perspective of the search for pioneering energy conversion systems, third generation photovoltaic quantum dot-sensitized solar cell (QDSSC) technology is attracting growing interest as a potential candidate. In particular, the photoanode geometry plays a vital role in shaping the conversion efficiency of the cells through controlling the amount of QD-loading and electrolyte penetration, as well as surface recombination and light scattering. In terms of tuning the absorption spectrum of semiconductor quantum dots (QDs), probing the particle size is an efficient way to harvest the entire range of the solar spectrum. In addition, owing to their unique electronic band structure, QDs can overcome the ShockleyQueisser limit of energy conversion efficiency. ${ }^{110,111}$ Recently, extending the light harvesting wavelength through panchromatic metal sulphide sensitizers has exhibited obvious advantages of both cost reduction and enhanced efficiency, owing to the adjustability of the sensitizer's band gap, high extinction coefficient, large intrinsic dipole moment, and potential to possess multiple exciton generation configurations, thereby, offering new avenues to attain high conversion efficiency. Jin et al. reported the fabrication of three dimensional networks of ITO NFs on a conductive glass substrate by electrospinning. ${ }^{112}$ Photoactive CdS nanocrystals were directly electrodeposited onto the 3D ITO NF networks, which resulted in ITO/CdS coaxial NFs being used as the photoanode in solar cells. The solar cell attained a conversion efficiency of $1.66 \%$ with the highest photocurrent density of $9.27 \mathrm{~mA} \mathrm{~cm}{ }^{-2}$ for the pure CdS sensitized solar cells. Shengyuan et al. demonstrated a CdS QDSSC featuring a CoS counter electrode prepared via a SILAR method with an overall power conversion efficiency of nearly $1 \%$ in the presence of a methanol-free polysulfide electrolyte. ${ }^{113}$ Sudhagar et al. reported QD-decorated highly porous networks of $\mathrm{TiO}_{2}$ nanofibrous electrodes, which afforded multiple carrier generations due to quantum confinement effects. ${ }^{114} \mathrm{CdS}(\sim 18 \mathrm{~nm})$ and CdSe $(\sim 8 \mathrm{~nm})$ QDs were sensitized onto the electrospun $\mathrm{TiO}_{2}$ nanofibrous electrodes with a diameter of $\sim 80-100 \mathrm{~nm}$. The photovoltaic performance of the single (CdS and CdSe) and coupled (CdS/CdSe) QD-sensitized $\mathrm{TiO}_{2}$ nanofibrous electrodes were demonstrated in sandwich-type solar cells using a polysulfide electrolyte, which resulted in an enhanced open-circuit voltage $(0.64 \mathrm{~V})$ with an efficiency of $2.69 \%$. Similarly, Sudhagar et al. reported surface treatment approaches aimed at improving the electronic interfaces of the QD-sensitized highly dense, continuous $\mathrm{TiO}_{2}$ fibrous electrodes. ${ }^{115} \mathrm{~F}$-ion post-treatment on the $\mathrm{TiO}_{2}$ fibrous membranes resulted in a $V_{\text {oc }}$ of $0.61 \mathrm{~V}$ and $J_{\mathrm{sc}}$ of $11.4 \mathrm{~mA} \mathrm{~cm}{ }^{-2}$ with an overall efficiency of $2.8 \%$. Simultaneously, a further enhancement of $V_{\text {oc }}$ was also observed after coating $\mathrm{ZnS}$ onto the sensitizer layer, which improved $V_{\mathrm{oc}}(0.69 \mathrm{~V})$ by passivating the QDs. A tetrahydrofuran (THF)-ion treatment combined with the $\mathrm{ZnS}$ passivation layer on the QD-sensitized $\mathrm{TiO}_{2}$ fibrous photoanode yielded a high device performance of $3.2 \%$ with a remarkable $V_{\text {oc }}$ of $0.69 \mathrm{~V}$. Han et al. reported the facile synthesis of branched $\mathrm{TiO}_{2}$ nanotubes of length $\sim 0.5 \mu \mathrm{m}$ and thin hollow-NFs as photoanodes in QDSSCs. ${ }^{116}$ The hierarchical three dimensional photoanodes exhibited 3-fold higher $\eta(\sim 2.8 \%)$ and $J_{\text {sc }}$ $\left(8.8 \mathrm{~mA} \mathrm{~cm}{ }^{-2}\right)$ than the directly grown nanotube arrays on a transparent conducting oxide (TCO) substrate with $\eta \sim 0.9 \%$, $J_{\mathrm{sc}}=2.5 \mathrm{~mA} \mathrm{~cm}^{-2}$.

Besides using $\mathrm{TiO}_{2} \mathrm{NFs}$ as an photoanode, several other electrospun metal oxide NFs such as $\mathrm{ZnO}, \mathrm{SnO}_{2}$ and $\mathrm{CuO}$ have been used as promising alternative light sensitizers to $\mathrm{TiO}_{2}$ nanostructures. Recently, Zhang et al. reported electrospun nanofibrous $\mathrm{ZnO}$ photoelectrodes with a tuneable thickness and self-relaxation layer. ${ }^{117}$ A maximum energy efficiency of $2.58 \%$ was observed for a device with a film thickness of $5.0 \mu \mathrm{m}$, which had a large surface area and high dye loading amount. Furthermore, a ZnO film calcined with $0.2 \mathrm{M} \mathrm{Zn}(\mathrm{OAc})_{2}$ yielded a $\eta$ of $3.02 \%$. Yun et al. fabricated DSSCs based on Al-doped ZnO (AZO) NF photoelectrodes with a energy conversion efficiency $(\eta)$ of $0.54-0.55 \%$, which was obtained under irradiation of AM 1.5 simulated sunlight $\left(100 \mathrm{~mW} \mathrm{~cm}{ }^{-2}\right) \cdot{ }^{118}$ Similarly, Kim et al. reported directly electrospun $\mathrm{ZnO} /$ poly(vinyl acetate) composite $\mathrm{NF}$ mats, which were calcined at $450{ }^{\circ} \mathrm{C} .{ }^{119}$ DSSCs were fabricated using ZnO NF mats $200-500 \mathrm{~nm}$ in length and with core diameters of $\sim 30 \mathrm{~nm}$ exhibited a conversion efficiency of $1.34 \%$ under $100 \mathrm{~mW} \mathrm{~cm}{ }^{-2}$ illumination. Kumar et al. synthesized flower shaped $\mathrm{SnO}_{2}$ nanostructures by electrospinning for the first time using precise control of the precursor concentration in a polymeric solution. ${ }^{120}$ SEM images showed the flower-like structure was made up of fibrils with diameters of $80-100 \mathrm{~nm}$, which in turn were made up of particles $\sim 20-30 \mathrm{~nm}$ in size (Fig. 10(a and b)). A flower-based DSSC with a thickness of $15 \mu \mathrm{m}$, showed a record $V_{\mathrm{oc}}$ of $\sim 700 \mathrm{mV}, J_{\mathrm{sc}}$ of $\sim 7.30 \mathrm{~mA} \mathrm{~cm}{ }^{-2}$, FF of $\sim 59.6$ and $\eta$ of $\sim 3.0 \%$, whereas a fiber based DSSC gave a $V_{\mathrm{oc}}$ of $\sim 600 \mathrm{mV}, J_{\mathrm{sc}}$ of $\sim 3.0 \mathrm{~mA} \mathrm{~cm}{ }^{-2}, \mathrm{FF}$ of $\sim 8.3$ and $\eta$ of $0.71 \%$,

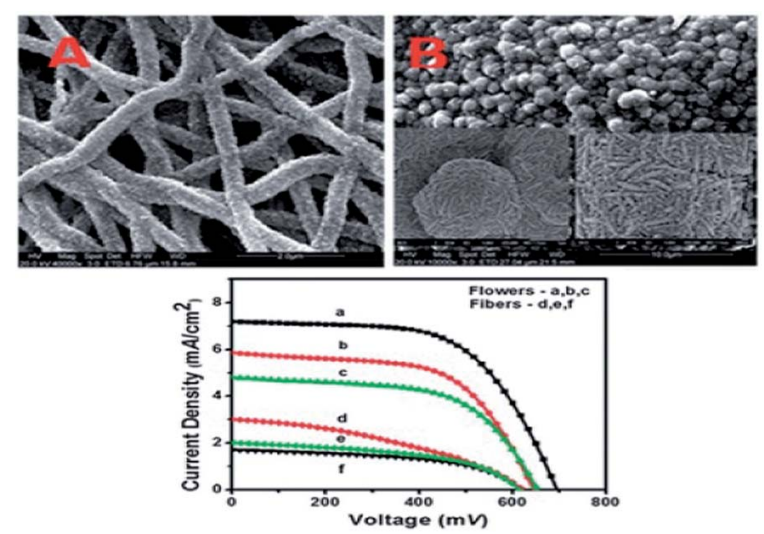

Fig. 10 (a and b) SEM images of $\mathrm{SnO}_{2}$ fibers and flowers. The inset images in (b) show magnified SEM images of the flower morphology. (c) Current-voltage characteristics of the solar cells made using fibers and flowers. ${ }^{120}$ 
i.e., the flower-based device showed a $\sim 140 \%$ increase in $J_{\mathrm{sc}}$, $\sim 16 \%$ increase in $V_{\text {oc }}$ and $\sim 55 \%$ increase in FF compared to the fiber based device, as shown in Fig. 10(c). The highest IPCE values for the devices based on the fibers and flowers were $\sim 12 \%$ and $42 \%$, respectively, where the $30 \%$ increase in IPCE observed for later case could be attributed to the enhanced electron density and charge transport efficiency, as well as a slightly higher amount of dye-loaded for the flower based device.

Krishnamoorthy et al. reported the large-scale production of aligned $\mathrm{SnO}_{2}$ NFs using multi-nozzle electrospinning. ${ }^{121}$ DSSCs fabricated using these $\mathrm{SnO}_{2}$ NFs as the working electrode yielded a $J_{\mathrm{sc}}$ of $9.9 \mathrm{~mA} \mathrm{~cm} \mathrm{~cm}^{-2}, V_{\mathrm{oc}}$ of $0.525 \mathrm{~V}$ and $\eta$ of $2.53 \%$, which was $42 \%$ higher than that of nanowires produced by other methods. Wang et al. also fabricated double layered DSSCs using hierarchical $1 \mathrm{D} \mathrm{SnO}_{2} \mathrm{NFs} / \mathrm{NPs}$ which were employed as an efficient light scattering layer. ${ }^{99}$ The photovoltaic performance of rhe double layer $\mathrm{SnO}_{2} \mathrm{NPs}(14.5 \mu \mathrm{m}) / \mathrm{NFs}(4.0 \mu \mathrm{m})$ exhibited a $26.3 \%$ enhancement compared to a single layer $\mathrm{SnO}_{2}$ NPs photoanode when used in DSSCs. Gao et al. synthesized a branched hierarchical nanostructure of $\mathrm{TiO}_{2}$ nanoneedles on a
$\mathrm{SnO}_{2} \mathrm{NF}$ network (B-SnO ${ }_{2} \mathrm{NF}$ ), which served as model structure for highly efficient DSSCs. ${ }^{122} \mathrm{SnO}_{2}$ NFs with a diameter of $\sim 52$ $\mathrm{nm}$ showed a power conversion efficiency of $7.06 \%$, which was an increase of $26 \%$ and $40 \%$ when compared to $\mathrm{B}-\mathrm{SnO}_{2} \mathrm{NFs}$ with a diameter of $\sim 113 \mathrm{~nm}(\eta=5.57 \%)$ and $\mathrm{TiO}_{2}$ (P25) NPs $(\eta=5.04 \%)$, respectively, and this was more than five times as large as $\mathrm{SnO}_{2}$ NFs $(\eta=1.34 \%)$. Sahay et al. synthesized electrospun copper based composite NFs using a copper acetate/ PVA solution as the starting material.42 They observed the formation of poly-crystalline $\mathrm{CuO}$ structures with a predominate (111) phase orientation and diameters of $\sim 141 \mathrm{~nm}$. Preliminary results for a CuO NF DSSC with $\mathrm{ZnO}$ as the blocking layer exhibited a $25 \%$ increase in current density.

Organic solar cells (OSCs) have also attracted considerable interest as a potential renewable energy device due to their low cost, lower environmental impact, flexibility and lighter weight compared to conventional silicon solar cells. Recent advances in developing new organic active layer materials and device processing techniques have led to an improvement in conversion efficiencies. Elumalai et al. reported usage of an electrospun $\mathrm{ZnO}$ architecture as an electron transporting layer (ETL),

Table 1 Summary of hierarchical electrospun DSSCs with a NF-based photoanode (PA), counter electrode (CE) and Scattering layer (SL)

\begin{tabular}{|c|c|c|c|c|c|}
\hline Material & Type & Structure & Properties & Efficiency $(\eta \%)$ & Ref. \\
\hline $\mathrm{TiO}_{2}$ & PA & Fiber to rice-shaped to leaf-shaped & NF dia. $\sim 100 \mathrm{~nm}$, rice dia. $\sim 120 \mathrm{~nm}$ & 4.5 & 75 \\
\hline $\mathrm{TiO}_{2}$ & PA & Porous nanorods & Dia. $\sim 50 \mathrm{~nm}$ & 4.56 & 127 \\
\hline $\mathrm{TiO}_{2}$ & PA & Hollow mesoporous NFs & $\begin{array}{l}\text { NF dia. } \sim 130 \mathrm{~nm}, \\
\text { surface area } \sim 118 \mathrm{~m}^{2} \mathrm{~g}^{-1}\end{array}$ & 5.6 & 128 \\
\hline $\mathrm{TiO}_{2}$ & $\mathrm{PA}$ & Nanorods & - & 6.2 & 72 \\
\hline $\mathrm{TiO}_{2}$ & PA & Hierarchically structured NFs & - & 7.93 & 130 \\
\hline $\mathrm{TiO}_{2}$ & PA & Nanorods & Thickness of $14 \mu \mathrm{m}$ & 9.52 & 131 \\
\hline $\mathrm{TiO}_{2}$-graphene composite & $\mathrm{PA}$ & & $\mathrm{NF}$ dia. $\sim 150 \mathrm{~nm}$ & 7.6 & 132 \\
\hline ITO/CdS & PA & Coaxial NFs & - & 1.66 & 112 \\
\hline $\mathrm{TiO}_{2}$ & PA & Porous NF networks & $\mathrm{NF}$ dia. $\sim 80-100 \mathrm{~nm}$ & 2.69 & 114 \\
\hline $\mathrm{SnO}_{2}$ & PA & Aligned NFs & - & 2.53 & 121 \\
\hline $\mathrm{SnO}_{2}$ & PA & NF networks & $\mathrm{NF}$ dia. $\sim 52 \mathrm{~nm}$ & 7.06 & 122 \\
\hline Anatase $\mathrm{TiO}_{2}$ & SL & Prickle-like NFs & Surface area $\sim 154 \mathrm{~m}^{2} \mathrm{~g}^{-1}$ & 7.86 & 135 \\
\hline $\mathrm{TiO}_{2}$ & SL & Nest-shaped NFs & - & 8.02 & 98 \\
\hline $\mathrm{TiO}_{2}$ & SL & NPs/NFs & $\mathrm{NF}$ layer $\sim 2 \mathrm{~mm}, \mathrm{NP} \sim 10 \mathrm{~mm}$ & $33 \%$ higher than $\mathrm{TiO}_{2} \mathrm{NPs}$ & 101 \\
\hline $\mathrm{SnO}_{2}$ & SL & NFs/NPs & Double layer NPs $(14.5 \mu \mathrm{m}) / \mathrm{NFs}(4.0 \mu \mathrm{m})$ & 5.44 & 99 \\
\hline \multirow[t]{2}{*}{$\mathrm{TiO}_{2}$} & SL & Rice grains and NFs & Rice-grain and NF layer thickness $\sim 2 \mu \mathrm{m}$ & 7.45 & 136 \\
\hline & & & & 7.06 & \\
\hline $\mathrm{TiO}_{2}$ & SL & Ultraporous nanorods & Bilayered porous nanorods & 8.53 & 100 \\
\hline $\mathrm{TiO}_{2}$ & SL & NF/NPs & & 8.8 & 137 \\
\hline $\mathrm{Pt}$ & $\mathrm{CE}$ & NFs & NF dia. $\sim 40-70 \mathrm{~nm}$ & 6.0 & 96 \\
\hline
\end{tabular}


which exhibited high photoelectric conversion efficiency and stability. ${ }^{123}$ They developed an inverted bulk hetero-junction organic solar cell device structure of ITO/ZnO/poly(3-hexylthiophene) (P3HT):[6,6]-phenyl-C61-butyric acid methyl ester (PCBM) $/ \mathrm{MoO}_{3} / \mathrm{Ag}$. The devices that employed a higher loading of $\mathrm{ZnO}$ nanowires showed a $20 \%$ higher photoelectric conversion efficiency (PCE), which mainly resulted from an enhancement in the fill factor (FF). Bedford et al. demonstrated NFbased bulk heterojunction organic photovoltaics (BHJ-OPVs) of the electron donor-electron acceptor pair P3HT:PCBM. ${ }^{124}$ These fibers were then incorporated into the active layer of a BHJ-OPV device, which resulted in improved short-circuit current densities, fill factors, and PCEs. The best-performing fiber-based devices exhibited a PCE of $4.0 \%$, while the best thin-film devices had a PCE of $3.2 \%$. Chen et al. reported patterned electrospun Ag/PVP composite NFs for P3HT:PCBM photovoltaic devices. ${ }^{125}$ The composite electrospun NFs were prepared using in situ reduction of Ag NPs in Ag/PVP via a two-fluid coaxial electrospinning technique resulting in a $18.7 \%$ enhancement in PCE of the photovoltaic device. Wu et al. reported a hybrid solar cell based on electrospun $\mathrm{ZnO}$ NFs/poly(3-hexylthiophene) (ZnO/ P3HT). An improved device efficiency from $0.3 \%$ to $0.65 \%$ was observed after modification with CdS, which was mainly due to the cascading band structure of the heterojunction that could facilitate charge transfer at the interface and induce higher light absorption in visible region. ${ }^{126}$ Similarly, Wu et al. also reported organic-inorganic hybrid solar cells based on P3HT and electrospun $\mathrm{TiO}_{2} \mathrm{NFs}^{126} \mathrm{~A}$ CdS modified layer led to an increase in both the open circuit voltage and the short circuit current of the device, which could be attributed to enhanced exciton dissociation and light absorption. It also suppressed carrier recombination at the heterojunction, which increased the PCE of the device by about $50 \%$. Table 1 shows a summary of hierarchical electrospun NFs used as photoanodes, counter electrodes (CEs) and scattering layers (SLS) in DSSCs. The application of hierarchical NFs such as random/aligned, porous, hollow and coreshell with tuneable structures, combined with their surface properties show the great potential of electrospun fibers for enhancing the efficiency of DSSCs, QD-DSSCs and OSCs over other physical or chemical methods. These results demonstrate that electrospun NF-based photoanode, $\mathrm{CE}$, electrolyte and SL materials like $\mathrm{TiO}_{2}, \mathrm{ZnO}, \mathrm{SnO}_{2}$, carbon-based NFs and their composites exhibit stable and high energy conversion efficiency.

\section{Photocatalysis}

In recent years, there has been an increasing global demand for clean water due to growing urbanization as well as industrial and man-made pollution. To overcome these issues, researchers have developed various advanced processes to effectively treat wastewater and re-utilize it for immediate human consumption and industrial needs. Among these treatment processes, semiconducting metal-oxide based photocatalytic treatments have received significant attention due to their low-cost, recyclability, reusability and environmental friendliness. Metal oxides with novel properties can be easily synthesized via simple and cost-effective electrospinning processes. These metal oxides have been widely utilized to remove the organic contaminants and microorganisms present in wastewater.

In photocatalysis, semiconducting metal oxide $\left(\mathrm{MO}_{\mathrm{x}}\right) \mathrm{NFs}$ such as $\mathrm{TiO}_{2}, \mathrm{ZnO}, \mathrm{Fe}_{2} \mathrm{O}_{3}, \mathrm{CeO}_{2}$ and $\mathrm{WO}_{3} \mathrm{NFs}$ have been used as sensitizers/catalysts in light induced redox processes to photodegrade toxic and hazardous compounds. ${ }^{141,142}$ Generally, upon photo-irradiation of a semiconducting $\mathrm{MO}_{\mathrm{x}}$ with photons of energy $h v \geq E_{\mathrm{g}}$, an electron, $\mathrm{e}_{\mathrm{CB}}{ }^{-}$is promoted from the valence band (VB) into the conduction band (CB), leaving a hole behind, $\mathrm{h}_{\mathrm{VB}}{ }^{+}$. These generated electron-hole pairs are powerful oxidizing and reducing agents (eqn (1) and (5)), and create reactive radicals $\left(\mathrm{OH}_{\mathrm{ads}}{ }^{{ }^{-}}, \mathrm{O}_{2}{ }^{{ }^{*-}}\right)$ during photocatalytic reactions (eqn (2)-(4)). These highly reactive radicals then react with pollutants and degrade them into non-toxic compounds. ${ }^{143-145}$

$$
\begin{gathered}
\mathrm{MO}_{\mathrm{x}}+h \nu \rightarrow \mathrm{e}_{\mathrm{CB}}{ }^{-}+\mathrm{h}_{\mathrm{VB}}{ }^{+} \\
\mathrm{H}_{2} \mathrm{O} \leftrightarrow \mathrm{OH}^{-}+\mathrm{H}^{+} \\
\mathrm{h}_{\mathrm{VB}}{ }^{+}+\mathrm{OH}_{\mathrm{aq}}{ }^{-} \rightarrow \mathrm{OH}_{\mathrm{ads}}{ }^{*-} \\
\mathrm{e}_{\mathrm{CB}}{ }^{-}+\mathrm{O}_{2} \rightarrow \mathrm{O}_{2} \\
\mathrm{~h}_{\mathrm{VB}}{ }^{+}+\text {Pollutant } \rightarrow \text { Pollutant*} \\
\text { Pollutant* }+\left(\mathrm{O}_{2}, \mathrm{OH}^{*-}\right) \rightarrow \text { Degraded products }
\end{gathered}
$$

There are several factors affecting the efficiency of the photocatalysis. The life time of the reactive radicals/species is generally found to be tens of nanoseconds, therefore, the excited electrons and holes need to be effectively utilized, otherwise electron-hole recombination occurs and diminishes the efficiency of the photocatalysis. In addition, the surface area and porous nature of the photocatalyst also play vital roles in improving the interaction between pollutants and $\mathrm{MO}_{\mathrm{x}} \mathrm{s}$ for effective degradation. Considering these factors, researchers have focused on addressing these issues by synthesizing one dimensional semiconducting $\mathrm{MO}_{\mathrm{x}}$ materials with novel properties like porous morphologies, higher surface areas and higher crystallinity. ${ }^{141,146-148}$

Anatase $\mathrm{TiO}_{2}$ with a band gap of $3.2 \mathrm{eV}$ has been widely used as an effective photocatalyst for wastewater treatment. Zhang et al. employed coaxial electrospinning to synthesize hollow mesoporous 1D $\mathrm{TiO}_{2} \mathrm{NFs}$ with a high surface area of $118 \mathrm{~m}^{2}$ $\mathrm{g}^{-1} \cdot{ }^{182}$ These hollow mesoporous $\mathrm{TiO}_{2}$ NFs with a close packing of grains demonstrated faster electron diffusion and longer electron recombination time than regular $\mathrm{TiO}_{2}$ NFs and P25 NPs. The hollow mesoporous $\mathrm{TiO}_{2} \mathrm{NFs}$ with higher surface area exhibited better interaction and diffusion with rhodamine $\mathrm{B}$ ( $\mathrm{Rh} \mathrm{B})$ dye and resulted in an increased catalytic activity compared to $\mathrm{P} 25 \mathrm{TiO}_{2}$ nanocatalysts. Ganesh et al. developed self-cleaning $\mathrm{TiO}_{2}$ coatings comprised of rice-grain shaped nanostructures on glass substrates. These coatings were transparent and exhibited a higher photocatalytic activity than spraycoated P25 NPs for the photodegradation of Alizarin red dye, which was due to their single crystalline nature and high 
surface area. ${ }^{149}$ Liu et al. investigated the role of the morphology of $\mathrm{ZnO}$ NFs in the photodegradation of $\mathrm{Rh} \mathrm{B}$ and acid fuchsine under visible light. ${ }^{150}$ The porous structure of ZnO NFs improved the interaction between the dye molecules and the catalyst surface area that was in contact, while the aggregation of $\mathrm{ZnO}$ NPs in the solution lowered the photocatalytic efficiency. Sundaramurthy et al. fabricated novel nanobraid and nanoporous morphologies of pure ceramic $\alpha-\mathrm{Fe}_{2} \mathrm{O}_{3}$ nanostructures by varying the precursor concentration. ${ }^{151}$ These novel morphologies of $\alpha-\mathrm{Fe}_{2} \mathrm{O}_{3}$ exhibited superior photocatalytic performance of up to $91.8 \%$ and $90.8 \%$, respectively, for the degradation of congo red in a short irradiation period of 140 min (Fig. 11).

The presence of the porous surface and smaller crystallite size of the $\alpha-\mathrm{Fe}_{2} \mathrm{O}_{3}$ nanostructures acted as an active catalytic centre and played vital role for allowing effective interaction between congo red and $\alpha-\mathrm{Fe}_{2} \mathrm{O}_{3}$, thereby, enhancing the photosensitized catalytic photodegradation. Zhao et al. synthesized strongly acidic $\mathrm{Bi}_{2} \mathrm{WO}_{6}$ NFs and showed their ability to photodegrade methylene blue by around $94.8 \%$ under visible light exposure for $3.5 \mathrm{~h}$, compared with $\mathrm{Bi}_{2} \mathrm{WO}_{6}$ powder, which exhibited photodegradation of around $44.1 \%{ }^{152}$ The band gap narrowing and the absorption edges of the $1 \mathrm{D} \mathrm{Bi}_{2} \mathrm{WO}_{6} \mathrm{NFs}$ shifted towards the infrared region, which in turn broadened their absorption ability in the visible light region. In addition, the number of surface active sites in the fibers was significantly increased compared to their powder counterpart, which in turn improved the absorption of hydroxide free radicals of methylene blue and reduced the distance between the catalyst and dye, thereby effectively improving utilization of photogenerated holes, electrons and radicals. Electrospun BiOI nanoplate-like structures were fabricated and their ability to degrade Alizarin Red S (ARS) dye was tested under UV light irradiation. ${ }^{153}$ The
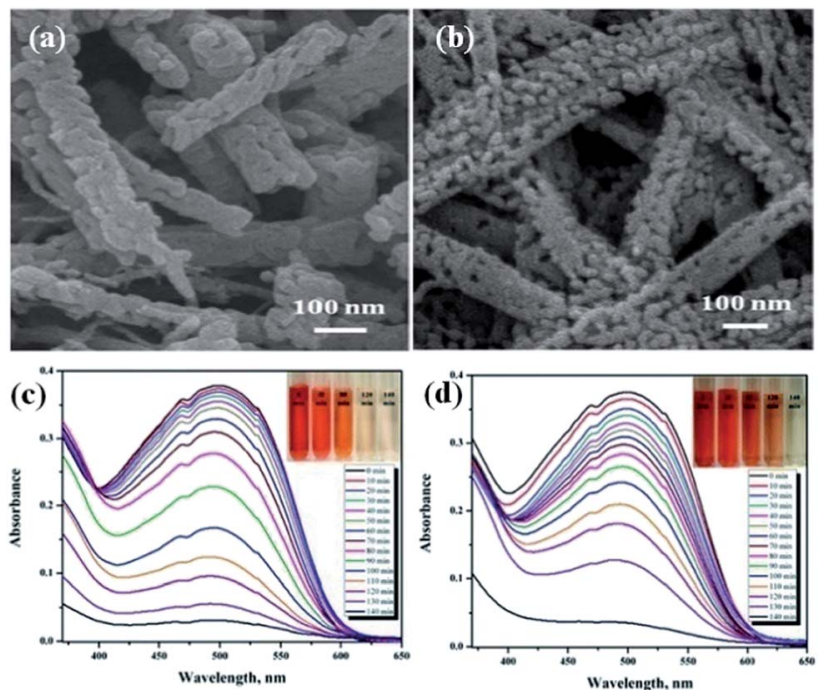

Fig. 11 FESEM images of (a) nanobraid and (b) nanoporous $\alpha-\mathrm{Fe}_{2} \mathrm{O}_{3}$ nanostructures after calcination of the as-electrospun $4 \mathrm{wt} \%$ and 6 wt\% iron acetylacetonate/PVP composite NFs. UV-visible absorbance spectra for the photodegradation of congo red in the presence of the (c) nanobraid and (d) nanoporous $\alpha-\mathrm{Fe}_{2} \mathrm{O}_{3}$ nanostructures. ${ }^{151}$ photocatalytic activity was also found to be dependent on the morphology ${ }^{154}$ and structure. ${ }^{155}$

However, the usage of $\mathrm{MO}_{\mathrm{x}} \mathrm{s}$ like $\mathrm{TiO}_{2}$ (3.2 eV for anatase) and $\mathrm{ZnO}(3.37 \mathrm{eV})$ possessing large band gaps has been limited to photoresponse in UV region, but only a small fraction of UV $(<4 \%)$ from the total solar spectrum reaches the Earth's surface. ${ }^{\mathbf{1 4 5 , 1 5 6}}$ In order to extend the photoresponse of $\mathrm{MO}_{\mathrm{x}} \mathrm{s}$ to the visible region, many research groups have focused on doping with transition metal ions or non-metal elements, such as V, Co, Ag, Au, Fe, C, N, S, or I. ${ }^{157-160}$ Zhang et al. successfully doped $\mathrm{V}$ ions into $\mathrm{TiO}_{2}$ NFs by electrospinning together vanadium and $\mathrm{TiO}_{2}$ precursors and calcining at $500{ }^{\circ} \mathrm{C} .{ }^{161}$ The fibers retained their anatase phase after calcination and XRD results confirmed the successful incorporation of $\mathrm{V}^{4+}$ or $\mathrm{V}^{5+}$ ions into the crystal lattice of the anatase $\mathrm{TiO}_{2}$ NFs and also showed slight variations in crystallite size with an increase in doping (Fig. 12(a and $\mathrm{b})$ ). $\mathrm{V}$ doping led to an extension of the absorption of $\mathrm{TiO}_{2}$ NFs in the visible light region (Fig. 12(c)) and the 1.0 and 5.0 wt $\%$ V-doped $\mathrm{TiO}_{2}$ NFs possessed higher activity for the photodegradation of methylene blue (MB). In addition, these NFs could also be recycled without a decrease in the photocatalytic activity. Xu et al. demonstrated the doping of $\mathrm{TiO}_{2} \mathrm{NFs}$ with metals like $\mathrm{Bi}$, which shifted the absorption spectra of $\mathrm{TiO}_{2}$ into the visible light region and effectively utilized lower energy photons for photocatalytic reactions. ${ }^{162}$ The Bi-doped $\mathrm{TiO}_{2} \mathrm{NFs}$ exhibited an enhanced $88.8 \%$ photodegradation of $\mathrm{Rh} \mathrm{B}$ due to the photosensitization effect and a better photocatalytic activity of $56.1 \%$ for phenol degradation compared with $\mathrm{TiO}_{2}$ NFs and P25 $\mathrm{TiO}_{2}$ NPs. Lin et al. fabricated a unique dimer-type heterostructure of $\mathrm{Ag}-\mathrm{ZnO}$ NFs using electrospinning and this coupled heterojunction structure improved charge separation and photon efficiency, allowing both photogenerated electrons and holes to participate in the overall photocatalytic reaction. ${ }^{\mathbf{1 6 3}}$ The photocatalytic activity for photodegradation of RhB was enhanced by a factor of more than 25 for Ag-ZnO NFs compared with pure ZnO NFs. Kim et al. synthesized graphene/carbon composite NFs (CCNFs) with $\mathrm{TiO}_{2}$ NPs uniformly coated onto the electrospun CCNFs. ${ }^{164}$ These composites NFs were very active photocatalysts in the photodegradation of $\mathrm{MB}$ under visible light irradiation and the NFs could be recycled for multiple degradation cycles without a decrease in the photocatalytic activity. The graphene acted as an electron acceptor and a photosensitizer, causing an increase in the photodegradation rate and reducing electron-hole pair recombination.
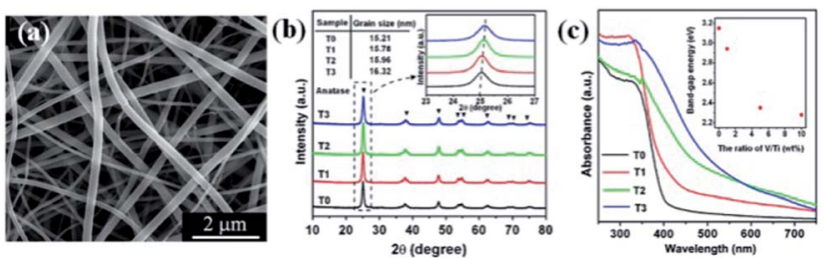

Fig. 12 (a) SEM image of $\mathrm{V}$-doped $\mathrm{TiO}_{2} \mathrm{NFs}$, (b) XRD patterns of $\mathrm{TiO}_{2}$ and $\mathrm{V}$-doped $\mathrm{TiO}_{2} \mathrm{NFs}$ : $\mathrm{TiO}_{2} \mathrm{NFs}$ (T0); 1.0 wt\% $\mathrm{V}$-doped $\mathrm{TiO}_{2} \mathrm{NFs}$ (T1); 5.0 wt\% V-doped $\mathrm{TiO}_{2} \mathrm{NFs}(\mathrm{T} 2) ; 10.0$ wt\% $\mathrm{V}$-doped $\mathrm{TiO}_{2} \mathrm{NFs}$ (T3) and UV-Vis diffuse reflectance (DR) spectra of $\mathrm{TiO}_{2}$ and $\mathrm{V}$-doped $\mathrm{TiO}_{2} \mathrm{NFs}^{161}$ 
Regular $1 \mathrm{D} \mathrm{TiO}_{2}$ NFs were prepared by electrospinning and a surface nitridation treatment in an $\mathrm{NH}_{3}$ atmosphere. ${ }^{165}$ These 1D nanostructures had extended visible-light absorption and the photocatalytic activity of $\mathrm{N}^{-\mathrm{TiO}_{2}} \mathrm{NFs}$ exceeded those of pure $\mathrm{TiO}_{2}$ NFs by a factor of 12 for the degradation of methylene blue dye. Zhang et al. demonstrated the improved performance of core-shell NFs of $\mathrm{TiO}_{2}$ @carbon embedded with $\mathrm{Ag}$ NPs $\left(\mathrm{TiO}_{2} @ \mathrm{C} / \mathrm{Ag}\right.$ ) for the photodegradation of $\mathrm{Rh} \mathrm{B}$ and methyl orange (MO) compared with pure $\mathrm{TiO}_{2} \mathrm{NFs}$, $\mathrm{TiO}_{2}$ @carbon coreshell NFs and $\mathrm{TiO}_{2} / \mathrm{Ag}$ NFs under visible light irradiation. ${ }^{\mathbf{1 6 6}}$ This significant enhancement in the photodegradation was due to the material's good light absorption capability and high separation efficiency of photogenerated electron-hole pairs based on a photo-synergistic effect. Although the above approaches partly improve the photocatalytic activity of $\mathrm{MO}_{\mathrm{x}} \mathrm{s}$, some issues like the thermal stability of the doped materials, photo-corrosion, lattice distortion, and an increase in the carrier recombination probability need to be addressed. .67-169 $^{\mathbf{1 6}}$ These issues can be solved by coupling with other narrow band gap semiconductors, which can serve as the sensitizer to absorb visible light. Liu et al. employed $\mathrm{TiO}_{2} / \mathrm{ZnO}$ composite NFs for the photodegradation of $\mathrm{RhB}$ and phenol under photoirradiation with UV light. ${ }^{\mathbf{1 7 0}}$ Blending $\mathrm{ZnO}$ into $\mathrm{TiO}_{2}$ lead to the formation of a new crystallite, $\mathrm{ZnTiO}_{3}$, which improved the absorption efficiency of ultraviolet light with an increase in the absorption edge of $20 \mathrm{~nm}$ and also reduced electron-hole pair recombination because of the coupling effect between $\mathrm{TiO}_{2}$ and the ZnO grain-like composite NPs. Shang et al. developed hierarchical hetero-nanostructures of a three-dimensional multicomponent oxide, $\mathrm{Bi}_{2} \mathrm{WO}_{6} / \mathrm{TiO}_{2}$, by combining electrospinning and a hydrothermal approach. ${ }^{171}$ The three dimensional multicomponent oxide hetero-nanostructures exhibited enhanced photodegradation of $\mathrm{Rh} \mathrm{B}$ dye in the visible range compared to bulk $\mathrm{Bi}_{2} \mathrm{WO}_{6} / \mathrm{TiO}_{2}$ powder, $\mathrm{Bi}_{2} \mathrm{WO}_{6} \mathrm{NPs}$, and $\mathrm{TiO}_{2}$ powder (Fig. 13(a and b)). The enhancement in the photocatalytic activity was due to the higher surface area, smaller grain size, which reduced the recombination of photogenerated electron-hole pairs, and the matching band potentials of the hierarchical hetero-nanostructures.

Zhang et al. created $1 \mathrm{D}$ electrospun p-type NiO/n-type $\mathrm{ZnO}$ NFs with different molar ratios and studied their photocatalytic activity with Rh B. ${ }^{172}$ Irradiation with UV light (onto the $\mathrm{p}-\mathrm{n}$
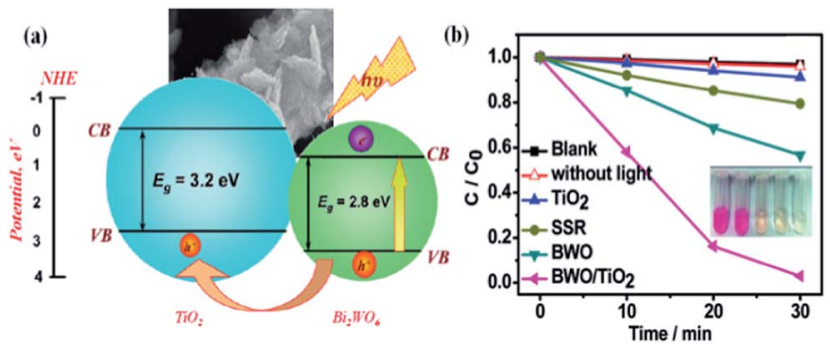

Fig. 13 (a) Schematic diagram show the energy band matching and electron-hole separations of $\mathrm{Bi}_{2} \mathrm{WO}_{6} / \mathrm{TiO}_{2}$ and (b) photocatalytic degradation of $\mathrm{Rh} \mathrm{B}$ in the presence of bulk and electrospun $\mathrm{Bi}_{2} \mathrm{WO}_{6} /$ $\mathrm{TiO}_{2}$ hierarchical hetero-nanostructures under visible-light irradiation. ${ }^{171}$
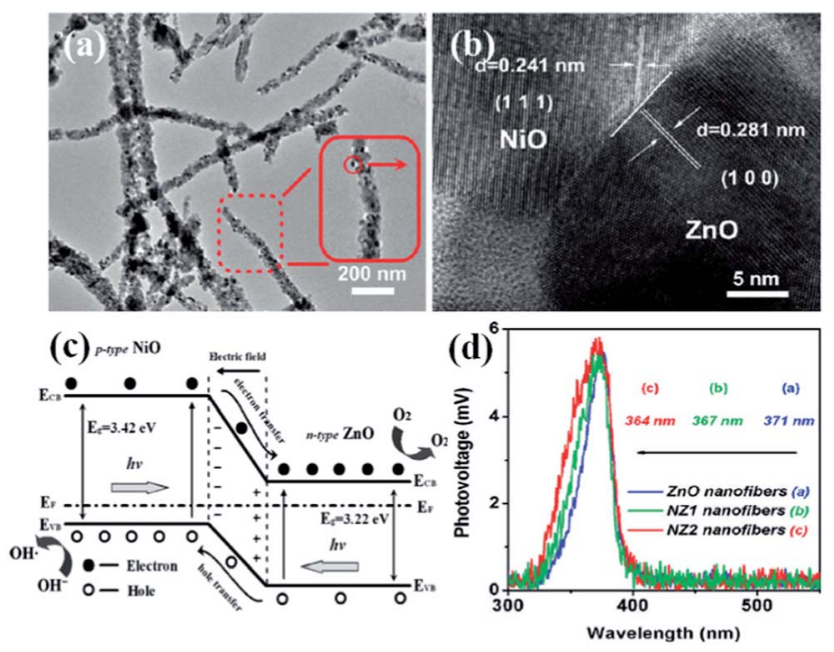

Fig. 14 (a) TEM image of electrospun p-type $\mathrm{NiO} / \mathrm{n}$-type $\mathrm{ZnO} \mathrm{NFs}$ after calcining at $550{ }^{\circ} \mathrm{C}$ for $2 \mathrm{~h}$, (b) HRTEM image of the heterojunction. (c) Schematic diagram showing the energy band structure and electron-hole pair separations and (d) surface photovoltage spectroscopy of the $\mathrm{ZnO}$ and $\mathrm{NiO} / \mathrm{ZnO}$ heterojunction NFs synthesized at different molar ratios. ${ }^{172}$

$\mathrm{NiO} / \mathrm{ZnO}$ heterojunction) (Fig. 14(a and b)) led to an efficient transfer of photogenerated electrons from the conduction band (CB) of p-type $\mathrm{NiO}$ to n-type $\mathrm{ZnO}$ and transfer of photogenerated holes to the valence band (VB) of p-type NiO due to the formation of an inner electric field (Fig. 14(c)). A trend of increasing photocatalytic reactivity was observed in the order of $\mathrm{NiO}<\mathrm{ZnO}$ $<\mathrm{TiO}_{2}<\mathrm{NiO} / \mathrm{ZnO}$ NFs.

Surface photovoltage spectroscopy also confirmed the efficient charge separation between the $\mathrm{NiO} / \mathrm{ZnO}$ heterojunction, which led to an increase in the lifetime of the charge carriers, thereby, enhancing the efficiency of interfacial charge transfer across the $\mathrm{NiO} / \mathrm{ZnO}$ heterojunction and accounting for the higher photocatalytic activity (Fig. 14(d)). Liu et al. also fabricated a novel NF structured photocatalyst consisting of $\mathrm{TiO}_{2}$ and $\mathrm{SnO}_{2}$, using a side-by-side dual spinneret approach in a simple electrospinning process. ${ }^{173}$ These bicomponent $\mathrm{TiO}_{2} /$ $\mathrm{SnO}_{2}$ NFs demonstrated improved photocatalytic activity for the photodegradation of $\mathrm{Rh} \mathrm{B}$ compared to pure $\mathrm{TiO}_{2} \mathrm{NFs}$ in a shorter period of time. In the $\mathrm{TiO}_{2} / \mathrm{SnO}_{2}$ heterojunction structure, band gap matching and the exposed morphology promoted the charge separation of photogenerated electrons and holes, allowing both photogenerated electrons and holes to participate in the overall photocatalytic reaction and effectively improve the photodegradation.

When nanostructured $\mathrm{Bi}_{2} \mathrm{WO}_{6}$ is coupled with $\mathrm{TiO}_{2}$, its performance for the photodegradation of organic compounds is enhanced significantly. A new generation of photocatalysts with tungsten and $\mathrm{TiO}_{2}$ was prepared by the thermal hydrolysis of aqueous solutions of peroxo complexes of titanium and tungsten, which enhanced the reaction rate for the photodegradation of Orange II dye in the UV and visible regions of the spectrum. ${ }^{195}$ Similarly, several researchers have attempted to synthesize a combination of different metal oxide nanostructures with matching band gaps like $\mathrm{TiO}_{2} / \mathrm{CdO},{ }^{196} \mathrm{CeO}_{2} /$ 
Table 2 Summary of commonly employed electrospun nanostructures for photocatalysis. (Abbreviations: Rh B: rhodamine B; MO: methyl orange; MB: methylene blue; AO7: acid orange II; MWCNTs: multiwalled carbon nanotubes)

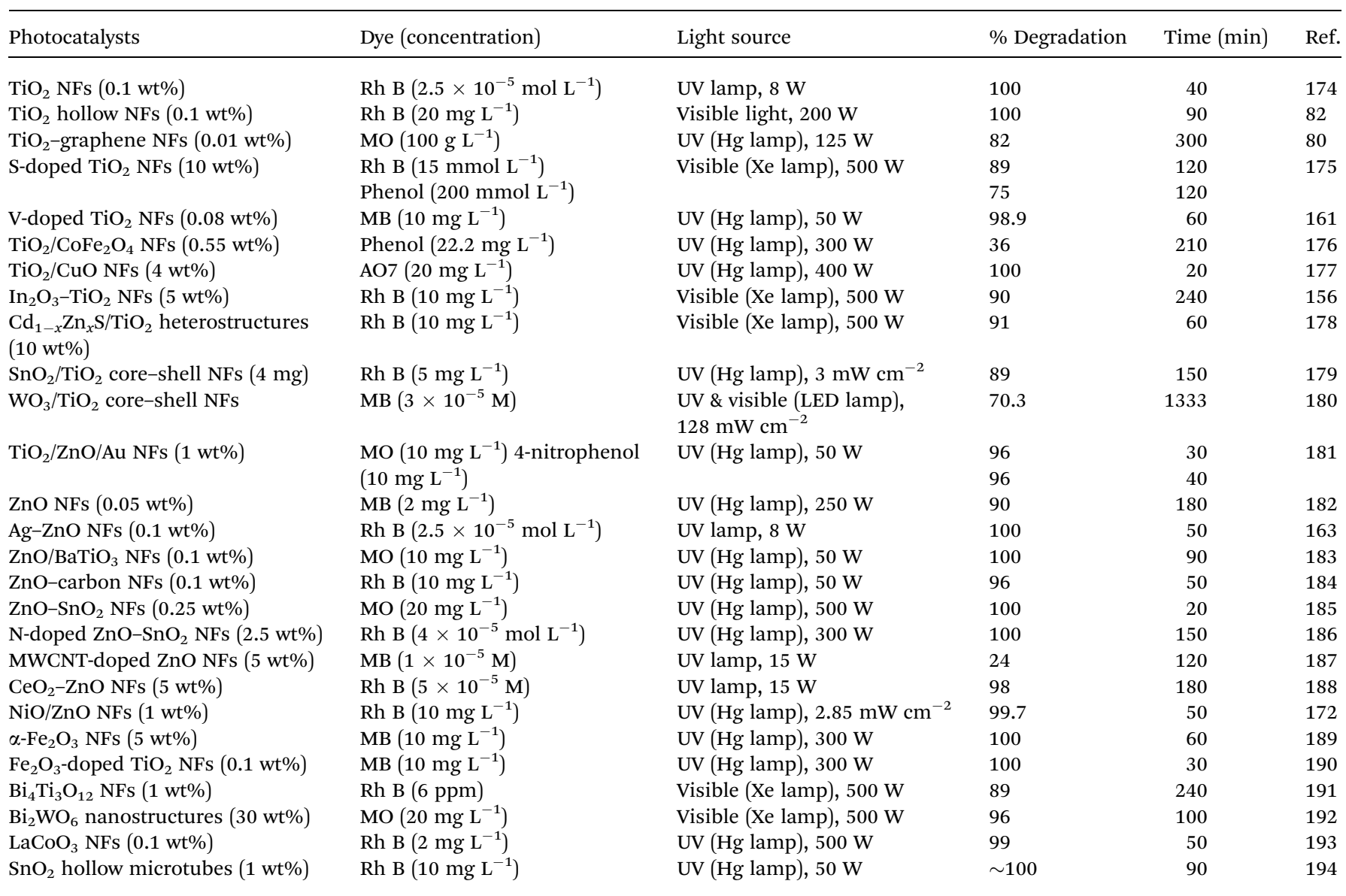

$\mathrm{ZnO},{ }^{188} \mathrm{ZnO} / \mathrm{SnO}_{2},{ }^{197} \mathrm{In}_{2} \mathrm{O}_{3} / \mathrm{TiO}_{2},{ }^{156} \mathrm{CeO}_{2} / \mathrm{TiO}_{2},{ }^{198} \mathrm{TiO}_{2} / \mathrm{SiO}_{2},{ }^{199}$ $\mathrm{ZnO} / \mathrm{BaTiO}_{3}{ }^{183} \mathrm{Bi}_{2} \mathrm{~S}_{3} / \mathrm{TiO}_{2}{ }^{200}$ and $\mathrm{ZnO} / \mathrm{CdO}^{201}$ using electrospinning or a combination of electrospinning and other approaches like hydrothermal synthesis. The synergistic properties that arise from the combination of metal oxides lead to improved light absorption, increased charge separation and reduced recombination of electron-hole pairs, and thereby, enhanced effectiveness for the photodegradation of organic pollutants and dyes under UV and visible light irradiation. Table 2 shows a summary of different electrospun metal oxide nanostructures employed in the photocatalysis of wide range of dyes and pollutants. Irrespective of the intensity of the light and the time of exposure, these metal oxides exhibited photocatalytic activity under both UV and visible light depending on their bandgap properties. However, electrospinning offers an added advantage for improving the visible-light photocatalytic activity of metal oxides and coupling metal oxides with other conductors or semiconductors by doping or forming core-shell nanostructures promotes the separation of photoexcited electron-hole pairs by mutual transfer of photogenerated electron

Table 3 Summary of photocatalytic hydrogen generation based on electrospun NFs produced to date

\begin{tabular}{|c|c|c|c|c|}
\hline $\begin{array}{l}\text { Photocatalyst (with } \\
\text { different morphology) }\end{array}$ & Light source & $\begin{array}{l}\text { Surface area } \\
\left(\mathrm{m}^{2} \mathrm{~g}^{-1}\right)\end{array}$ & $\begin{array}{l}\mathrm{H}_{2} \text { production } \\
\text { rate }\left(\mu \mathrm{mol} \mathrm{h} \mathrm{h}^{-1}\right)\end{array}$ & Ref. \\
\hline $\mathrm{TiO}_{2}\left(450{ }^{\circ} \mathrm{C}\right)$ & $450 \mathrm{~W} \mathrm{Hg}$ (UV) & 56.3 & 54 & 221 \\
\hline $\mathrm{TiO}_{2}\left(450^{\circ} \mathrm{C}\right)$ & $400 \mathrm{~W} \mathrm{Hg}$ (UV) & 47.75 & 90 & 242 \\
\hline $\mathrm{TiO}_{2}\left(500^{\circ} \mathrm{C}\right)$ & >420 nm (visible) & 96.3 & 206 & 248 \\
\hline $\mathrm{TiO}_{2}\left(500{ }^{\circ} \mathrm{C}\right)$ & $450 \mathrm{~W} \mathrm{Hg}$ (UV) & 58.2 & 19.1 & 240 \\
\hline $\mathrm{TiO}_{2} / \mathrm{N}_{2}\left(450^{\circ} \mathrm{C}\right)$ & $150 \mathrm{~W}$ Xe (visible) & 70 & 28 & 249 \\
\hline $\mathrm{TiO}_{2} / \mathrm{Pt}\left(500^{\circ} \mathrm{C}\right)$ & $>420 \mathrm{~nm}$ (visible) & 96.3 & 7110 & 248 \\
\hline $\mathrm{TiO}_{2} / \mathrm{SrTiO}_{3}$ & $400 \mathrm{~W} \mathrm{Hg}$ (UV) & 50.33 & 330 & 242 \\
\hline $\mathrm{SrTiO}_{3}\left(500{ }^{\circ} \mathrm{C}\right)$ & $450 \mathrm{~W} \mathrm{Hg}$ (UV) & 122 & 81 & 250 \\
\hline $\mathrm{TiO}_{2} / \mathrm{CuO}\left(450{ }^{\circ} \mathrm{C}\right)$ & $400 \mathrm{~W} \mathrm{Hg}$ (UV) & 108.1 & 62.7 & 177 \\
\hline $\mathrm{TiO}_{2} / \mathrm{SnO}_{2}\left(450^{\circ} \mathrm{C}\right)$ & $400 \mathrm{~W} \mathrm{Hg}$ (UV) & 73.1 & 200 & 243 \\
\hline
\end{tabular}


or holes within the heterojunction, thus extending the lightresponse range. Eletrospun photocatalysts have also shown excellent recyclability for a number of times as photocatalysts without any deterioration in the photocatalytic effect.

\section{Hydrogen energy harvesting from nanostructured photocatalysts}

\subsection{Hydrogen energy production}

Nanotechnology is a fast growing area of scientific advancement for both present and future energy requirements since nanostructured semiconductor materials (e.g., Si nanowires and $\mathrm{TiO}_{2}$ ) can facilitate cost reductions in device processing and effectively enhance energy conversion efficiency. Several research groups have focused on the preparation of low cost nanomaterials for obtaining high energy efficiency. ${ }^{58,202,203}$ These nanostructures have high specific surface areas (which provide active sites) compared to bulk silicon based photovoltaics (PVs). ${ }^{204,205}$ Obviously, if the cost of the nanomaterials goes down and efficiency is also quite promising then these nanomaterials will be used rather than the bulk materials. Facile synthesis methods for the production of nanostructured materials have demonstrated cost reductions compared with the expensive epitaxially grown thin-film solar cells. ${ }^{206-210}$ 1D nanofibers (NFs) have already proven their importance in electronics, optoelectronics, optical sensing, dye photodegradation and energy harvesting technologies ${ }^{211}$. Functional electrospun NFs exhibit numerous optical ${ }^{212-215}$ and/or electronic ${ }^{216-218}$ properties at the nanoscale. Their electrical transport, optical, and photocatalysis properties are closely related to the electronic band gap of the materials. ${ }^{219,220}$ In addition, $\mathrm{TiO}_{2}$ electrospun NFs show enhanced crystallinity, high surface areas, and photocatalytic activity (PCA) for hydrogen evolution compared to those made by hydrothermal synthesis. ${ }^{221}$ Electrospun NFs with a high specific surface area facilitate the effective absorption of emitted light, so can be potentially useful in solar energy conversion especially for metal oxides $\left(\mathrm{TiO}_{2}\right){ }^{214}$ In general, using suitable 1D NF structures can help trap photons more effectively with the appropriate geometrical configuration during the generation of excitons $\left(\mathrm{e}^{-} / \mathrm{h}^{+}\right)$. The overall dimensions of the nanostructures are similar to the carrier diffusion lengths needed to facilitate the collection of free carriers in the exciton separation process. Effective exciton generation and charge separation result in increased energy conversion efficiency. ${ }^{209,222,223}$ Despite the length of 1D nanomaterials ranging from hundreds of nanometres to tens of micrometres, they can scatter light as effectively as large NPs. ${ }^{224,225}$ Lee et al. reported that $\mathrm{ZnO}$ nanorod arrays can serve as an effective anti-reflection coating at a long range of wavelengths from 400 to $1200 \mathrm{~nm}$, due to their regular texture, morphology and nanoscale dimensions. ${ }^{226}$

\subsection{Principle mechanism}

The first attempt at photo electrochemical hydrogen production by splitting water was reported in early 1972 by Fujishima and Honda. ${ }^{227}$ Single crystalline $\mathrm{TiO}_{2}$ wafers were used as a working electrode, while a platinum block was used as a counter electrode and they found $\mathrm{H}_{2}$ and $\mathrm{O}_{2}$ generation at the counter and working electrode, respectively. They suggested that adding a reducible ion species into the counter electrode leads to more current being produced, resulting in a higher water splitting efficiency via electrolysis. In recent years, many researchers have explored semiconductor photocatalytic hydrogen conversion. ${ }^{228,229}$ Photocatalytic hydrogen production essentially requires the photogeneration of hole-electron pairs. The basic mechanism of photocatalytic water-splitting can be divided into several intermediate processes: (a) the absorption of photons, (b) recombination, separation, migration, trapping, and transfer of the resulting excited charges, and (c) surface chemical reactions. All of these components effect the final generation of $\mathrm{H}_{2}$ using the photocatalytic material. In general, electrons in the VB of the photocatalyst are excited to the CB by irradiation with photons and the holes that are left in the VB leads to the creation of $\mathrm{e}^{-} / \mathrm{h}^{+}$pairs, which are referred as photoexcitons. These photoexcited electrons and holes separate and migrate to the surface of the photocatalyst. A list of various photocatalysts and their valance band (VB) and conduction band (CB) energy levels is presented in Fig. 15, with respect to a normal hydrogen electrode $\left(E_{\mathrm{NHE}}\right)$ and a vacuum $\left(E_{\mathrm{vcc}}\right)$. As shown in Fig. 15 , the photocatalysts with a suitable band gap are those whose electronic structures match well with the redox potential of water to convert into $\mathrm{H}_{2}$ and $\mathrm{O}_{2}$ molecules. The band levels of oxide materials for water-splitting generally change with $\mathrm{pH}$. Despite the fact that some of these semiconductors have suitable $E_{\mathrm{g}}$ values for visible light response, they are not active for water splitting and can be considered to be photocorrosives. ${ }^{230}$ For example, CdS and $\mathrm{WO}_{3}$ fall into photocorrosive category because their conduction band minima are at low levels and their band structures are just a thermodynamic requirement, but not a sufficient condition for $\mathrm{H}_{2}$ evolution. Therefore, suitable band gap engineering is required for the design of appropriate photocatalysts for $\mathrm{H}_{2}$ generation.

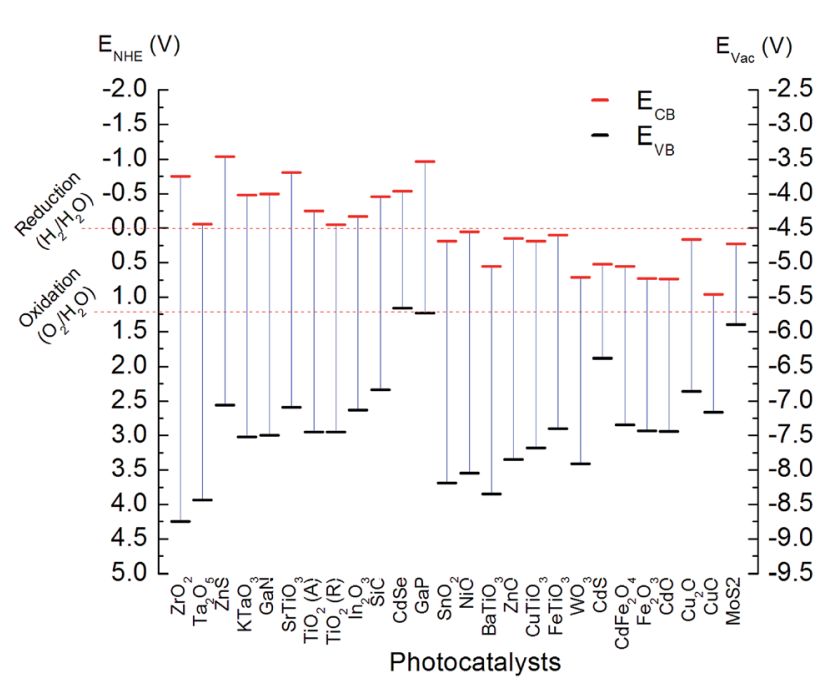

Fig. 15 Relationship between the absolute CB and VB energy levels for various photocatalysts with respect to the normal hydrogen electrode (NHE) potential and vacuum energy $\left(V_{\mathrm{ac}}\right)$. 


\subsection{Hydrogen generation using photocatalysts}

In photocatalytic water-splitting for $\mathrm{H}_{2}$ production, electrons in $\mathrm{CB}$ are the most important as they reduce protons to hydrogen molecules. However, the CB level must be more negative than the hydrogen evolution level in order to initiate $\mathrm{H}_{2}$ production. ${ }^{228}$ Metal ion-insertion or dye sensitization are two methods to extend the activation of $\mathrm{TiO}_{2}$ to visible light activation. Early experimental work from several different researchers focused on the correlation between visible light absorption and the photocatalytic activity in nitrogen doped $\mathrm{TiO}_{2}$ photocatalysts. By recording XPS spectra, the state of $\mathrm{N}$ 1s was revealed, showing two main peaks at 396 and $400 \mathrm{eV}$. However, other research groups reported that nitrogen doping caused peaks for $\mathrm{N}-\mathrm{O}$, interstitial $\mathrm{N}$, and $\mathrm{N}-\mathrm{H}$ complexes. ${ }^{231-234}$ The nature of the nitrogen related defects associated with visible light absorption remains an issue. Wu et al. reported nitrogen doped $\mathrm{TiO}_{2} \mathrm{NFs}$ decorated with approximately $2 \mathrm{~nm}$ diameter Pt NPs, which were tested for hydrogen generation at different wavelengths. ${ }^{235}$ The catalysts were found to be effective for the production of hydrogen energy, exhibiting conversion efficiencies of $3.6 \%$ and $12.3 \%$ at $365 \mathrm{~nm}$ and $312 \mathrm{~nm}$ UV light irradiation, respectively. Fig. 16(a and b) shows hydrogen evolution from the nitrogen doped $\mathrm{TiO}_{2}$ NFs under UV-A and UV-B irradiation, respectively. Gaseous $\mathrm{N}_{2}$ was bubbled at flow rate of $400 \mathrm{~mL} \mathrm{~min}^{-1}$, serving as a purge gas for gaseous state collection.

By employing thermodynamic approaches, Varley et al. attempted to explain the nitrogen impurities seen on visible light absorption in $\mathrm{TiO}_{2}$ and found that the nitrogen impurities gave rise to sub-band gap absorption, which could be clearly attributed to substitutional $\mathrm{N}$ and not interstitial nitrogen. ${ }^{236}$ Sun et al. synthesized $\mathrm{TiO}_{2}$ co-doped with cerium/N and found that the enhanced lattice distortion caused a high production rate of hydrogen. ${ }^{237}$ Due to the formation of $\mathrm{N}-\mathrm{Ti}$ and $\mathrm{N}-\mathrm{Ti}-\mathrm{O}$ bonding, the band gap energy was narrowed and resulted in an extension of the absorption edge towards the visible region. These co-doped photocatalysts were stable, with an increased amount of hydrogen production over longer time periods. Electrospun NF composites for hydrogen generation have been demonstrated using PVDF and ionic liquids. ${ }^{238}$ These catalytic ionic liquids were used only with PVDF for electrospinning. They showed that the complete release of hydrogen could be achieved using composite NFs.
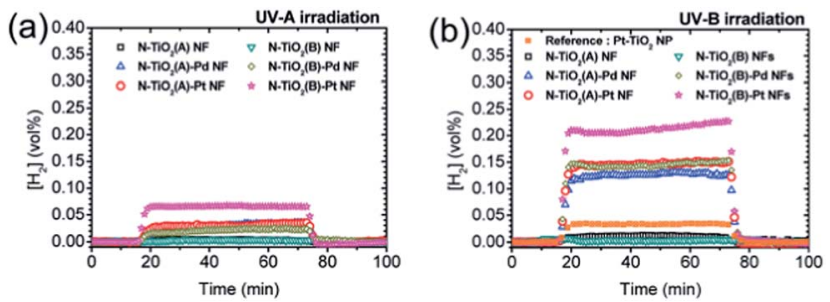

Fig. 16 Hydrogen evolution from ethanol-water mixture (molar ratio $1: 3)$ over parent and noble metal loaded (1.0 wt\%) catalyst materials (100 mg each) under (a) UV-A (1.54 W) and (b) UV-B (1.46 w) irradiation. ${ }^{235}$
Lee et al. reported enhanced photocatalytic hydrogen production from electrospun $\mathrm{TiO}_{2} / \mathrm{CuO}$ NFs, which had a high surface area and visible light absorbance. ${ }^{239}$ The heterojunctions between $\mathrm{TiO}_{2}$ and $\mathrm{CuO}$ yield a good separation of electrons and holes. The mixed semiconductor $\left(\mathrm{TiO}_{2} / \mathrm{CuO}\right)$ electrospun NFs at low and high magnification are shown in Fig. 17( $\mathrm{a}$ and $\mathrm{b})$. The reported photocatalytic $\mathrm{H}_{2}$ generation under UV light irradiation over $4 \mathrm{~h}$ is shown in Fig. 17(c). At a certain level of $\mathrm{CuO}$ doping, the hydrogen production rate reached a maximum after which the generation rate reduced. A band alignment scheme is presented in Fig. 17(d) for the purpose of better understanding the electron and hole transportation. The same authors reported that the $\mathrm{TiO}_{2} / \mathrm{CuO}$ composite fibers had the multifunctional ability for photocatalytic organic dye degradation and efficient $\mathrm{H}_{2}$ generation from dye waste water. ${ }^{177}$ The composite fibers exhibited excellent synergistic effects like (a) a large specific surface area, (b) absorbance at higher wavelength regions, (c) continuous and long nanofibers for efficient charge transfer, (d) heterojunction that could enhance the separation of $\mathrm{e}^{-} / \mathrm{h}^{+}$and (e) a second metal oxide that could serve as a co-catalyst for $\mathrm{H}_{2}$ generation. Fig. 18(a and b), show the defect free $\mathrm{TiO}_{2} / \mathrm{CuO}$ electrospun composite nanofibers at low and high magnification. These nanostructures were also a promising candidate for photocatalytic applications as well. Fig. 18(c) shows the $\mathrm{e}^{-} / \mathrm{h}^{+}$transfer pathways within the composite nanofibers $\left(\mathrm{TiO}_{2} / \mathrm{CuO}\right)$. Once a photon is absorbed by the catalyst surface, due to the potential difference electrons are transferred from $\mathrm{CB}$ of $\mathrm{TiO}_{2}$ into the $\mathrm{CB}$ of $\mathrm{CuO}$ in the heterojunction. Consequently, the excess of electrons which accumulates in the $\mathrm{CB}$ of $\mathrm{CuO}$ causes a negative shift in its Fermi level, rendering a higher electron availability for interfacial transfer to $\mathrm{H}^{+}$in solution to produce $\mathrm{H}_{2}$.

Chuangchote et al. reported highly efficient photocatalytic hydrogen generation using $\mathrm{TiO}_{2}$ electrospun NFs in combination with a sol-gel methodology. ${ }^{221}$ The hydrogen energy

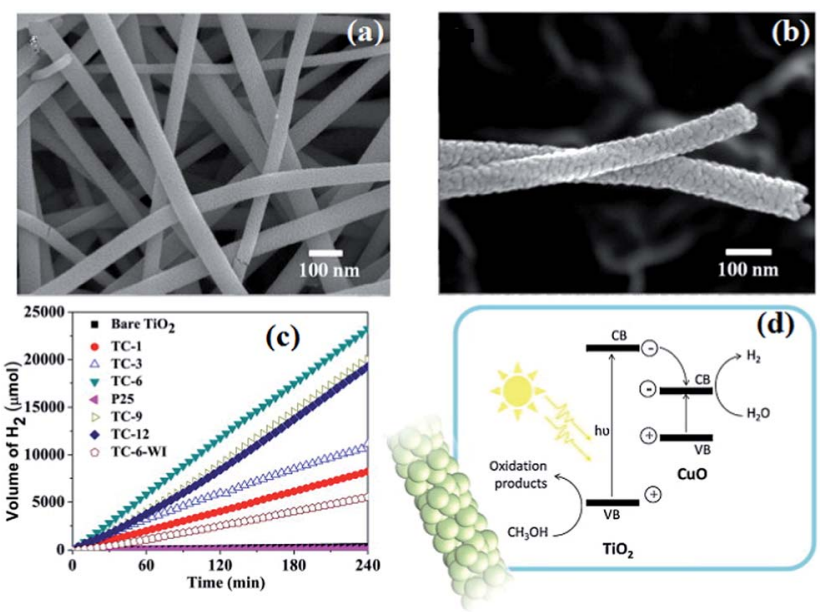

Fig. 17 (a) FESEM image of $\mathrm{TiO}_{2}-\mathrm{CuO}$ with 6 mol\% of $\mathrm{Cu}$ nanofibers, (b) high magnification FESEM image of $\mathrm{TiO}_{2}-\mathrm{CuO}$ with $6 \mathrm{~mol} \%$ of $\mathrm{Cu}$ nanofibers, (c) photocatalytic $\mathrm{H}_{2}$ evolution within $4 \mathrm{~h}$ of irradiation time and (d) a schematic illustration for photocatalytic $\mathrm{H}_{2}$ generation over the $\mathrm{TiO}_{2} / \mathrm{CuO}$ heterojunction. ${ }^{239}$ 

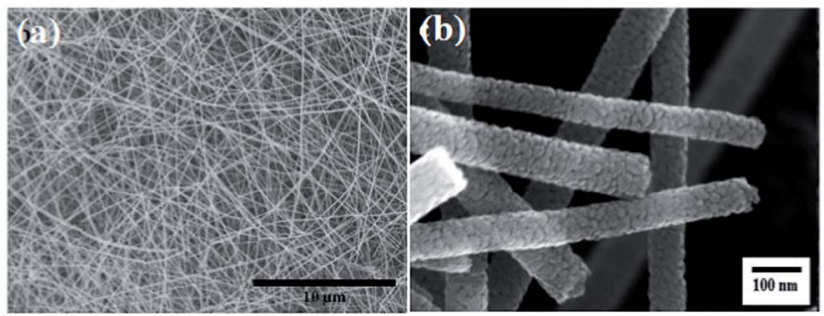

(c)

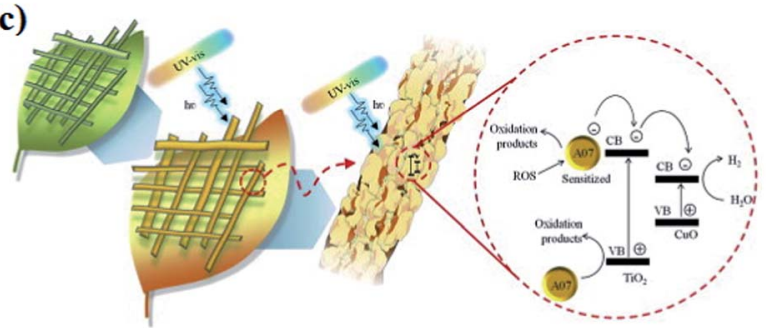

Fig. 18 FESEM images of the $\mathrm{TiO}_{2} / \mathrm{CuO}$ nanofibers at (a) low and (b) high magnifications and (c) a schematic representation of the photogenerated $\mathrm{e}^{-} / \mathrm{h}^{+}$transfer between the $\mathrm{TiO}_{2} / \mathrm{CuO}$ heterojunction. ${ }^{177}$

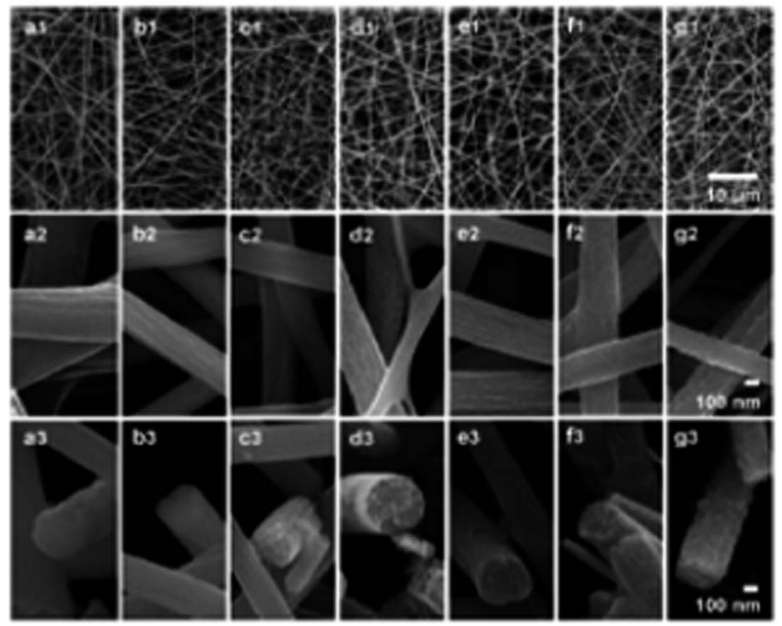

Fig. $19 \mathrm{SEM}$ images of (a) as-spun PVP/TiO 2 composite nanofibers and $\mathrm{TiO}_{2}$ nanofibers after calcination at various temperatures of (b) 300, (c) 400, (d) 450, (e) 500, (f) 600 , and (g) $700{ }^{\circ} \mathrm{C}$ for 3 h. ${ }^{221}$

production rate significantly depended on the surface area and crystallinity as well as having a high photocatalytic activity and calcination temperatures. The morphological structures of the electrospun NFs were not affected much up to $400{ }^{\circ} \mathrm{C}$, as they were still fibrous in nature, which can be observed in Fig. 19(a and b). However, the fiber diameters shrunk and the alignment of the fibers improved from 400 to $500{ }^{\circ} \mathrm{C}$ (Fig. 19(c-e)). A further increase in temperature up to $700{ }^{\circ} \mathrm{C}$ and the fiber structures converted into large sized interlinking particles (Fig. 19(f-g)). The calcination temperature and phase transition played a crucial role in determining the amount of hydrogen produced. The electrospun NFs calcined at $450{ }^{\circ} \mathrm{C}$ resulted in predominantly in an anatase $\mathrm{TiO}_{2}$ phase and led to a fast rate of hydrogen production $\left(270 \mu \mathrm{mol} \mathrm{g}^{-1}\right.$, under UV light). The electrospun NFs showed greater hydrogen evolution compared to samples prepared using a hydrothermal
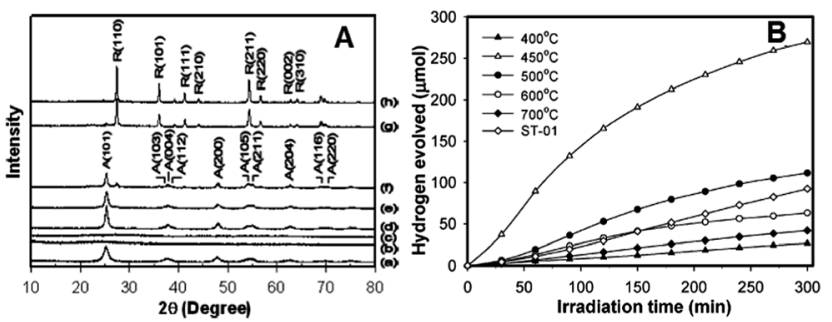

Fig. 20 (A) XRD patterns of (a) $\mathrm{TiO}_{2}$-Deggusa (ST-01), (b) pre-calcined as-spun NFs and NFs calcined at (c) $300^{\circ} \mathrm{C}$, (d) $400{ }^{\circ} \mathrm{C}$, (e) $450{ }^{\circ} \mathrm{C}$, (f) $500{ }^{\circ} \mathrm{C}$, (g) $600{ }^{\circ} \mathrm{C}$ and (h) $700{ }^{\circ} \mathrm{C}$. The lattice planes of $\mathrm{A}$ and $\mathrm{R}$ represents anatase and rutile phases. (B) The corresponding photocatalytic hydrogen evolution for the $\mathrm{TiO}_{2}$ fibers calcined at various temperatures compared to $\mathrm{TiO}_{2} \mathrm{NP}$ powder (Ishihara ST-01). ${ }^{221}$

method. ${ }^{240}$ The XRD patterns of the $\mathrm{TiO}_{2} \mathrm{NFs}$ calcined at different temperature are shown in Fig. 20(a), and the corresponding hydrogen evolution rates with respect to the irradiation time are shown in Fig. 20(b).

A suitable combination of a photocatalyst (semiconductor) with another semiconductor such as $\mathrm{SnO}_{2},{ }^{241}$ can promote UV light absorption. Electrospun strontium titanate $\left(\mathrm{SrTiO}_{3}\right) \mathrm{NFs}$ can also be utilized for photocatalytic hydrogen generation via water splitting. ${ }^{242}$ The amount of hydrogen obtained was $c a .1100$ and $300 \mu \mathrm{mol}$ within 200 min for $\mathrm{SrTiO}_{3}$ and $\mathrm{TiO}_{2}$ electrospun NFs, respectively. Lee et al. has also reported experimental studies on $\mathrm{SnO}_{2}$ doped $\mathrm{TiO}_{2}$ electrospun nanofibers and studied their photocatalytic hydrogen conversion from water-splitting. ${ }^{243}$

Tong et al. fabricated electrospun PAN/Ag/Pd composite fibers and demonstrated their high performance photocatalytic hydrogen generation. ${ }^{244}$ This catalyst material had also shown excellent recycling stability, which is presented in Fig. 21. Electrospun nanofibers of the PAN/Ag/Pd catalyst appeared like networked structures both before and after catalytic testing as shown in Fig. 21(a and b). $\mathrm{H}_{2}$ evolution for the PAN/Ag/Pd
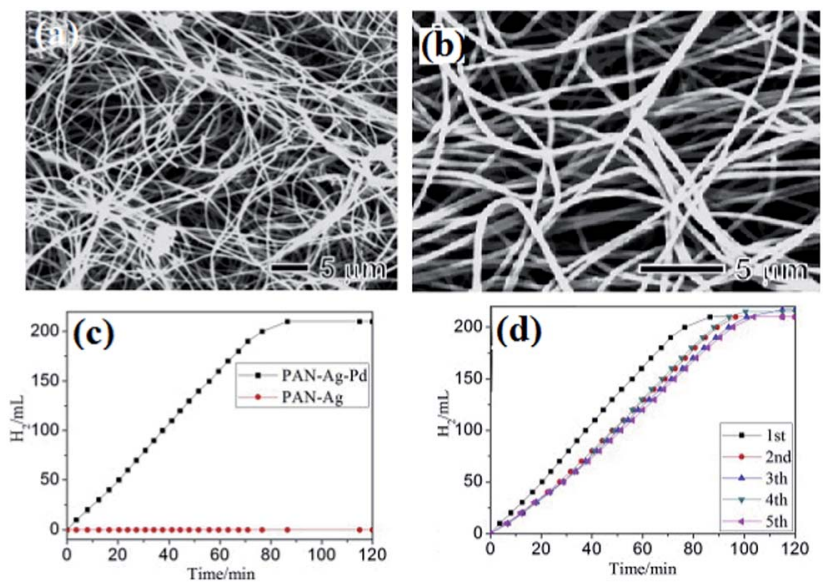

Fig. 21 (a) FESEM image of the PAN/Ag/Pd nanofibers. (b) FESEM image of the PAN/Ag/Pd nanofibers after a 5th cycle of the catalytic reaction. (c) $\mathrm{H}_{2}$ generation in the presence of the PAN/Ag/Pd nanofibers and PAN/Ag nanofibers with respect to time and (d) results for five cycles of the catalytic reaction. ${ }^{244}$ 
and PAN/Ag nanofibers with respect to time is presented in Fig. 21(c and d). The amount of $\mathrm{H}_{2}$ generated using the PAN/Ag/ $\mathrm{Pd}$ nanofibers is much higher than that for the PAN/Ag and it is also stable over 5 cycles. Compound semiconductors provide interesting properties for the enhancement of overall watersplitting in photocatalytic hydrogen generation. Maeda et al. reported a highly photoactive catalyst solid solution compound $\left(\mathrm{Ga}_{1-x} \mathrm{Zn}_{x}\right)\left(\mathrm{N}_{1-x} \mathrm{O}_{x}\right)$, which exhibited an overall quantum efficiency of about $2.5 \%$ under visible light (420-440 nm) irradiation. ${ }^{245}$ The quantum efficiency decreased with increasing wavelength, and it was suggested that the longer wavelengths were more suitable for the solid solutions for overall water splitting to produce hydrogen. Total hydrogen production was about $16.2 \mathrm{mmol}$ after irradiation. ${ }^{246}$ Recently our group, Babu et al. have studied electrospun MWCNT-doped $\mathrm{TiO}_{2}$ hybrid nanostructures for photocatalytic degradation and hydrogen evolution. ${ }^{247}$ Doping changed the hydrogen yield, increased the solar to hydrogen conversion efficiency and it led to an improvement in the charge separation and extended photoexcitation at the interface between the working electrode and the electrolyte in the system. Choi et al. prepared directionally aligned NFs consisting of three dimensional (3D) spherical $\mathrm{TiO}_{2}$ NPs via electrospinning. ${ }^{248}$ Light induced hydrogen production using Eosin dye sensitization improved by a factor of 140 in the presence of triethanolamine (TEOA) as an electron donor. This enhancement in hydrogen generation was due to changes in the physicochemical properties such as solubility changes, $\mathrm{pH}$ and adsorption range of the dye as well as the BET surface area and diameter of the particles and their crystalline nature.

Table 3 summarizes the electrospun nanofibers that have been employed for hydrogen energy generation and shows that hydrogen generation is dependent on the surface area, morphology and calcination temperature.

\section{Fuel cells}

Fuel cells are electrochemical devices where energy is stored in chemical fuel is converted into electricity in the presence of a metal catalyst. Hydrocarbons such as methanol and renewable fuel sources such as bioethanol have been used as fuel sources in fuel cells. Among the different types of cell, direct methanol fuel cells (DMFCs) have been found to be simple and low cost with low temperature operation making them economically viable. Proton exchange membrane fuel cells (PEMFCs) and DMFCs have been demonstrated in portable applications such as cellular phones, laptops and personal digital assistants (PDAs). The use of a high loading of catalyst such as Pt (20-60 $\mathrm{wt} \%$ ) and the high cost of this catalyst has limited their potential commercial application. Thus, various carbon materials such as mesocarbon microbeads, ${ }^{251}$ ordered mesocarbon microbeads, activated carbon NFs (CNFs), ${ }^{252,253}$ graphene, ${ }^{254-256}$ activated carbon NFs (CNFs) with nanofibers ${ }^{257,258}$ and other carbonaceous materials have been used as supports. Some of the support materials that have been tested are shown in Fig. 22 .

Kim et al. demonstrated an enhancement in the electrochemical activity of Pt nanowires by electrospinning PVP-Pt

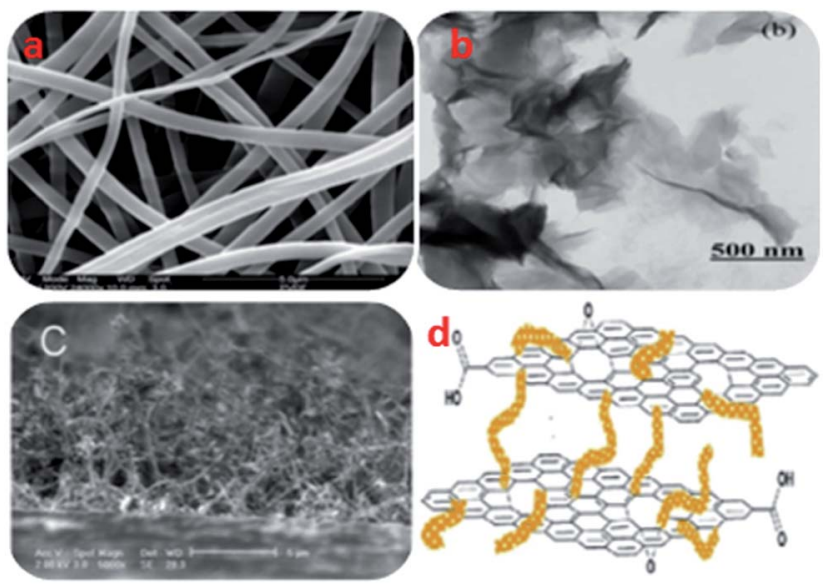

Fig. 22 Support materials used for fuel cell applications: (a) CNFs, (b) graphene, ${ }^{256}$ (c) vertically grown CNTs, ${ }^{259}$ and (d) CNTs on graphene. ${ }^{252}$

composite fibers followed by a heat treatment. The physicochemical and electrochemical properties of the Pt nanowires were dependent on the heat treatment conditions such as the heating rate, temperature, time, and atmosphere used. Although a higher methanol oxidation rate value of $1.41 \mathrm{~mA}$ $\mathrm{cm}^{-2}$ was observed for Pt nanowires when compared with commercial Pt black (1.36 $\left.\mathrm{mA} \mathrm{cm}^{-2}\right)$, a lower surface area of 6.2 $\mathrm{m}^{2} \mathrm{~g}^{-1}$ was observed for the Pt nanowires, which could be improved using a stepwise heat treatment. ${ }^{260}$ Polyamide composite Pd/PA6 NFs with a highly porous structure and excellent mechanical properties were fabricated using a combination of electrospinning and an electroless plating approach and then tested for the electro-oxidation of alcohols in alkaline medium. ${ }^{261}$ They observed a high current density, low $I_{\mathrm{b}} / I_{\mathrm{f}}$ and enhanced performance, which could be ascribed to the large surface area, reduced diffusion resistance and excellent poisoning tolerance.

\subsection{Carbon based NFs}

1D materials such as CNTs and CNFs are considered to be promising support materials for catalysts in fuel cells, due to their unique structures, high electronic and thermal conductivities, and good electrochemical stability. Compared with CNTs, carbon NFs are cheap, easy to produce, and different architectures can be prepared. Electrospun CNFs have been found to be an alternative to Pt catalytic particles due to their high porosity and surface area to volume ratio, thereby, making both protons and reactants accessible for improved performance. Polyacrylonitrile (PAN) and polyimide (PI) polymers have been widely used as the polymers of choice to produce CNFs. Researchers have reported the synthesis of polyimidebased CNFs through electrospinning techniques followed by subsequent heat treatment processes. ${ }^{262,263}$ The conductivity of such NFs was much higher than those of other types of CNF mats. They noticed that the conductivity increased with decreasing diameter, which could be attributed to the packing density and diameter of NFs, both these parameters affect the number of cross-junctions between NFs per unit volume of the 
mat. ${ }^{264}$ Park et al. reported that Pt catalyst utilization could be increased (to 69\%) when the catalyst was deposited onto electrospun CNFs compared to $35 \%$ utilization on carbon black Pt/ XC-72R. ${ }^{265}$ This demonstrated that CNFs were a better support material for Pt catalysts. In another study, Pt/C supported on CNFs exhibited higher electrocatalytic activity, better stability, a larger exchange current and a smaller charge transfer resistance than that supported on commercial carbon paper. This fact was ascribed to the good dispersion of catalyst particles into the CNF mats, which led to a smaller contact resistance between the catalyst particles and the support material. ${ }^{266} \mathrm{Li}$ et al. reported Pt clusters of 50-200 $\mathrm{nm}$ in size that were electrodeposited onto CNF electrodes, achieving a catalytic peak current of $420 \mathrm{~mA}$ $\mathrm{mg}^{-1}$, compared to a commercial catalyst at $185 \mathrm{~mA} \mathrm{mg}{ }^{-1}$. Although the Pt clusters relatively larger in size, this was favourable for improved performance. ${ }^{267}$ Similarly, several research groups have performed similar electrodepositions such as Pt NPs on PAN CNFs ${ }^{268}$ and gold on PAN CNFs. ${ }^{269}$ Guo et al. noticed that the current exchange upon oxidation of methanol was easier and the exchange current density $\left(J_{\mathrm{o}}\right)$ of the gold NPs on PAN CNFs was 2.7 times larger than that of pure gold electrodes. ${ }^{269}$ Xuyen et al. immobilized Pt precursors through a nucleation process on polyimide NFs and subsequent heating produced Pt loaded PI based CNFs, which were used as electrodes for a fuel cell. ${ }^{270}$ Recently, researchers have reported 1-aminopyrene functionalized (APF) Pt NPs formed on CNFs through a polyol process, which tend to form NPs with a smaller size and a better distribution compared to conventional and acid treated catalysts. In addition, these APF carbon NFs possessed excellent properties such as a high active surface area, improved performance toward the electrocatalytic oxidation of methanol, and relatively good long-term stability. ${ }^{271}$

$\mathrm{Pt} / \mathrm{CNF}$ nanocomposites were produced via the reduction of hexachloroplatinic acid $\left(\mathrm{H}_{2} \mathrm{PtCl}_{6}\right)$ using formic acid $(\mathrm{HCOOH})$ in an aqueous solution containing CNFs by Wang et al. ${ }^{272}$ These $\mathrm{Pt} / \mathrm{CNF}$ nanocomposites showed higher electrocatalytic activity toward methanol oxidation compared with a commercial E-tek $\mathrm{Pt} / \mathrm{C}$ catalyst, which is shown in Fig. 23. Several research groups have reported combinations of semiconducting oxide materials with catalytically active noble metals such as $\mathrm{Pd} / \mathrm{TiO}_{2}$ and $\mathrm{Pt} / \mathrm{WO}_{3}$ for not only to act as a support material, but also to achieve enhanced electrocatalytic properties. ${ }^{273-275}$ Several techniques such as electroless plating, galvanic replacement methods and polyol processes have been employed to deposit the noble metals onto the oxide materials. Pd is found to be a promising substitute for $\mathrm{Pt}$ in alcohol oxidation reactions, due to its outstanding electrocatalytic activity and greater abundance in nature. Su et al. employed electroless-plating of $\mathrm{Pd}$ onto electrospun $\mathrm{TiO}_{2} \mathrm{NFs}$. They fabricated $\mathrm{Pd} / \mathrm{TiO}_{2} \mathrm{NFs}$ with excellent electro-oxidation behaviour towards glycerol in an alkaline medium. ${ }^{273}$ Zhao et al. fabricated Pt nanospheres and Pt nanocubes on electrospun $\mathrm{WO}_{3}$ and observed that the $\mathrm{Pt}$ nanocubes were much more active than the Pt nanospheres, and also that the activity of the Pt supported on $\mathrm{WO}_{3} \mathrm{NFs}$ (Fig. 24) was higher than that supported on commercial $\mathrm{WO}_{3} \cdot{ }^{274}$

Pt NPs and nanowires decorated onto electrospun anatase NFs were proven to be effective electrocatalysts for direct

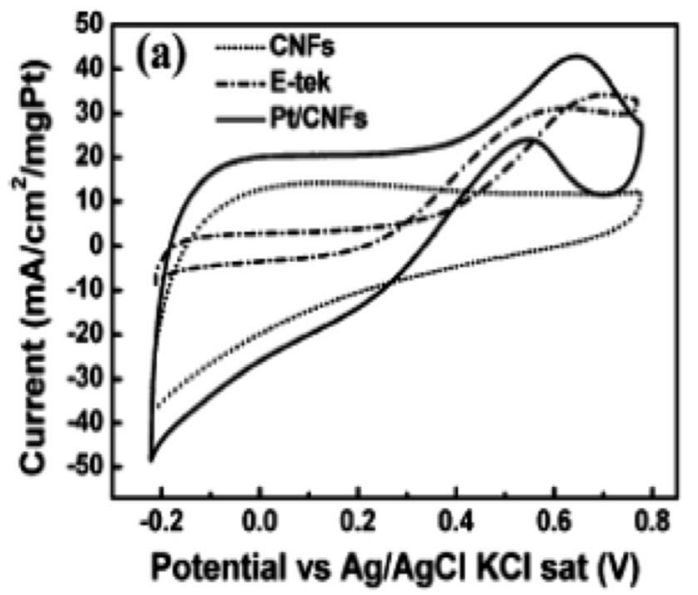

Fig. 23 Cyclic voltammetry of E-tek, Pt/CNFs and CNF mats without Pt loading. ${ }^{273}$

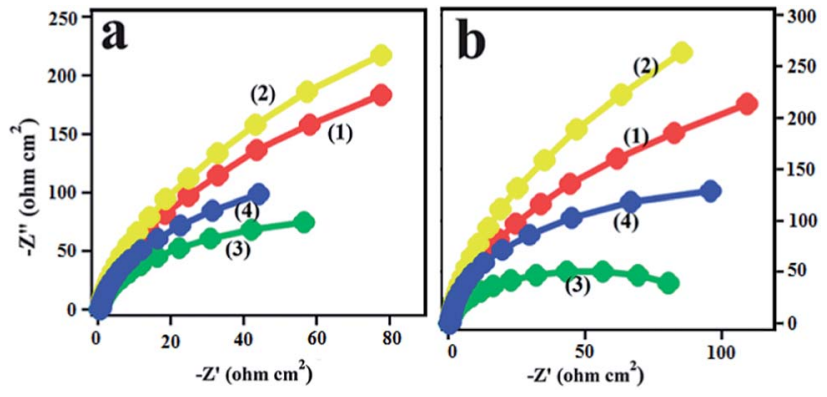

Fig. 24 Impedance spectra of various catalysts in $1 \mathrm{M} \mathrm{CH}_{3} \mathrm{OH}-1 \mathrm{M}$ $\mathrm{H}_{2} \mathrm{SO}_{4}$ at (a) $0.4 \mathrm{~V}$ and (b) $0.5 \mathrm{~V}$. In the figure: (1) Pt nanospheres $-\mathrm{WO}_{3}$ nanofibers (2) Pt nanospheres-commercial $\mathrm{WO}_{3}$ (3) Pt nanocubes$\mathrm{WO}_{3}$ nanofibers and (4) Pt nanocubes-commercial $\mathrm{WO}_{3} \cdot{ }^{274}$

methanol oxidation. ${ }^{275}$ Similarly, various researchers have attempted to use CNFs as supports for alloy deposition (such as Pt-Pd $)^{276}$ and hetero-polyacids (HPA). ${ }^{277}$ Among the various tested compositions of alloys, nanocomposites with $\mathrm{Pt}_{50} \mathrm{Pd}_{50} /$ CNFs had the best electrocatalytic activity by mass toward oxygen reduction. In an another study, HPA was incorporated into PAN CNFs to increase the electrical conductivity of the CNFs. ${ }^{277}$ Increasing the HPA content increased both the electrical conductivity and the surface area of CNFs. PAN CNF supported $\mathrm{Fe} / \mathrm{Co} / \mathrm{Ni}$ ternary alloy NPs were also prepared by using an electrospinning technique for potential fuel cell application. ${ }^{278}$ Seki et al. showed that the electrical conductivity of CNFs can be further increased by applying ion-beam irradiation, during which the irradiation results in a structural change to more ordered graphitic structures. ${ }^{279}$ Chang et al. fabricated graphene-modified CNF mats (GCNFs) using a thermal treatment on electrospun PAN NFs decorated with graphene oxide. ${ }^{280}$ The Pt particles were then adsorbed onto the GCNFs using formaldehyde vapor and $\mathrm{H}_{2} \mathrm{PtCl}_{6} / \mathrm{E}_{6} \mathrm{H}_{2} \mathrm{O}$. The resulting Pt-GCNFs electrode exhibited excellent electrocatalytic activity and long-term stability toward methanol oxidation, which showed that they can be used as the anode in DMFCs for long-term applications. Furthermore, the electrode 
yielded a high conductivity of about $65 \mathrm{~S} \mathrm{~cm}^{-1}$ with good flexibility. ${ }^{280}$

Electroactive bacteria have been explored as electrocatalysts to facilitate anodic oxidation in microbial fuel cells (MFCs). Chen et al. reported the fabrication of a layered architecture of CNFs using layer-by-layer (LBL) electrospinning of PAN onto cellulose paper and subsequent carbonization. This layered CNF structure was shown to be a promising material for continuous layered biofilm growth and generated a high current density. The current density observed for conventional CNFs, natural cellulose paper derived CNFs, two dimensional polyacrylonitrile CNFs and layered CNFs were 1.21, 0.53, 0.17 and $2.0 \mathrm{~mA} \mathrm{~cm}^{-2}$, respectively. ${ }^{281}$ Similarly, the same group achieved a highest anode current density of up to $30 \mathrm{~A} \mathrm{~m}^{-2}$ for an electroactive microbial fuel cell. The current density for the cell was higher when poly(acrylonitrile-co-itaconic acid-co-butyl acrylate) was used as a precursor during gas-assisted electrospinning in comparison to using pure PAN as a precursor and solution blowing. ${ }^{282}$ This shows NFs are a potential electroactive biofilm material for sustainable energy supply and handling. Ghasemi et al. have tested chemically and physically activated electrospun CNFs (ACNFs) in an MFC and compared their performance with that of conventional carbon paper. The chemically activated CNFs with $8 \mathrm{M} \mathrm{KOH}$ exhibited better oxygen reduction reaction (ORR) activity and generated $78 \%$ more power than that both the physically activated ACNFs and conventional carbon paper. ${ }^{283}$ Zhang et al. employed a dip coating method to functionalize PAN CNF surfaces with carbon or silica NPs for MFC application. Furthermore, CNFs with higher surface roughness were achieved by optimization of the furfuryl alcohol (FFA) concentration and subsequent heating produced carbon NPs (CNPs) at the fiber surface. The electrical conductivities of the PAN CNFs decorated with carbon and PAN + CNPs with FFA treatment were 126 and $290 \mathrm{~S} \mathrm{~m}^{-1}$, respectively. ${ }^{284}$

A new class of CNFs, Fe containing carbon NFs (Hb-CNFs) were fabricated by electrospinning hemoglobin $(\mathrm{Hb})$ with polyacrylonitrile followed by calcination. The resulting $\mathrm{Hb}$-CNF glassy carbon electrodes were tested for the amperometric detection of $\mathrm{H}_{2} \mathrm{O}_{2}$ and they exhibited a fast response, high sensitivity, excellent reproducibility, good selectivity and wide dynamic range with a good limit of detection. ${ }^{285}$ Electrospun polycaprolactone NFs containing Ag have also been tested as electrocatalytic anode membranes for the oxidation of glucose in an alkaline fuel cell. ${ }^{286}$ Electrospun NFs fabricated from electrospun NFs composed of sulfonated poly(arylene ether sulfone) with sulfonated polyhedral oligomeric silsesquioxane (SPOSS) as a proton conductivity enhancer showed a protonic conductivity that was 2.4 times higher than a nafion membrane. ${ }^{287}$

\subsection{Solid oxide fuel cells (SOFCs) based on electrospun metal oxides}

Electrospun NFs have also been explored as electrode materials in SOFC applications. Electrospinning of lanthanum strontium cobalt ferrite (LSCF) NFs was carried out and the resulting materials used as the cathode of an intermediate-temperature SOFC. ${ }^{288}$ The electrochemical performance of the fuel cell with
LSCF NFs as the cathode exhibited a power density of $0.90 \mathrm{~W}$ $\mathrm{cm}^{-2}$ at $1.9 \mathrm{~A} \mathrm{~cm}^{-2}$ and $750{ }^{\circ} \mathrm{C}$, which was further improved by incorporation of $20 \mathrm{wt} \%$ gadolinia-doped ceria (GDC) into the LSCF NF cathode. It exhibited a power density of $1.07 \mathrm{~W} \mathrm{~cm}^{-2}$ at $1.9 \mathrm{~A} \mathrm{~cm}^{-2}$ and $750{ }^{\circ} \mathrm{C}$. This improved performance has been ascribed to (i) higher porosity, (ii) higher percolation, (iii) continuous pathways for charge transport, (iv) provision of an excellent scaffold for infiltration and (v) the good thermal stability of the NFs. $\mathrm{Ba}_{0.5} \mathrm{Sr}_{0.5} \mathrm{Fe}_{0.8} \mathrm{Cu}_{0.2} \mathrm{O}_{3-\delta}$ (BSCF) NFs with a high porosity and surface area have been fabricated and compared with the powder form for low-temperature SOFCs. ${ }^{289}$ The area specific resistance (ASR) of the BSCF NF cathode was $0.094 \Omega \mathrm{cm}^{2}$ at $600{ }^{\circ} \mathrm{C}$, whereas that of the BSCF powder cathode was $0.468 \Omega \mathrm{cm}^{2}$, which suggested that reduction of the interfacial resistance was important for improving the performance of the cell. Yttria stabilized Zirconia (YSZ) NFs were fabricated by electrospinning and the fiber surfaces were coated with a layer of $\mathrm{Ni}$ using an electroless plating method for use in SOFCs. ${ }^{165}$ The peak power density of the fiber-derived anode cell was found to be twice that of the powder-derived anode. This was attributed to the well-structured and interconnected fibers in the former case. Metal oxides have been explored as low cost alternative catalysts for methanol oxidation. Zhang et al. prepared a $\mathrm{PdO}-\mathrm{Co}_{3} \mathrm{O}_{4} \mathrm{NF}$ composite with good electrocatalytic activity toward methanol when Nafion/PdO- $\mathrm{Co}_{3} \mathrm{O}_{4} / \mathrm{GCE}$ was used as an electrode. ${ }^{15}$ Similarly, Al-Enizi et al. reported a nanocomposite made of electrospun cobalt oxide and CNFs as an electrode material for fuel cell applications, where the enhanced electrochemical activity was achieved by the well dispersed cobalt oxide NPs within the framework of CNFs. ${ }^{290}$

\subsection{Electrospun nanofibrous membranes}

In the case of PEMFCs, the handling of hydrogen as fuel is critical. In order to achieve efficient proton conduction, the water management in PEM is also crucial. Although a variety of solutions have been proposed for this issue, DMFCs have been studied as an alternative to PEMFCs in portable applications. Currently, DMFC efficiency has been achieved up to $40 \%$. Therefore, researchers are focusing on the development of efficient membranes that will prohibit methanol crossover. Various contributing factors include the methanol concentration, PEM material, thickness of PEM, operating current density, pressure and temperature. Nafion is one of the most widely studied polymers used as a membrane in fuel cell applications. Several researchers have attempted to modify Nafion with NPs as well as reinforce them with other polymers or interesting nanostructures in order to reduce methanol crossover and swelling to increase protonic conductivity or increase the mechanical properties of the membranes. Electrospun NFs are known to contribute additional morphology effects to the resulting membranes. Electrospun PVA and poly(4-styrenesulfonic acid) polymers with fiber diameters ranging from 176 to $766 \mathrm{~nm}$ that were subsequently heat treated were used to synthesis water stable PEM membranes. ${ }^{291}$ Choi et al. fabricated perfluorosulfonic acid (PFSA) NF membranes in the presence of PEO as a carrier polymer with a Norland optical 
adhesive. The fibers were cross linked using adhesive chemistry and PEO was subsequently removed. They reported NFs with higher proton conductivities $\left(0.16 \mathrm{~S} \mathrm{~cm}^{-1}\right)$ and improved mechanical properties when compared to that of a commercial Nafion 212 membrane $\left(0.048 \mathrm{~S} \mathrm{~cm}^{-1}\right)$ in film form. ${ }^{292}$ Several researchers have used PVP and/or PS, PEO and PVA as carrier polymers. ${ }^{293,294}$ Ballengee et al. used a carrier polymer of a different molecular weight at a low concentration (1-2 wt\%) and observed various morphologies such as bead-on-fiber structures and ribbon-like morphology depending on the polymer molecular weight and electrospinning conditions used such as the humidity, voltage and flow rate. ${ }^{295}$ Some groups have fabricated composite membranes from electrospun poly(ether sulfone) (PES) ${ }^{296,297}$ or poly(vinylidene fluoride) (PVDF) NFs, ${ }^{298}$ where the pores were filled with a nafion matrix. This resulted in higher proton to methanol selectivity and single cell DMFC performance for the composite membranes compared to Nafion 112 and Nafion 117 membranes. Tamura et al. demonstrated that PI within NFs was significantly oriented in a composite membrane and the resulting aligned nanostructures were found to possess high proton conductivity and low gas permeability into the fuel for PEMFCs (Fig. 25). ${ }^{258}$

The same group reported aligned PI NFs and they observed that the parallel conductivity was higher than the perpendicular conductivity. ${ }^{299}$ Subianto et al. studied the effect of the sidechain length (short side chains (SSC) and long side chains (Nafion)) in perfluorosulfonic acid (PFSA) monomers on the conducting properties of NFs. In the case of a SSC PFSA/carrier polymer, a lower average fiber diameter and a markedly narrower fiber size distribution were observed due to enhanced inter-chain interactions. The proton conductivity of NF mats of SSC PFSA was $102 \mathrm{mS} \mathrm{cm}^{-1}$ compared $58 \mathrm{mS} \mathrm{cm}^{-1}$ for Nafion at $80{ }^{\circ} \mathrm{C} .{ }^{300}$ Ballengee et al. fabricated two structures; (i) Nafion

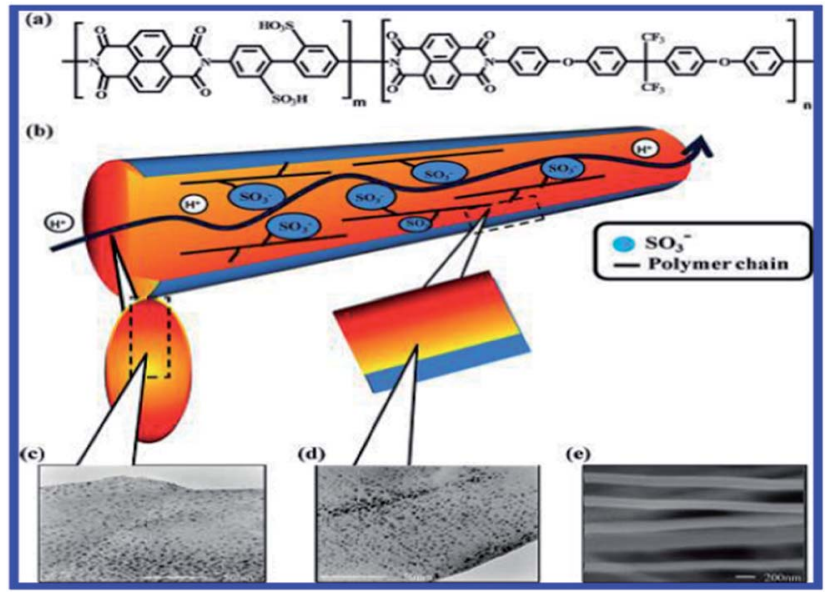

Fig. 25 (a) Chemical structure of random copolyimide $(1,4,5,8$ naphthalene tetracarboxylic dianhydride-4,4' -diamino-biphenyl 2,2' disulfonic acid-random-2,2-bis[4-(4-aminophenoxy)phenyl]-hexafluoropropane, abbreviated as NTDA-BDSA-r-APPF). (b) A schematic representation of sulfonated copolyimide NFs. (c) TEM image of a cross-sectional aligned NF in the radial direction. (d) TEM image of a cross-sectional aligned NF in the axial direction. (e) SEM image of aligned NFs electrospun on a specially designed collector. ${ }^{258}$

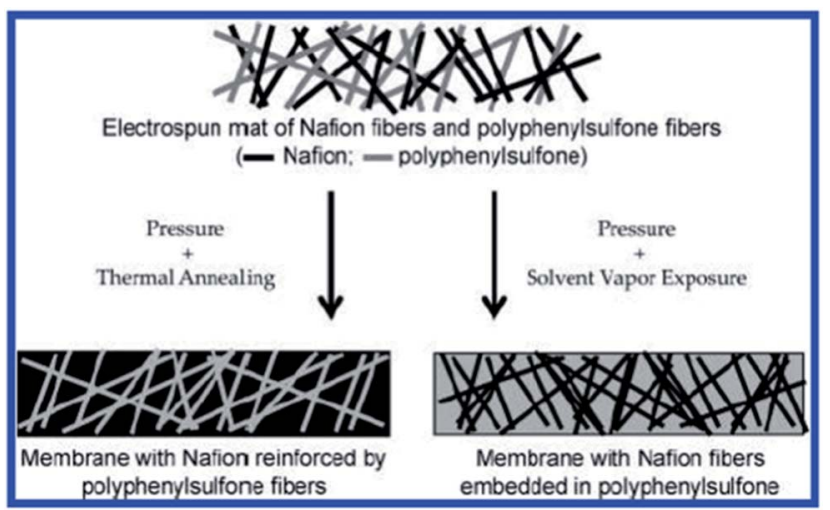

Fig. 26 Creation of two NF composite Nafion/poly(phenyl sulfone) membrane structures from the same dual fiber electrospun mat. ${ }^{257}$

reinforced by a poly(phenyl sulfone) NF network (structure 1) and (ii) Nafion NFs embedded in poly(phenyl sulfone) NFs (structure 2), using a side-by-side dual spinneret approach in a simple electrospinning process for use in PEMFCs. They compared structure 2 with structure 1 (Fig. 26). Structure 2 exhibited very low water swelling and better mechanical properties when compared to structure $1 .^{257}$ Similarly, Liu et al. reported electrospun nanofibrous membranes made of hydrophilic sulfonated poly(fluorenyl ether ketone) (SPFEK) NFs and hydrophobic beaded PES NFs synthesised using a co-electrospinning method followed by the removal of PES in a dissolution process. Finally, in situ gap filling was achieved via the electrostatic layer by layer (LBL) self-assembly of anionic and cationic polyelectrolyte polymers. The resulting membrane possessed excellent oxidative stability, a high proton conductivity of $0.056-0.061 \mathrm{~S} \mathrm{~cm}^{-1}$ at $30-80^{\circ} \mathrm{C}$, and a power density of $0.28 \mathrm{~W} \mathrm{~cm}^{-2}$ at $80{ }^{\circ} \mathrm{C}$. The fabricated membranes provided a facile proton conducting pathway with an activation energy $\left(E_{\mathrm{a}}\right)$ of $1.30 \mathrm{~kJ} \mathrm{~mol}^{-1}$, which was lower than the value of $8.14 \mathrm{~kJ}$ mol $^{-1}$ for Nafion. ${ }^{301}$

Yao et al. fabricated a hybrid membrane consisted of superacidic electrospun sulfated zirconia $\left(\mathrm{S}-\mathrm{ZrO}_{2}\right)$ fibers in order to recast Nafion for use in PEMFCs. The $\mathrm{S}^{-} \mathrm{ZrO}_{2}$ was fabricated from the electrospinning of a $\mathrm{Zr}$ precursor in the

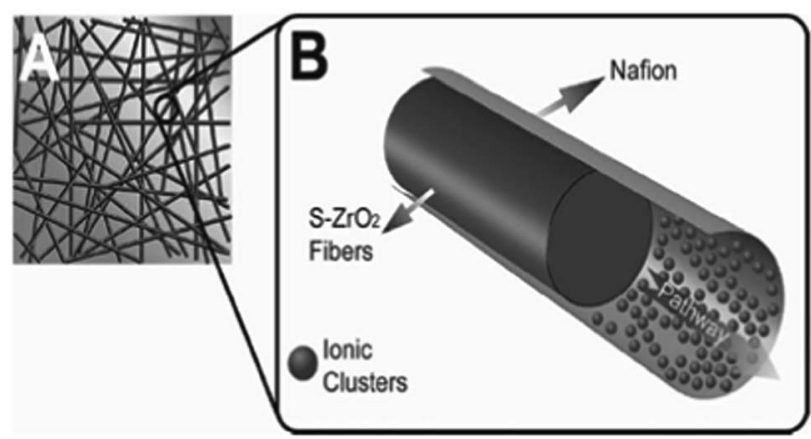

Fig. 27 Schematic diagrams of (a) a $\mathrm{S}-\mathrm{ZrO}_{2}$ fiber-Nafion hybrid membrane, and (b) the interface between the $\mathrm{S}-\mathrm{ZrO}_{2}$ fiber and the Nafion matrix with ionic clusters aggregating on the $\mathrm{S}-\mathrm{ZrO}_{2}$ fiberNafion interface. ${ }^{302}$ 
presence of a carrier polymer, followed by sulfonation and calcination (Fig. 27(a)). The solid S-ZrO $\mathrm{Zr}_{2}$ fibers helped to gather a large number of the protogenic groups of Nafion to the interfaces, which favour continuous ionic pathways for effective proton transport in the membranes (Fig. 27(b)). A high proton conductivity of $3.1 \times 10^{-1} \mathrm{~S} \mathrm{~cm}^{-1}$ was achieved for the hybrid membrane compared to the value for Nafion of $9.1 \times 10^{-2} \mathrm{~S}$ $\mathrm{cm}^{-1}$, by selectively adjusting the fiber diameter and fiber volume fraction. ${ }^{302}$

In another study, the same group reported the fabrication of a Nafion hybrid membrane where $\mathrm{S}^{-} \mathrm{ZrO}_{2}$ was replaced with sulfonated polystyrene (S-PS) electrospun fibers. Similar to $\mathrm{S}^{-} \mathrm{ZrO}_{2}$, the S-PS favored aggregation of a large amount of sulfonic acid groups in Nafion onto the interfaces between the S-PS fibers and the ionomer matrix, thereby, forming continuous pathways for facile proton transport. A high proton conductivity of $1.8 \times 10^{-1} \mathrm{~S} \mathrm{~cm}^{-1}$ was observed at $80^{\circ} \mathrm{C}$ and $100 \% \mathrm{RH}$ for the fibers with diameters of $0.98 \mu \mathrm{m} .{ }^{303}$ Electrospun NFs are promising materials for use in SOFCs, which provide high power densities due to their high porosity, high percolation, continuous pathways for charge transport, excellent ability to act as scaffolds for infiltration and good thermal stability. The materials can be fabricated on a large scale and tested for their performance in the future for the large scale production of NFs through electrospinning. Several studies have shown that electrospun NFs are the best choice to use as support materials for the purpose of catalyst anchoring in fuel cell electrodes and as PEMs, which have to be fabricated and tested on a large scale.

\section{Future perspectives}

Electrospun nanostructures of various metal oxides and composites with well controlled structures have been shown to be promising materials for energy efficient devices and environmental applications. In this review, several formulations of NFs formed by one step electrospinning with different spinnerets (dual spinnerets, core-shell spinneret) and collectors with post-modification/treatment have been discussed for the synthesis of different hierarchical NFs with superior functional properties. The morphology and diameters of the NFs can be optimized by changing the electrospinning parameters, which would be beneficial for retarding photo induced electron and hole recombination. Highly crystalline NFs with different morphologies (random, hollow, mesoporous structures) are widely used as low cost photoanodes and counter electrodes in DSSCs and QDSSCs, which have shown significant increases in energy conversion efficiency when compared to other nanomaterial made by other syntheses and growth processes. The synthesized electrospun nanostructured fibers exhibited improved photocatalytic performance in water splitting compared to other nanostructures produced using other conventional methods. The photocatalytic properties including the photocurrent with respect to the potential not only affected the system resistance, but also strongly influenced the carrier separation, recombination, and transfer process through variation in the band structure of the nanostructures. This review provides a critical insight into the different designs of nanostructured NFs for hydrogen generation through direct photocatalytic water splitting under UV and visible light irradiation.

Electrospun NFs have already proven that they have potential to act as anchors for catalysts in fuel cell electrodes. The contribution of NFs in the enhancement of conductivity and performance, which are dependent on the morphology and lowering the activation energy, has also been proven for use in PEMFC applications. Electrospun NFs are promising materials in SOFCs, providing high power density due to their high porosity, high percolation, continuous pathways for charge transport, ability to act as excellent scaffolds for infiltration and good thermal stability.

\section{Summary and outlook}

In summary, electrospun 1D NFs are versatile in photon absorption and carrier separation/collection due to their large surface area and anisotropic properties, which can enhance solar energy harvesting efficiency. In addition, NFs formed by electrospinning have shown enhanced crystallinity, larger surface areas and better photocatalytic activity for hydrogen evolution compared to NFs produced by other synthesis methods. These 1D nanotubular structures have demonstrated their apparent advantages for photocatalytic hydrogen generation over NPs, which is due to favorable electron transfer and a reduced recombination of electron-hole pairs. Modification of 1D NFs into hierarchical nanostructures or hybrid structures (core-shell, 0D and 1D) with support materials can further increase the light absorbance and/or improve the carrier collection efficiency. Therefore, by using band gap tuning and nanostructure design, 1D NFs hold the potential for creating cost effective and high efficiency PV and PEC solar cells for hydrogen energy generation. Above all, the electronic structure of the semiconductor plays a key role in photocatalytic watersplitting, as the photogenerated $\mathrm{e}^{-} / \mathrm{h}^{+}$pairs can recombine in very short times by releasing energy in the form of photons on the surface of the photocatalyst. Reduction and oxidation reactions are the two necessary mechanisms in photocatalytic hydrogen generation. The surface adsorption and photocatalytic activity could be enhanced by reducing the dimensionality, which facilitates a more reactive surface area in nanostructured catalysts. For efficient hydrogen production, the CB level of the catalyst should be more negative than the hydrogen production level, while the VB should be more positive than the water oxidation level for oxygen from water splitting. Theoretically, the catalysts should fulfil these conditions for the generation of hydrogen. A high chemical stability and long lifetime of $\mathrm{e}^{-} / \mathrm{h}^{+}$pairs are key parameters that lead to strong photocatalytic hydrogen generation. However, solar to hydrogen conversion by water splitting is limited by a few challenging factors such as (a) recombination: the electrons from $\mathrm{CB}$ can recombine with holes in VB within a short time frame and release energy in the form of photons; (b) backward reaction: the decomposition of $\mathrm{H}_{2} \mathrm{O}$ into $\mathrm{H}_{2}$ and $\mathrm{O}_{2}$ is an energy increasing process, so the reaction can proceed backwards to form $\mathrm{H}_{2} \mathrm{O}$ from $\mathrm{H}_{2}$ and $\mathrm{O}_{2}$; and (c) effective utilization of visible 
light: nearly $50 \%$ of the contribution from solar energy is visible light, but most of our the present technology is dependent on large band gap semiconducting catalysts and, therefore, visible light utilization is also one of the important issues for solar photocatalytic hydrogen energy generation. In order to overcome these challenges, and efficiently produce hydrogen one needs to modify the semiconductors using one of the following methods: addition of electron donors (hole scavengers), addition of carbonate salts, noble metal loading, metal ion doping, anion doping, dye sensitization, compositing with another semiconductor, metal ion implantation and improving the surface area, thereby, reducing the band gap energy. ${ }^{228}$ Due to the strict confinement of band energy alignment with the watersplitting potential and their stability in electrolyte solutions, there is still a huge demand to explore and fabricate more 1D based hierarchical nanostructured designs in order to further increase solar hydrogen production efficiency.

Electrospun NFs have been shown to be an alternative materials for anchoring catalysts in fuel cell electrodes as well as acting as membranes in PEMFCs and SOFCs. Some of the issues to be solved for commercial application of NFs in fuel cell applications are: (i) achievement of uniform fiber diameters below $50 \mathrm{~nm}$; (ii) green processing of nanofibrous membranes and catalysts using an eco-friendly medium; and (iii) large scale production. Although better performance has been shown by NFs when used as catalyst electrodes and membranes, which is encouraging for their use in fuel cell applications, the costs have to be reduced before their potential exploration in commercial applications.

\section{Acknowledgements}

This work was supported by a grant from the Russian Science Foundation (No: 14-14-00039) to SIA. Author VJB acknowledges The Scientific \& Technological Research Council of Turkey (TUBITAK) (TUBITAK-BIDEB 2221, Fellowships for visiting scientists and scientists on sabbatical leave) for their fellowship.

\section{Reference}

1 J. A. Turner, Science, 1999, 285, 687-689.

2 N. S. Lewis, MRS Bull., 2007, 32, 808-820.

3 V. S. Arunachalam and E. L. Fleischer, MRS Bull., 2008, 33, 264-288.

4 International Energy Agency, http:/www.iea.org/aboutus/ faqs/renewableenergy/.

5 Y. Gu, I. L. Kuskovsky, M. Yin, S. O'Brien and G. F. Neumark, Appl. Phys. Lett., 2004, 85, 3833-3835.

6 A. Gasparotto, D. Barreca, C. Maccato and E. Tondello, Nanoscale, 2012, 4, 2813-2825.

7 Y. Yin and D. Talapin, Chem. Soc. Rev., 2013, 42, 2484-2487. 8 V. J. Babu, S. Vempati, S. Sundarrajan, M. Sireesha and S. Ramakrishna, Sol. Energy, 2013, 106, 1-22.

9 Q. Zhang, E. Uchaker, S. L. Candelaria and G. Cao, Chem. Soc. Rev., 2013, 42, 3127-3171.

10 Y. Ye, C. Jo, I. Jeong and J. Lee, Nanoscale, 2013, 5, 45844605 .
11 Y. Li and J. Z. Zhang, Laser Photonics Rev., 2010, 4, 517-528.

12 H. K. Raut, V. A. Ganesh, A. S. Nair and S. Ramakrishna, Energy Environ. Sci., 2011, 4, 3779-3804.

13 N. Nuraje, W. S. Khan, Y. Lei, M. Ceylan and R. Asmatulu, J. Mater. Chem. A, 2013, 1, 1929-1946.

14 M. M. Khin, A. S. Nair, V. J. Babu, R. Murugan and S. Ramakrishna, Energy Environ. Sci., 2012, 5, 8075-8109.

15 Y. Zhang, Y. Wang, J. Jia and J. Wang, Int. J. Hydrogen Energy, 2012, 37, 17947-17953.

16 L.-C. Cheng, X. Jiang, J. Wang, C. Chen and R.-S. Liu, Nanoscale, 2013, 5, 3547-3569.

17 C. Zhao, A. Tan, G. Pastorin and H. K. Ho, Biotechnol. Adv., 2013, 31, 654-668.

18 A. Dhayal Raj, P. Suresh Kumar, Q. Yang and D. Mangalaraj, Phys. E., 2012, 44, 1490-1494.

19 P. S. Kumar, A. D. Raj, D. Mangalaraj and D. Nataraj, Appl. Surf. Sci., 2008, 255, 2382-2387.

20 A. Joseph Nathanael, D. Mangalaraj, P. C. Chen and N. Ponpandian, Compos. Sci. Technol., 2010, 70, 419-426.

21 Y. Liu, J. Goebl and A. Y. Yin, Chem. Soc. Rev., 2013, 42, 2610-2653.

22 B. B. Lakshmi, P. K. Dorhout and C. R. Martin, Chem. Mater., 1997, 9, 857-862.

23 P. Suresh Kumar, J. Sundaramurthy, D. Mangalaraj, D. Nataraj, D. Rajarathnam and M. P. Srinivasan, J. Colloid Interface Sci., 2011, 363, 51-58.

24 Y. Li, X.-Y. Yang, Y. Feng, Z.-Y. Yuan and B.-L. Su, Crit. Rev. Solid State Mater. Sci., 2012, 37, 1-74.

25 C. Zhang, Y. Yan, Y. S. Zhao and J. Yao, Annu. Rep. Prog.Chem., Sect. C: Phys. Chem., 2013, 109, 211-239.

26 C. N. R. Rao, S. R. C. Vivekchand, K. Biswas and A. Govindaraj, Dalton Trans., 2007, 3728-3749.

27 S. Kalluri, K. H. Seng, Z. Guo, H. K. Liu and S. X. Dou, RSC Adv., 2013, 3, 25576-25601.

28 B. Ding, M. Wang, X. Wang, J. Yu and G. Sun, Mater. Today, 2010, 13, 16-27.

29 H. Ma, C. Burger, B. S. Hsiao and B. Chu, J. Mater. Chem., 2011, 21, 7507-7510.

30 J. Xie, M. R. MacEwan, A. G. Schwartz and Y. Xia, Nanoscale, 2010, 2, 35-44.

31 BCC Research, 2010, Nanofibers: Technologies and Developing Markets, Report Code: NAN043B.

32 C. J. Luo, S. D. Stoyanov, E. Stride, E. Pelan and M. Edirisinghe, Chem. Soc. Rev., 2012, 41, 4708-4735.

33 R. Sahay, P. S. Kumar, V. Aravindan, J. Sundaramurthy, W. C. Ling, S. G. Mhaisalkar, S. Ramakrishna and S. Madhavi, J. Phys. Chem. C, 2012, 116, 18087-18092.

34 T. Maiyalagan, J. Sundaramurthy, P. S. Kumar, P. Kannan, M. Opallo and S. Ramakrishna, Analyst, 2013, 138, 17791786.

35 P. S. Kumar, V. Aravindan, J. Sundaramurthy, V. Thavasi, S. G. Mhaisalkar, S. Ramakrishna and S. Madhavi, RSC Adv., 2012, 2, 7983-7987.

36 V. Aravindan, P. S. Kumar, J. Sundaramurthy, W. C. Ling, S. Ramakrishna and S. Madhavi, J. Power Sources, 2013, 227, 284-290. 
37 C. T. Cherian, J. Sundaramurthy, M. V. Reddy, P. S. Kumar, K. Mani, D. Pliszka, C. H. Sow, S. Ramakrishna and B. V. R. Chowdari, ACS Appl. Mater. Interfaces, 2013, 5, 9957-9963.

38 S. Jayaraman, V. Aravindan, P. S. Kumar, W. C. Ling, S. Ramakrishna and S. Madhavi, ACS Appl. Mater. Interfaces, 2014, 6(11), 8660-8666.

39 S. Jayaraman, V. Aravindan, P. S. Kumar, W. C. Ling, S. Ramakrishna and S. Madhavi, Chem. Commun., 2013, 49, 6677-6679.

40 V. Aravindana, J. Sundaramurthy, E. N. Kumar, P. S. Kumar, W. C. Ling, R. v. Hagen, S. Mathur, S. Ramakrishna and S. Madhavi, Electrochim. Acta, 2014, 121, 109-115.

41 X. Zhang, P. S. Kumar, V. Aravindan, H. H. Liu, J. Sundaramurthy, S. G. Mhaisalkar, H. M. Duong, S. Ramakrishna and S. Madhavi, J. Phys. Chem. C, 2012, 116, 14780-14788.

42 R. Sahay, P. S. Kumar, R. Sridhar, J. Sundaramurthy, J. Venugopal, S. G. Mhaisalkar and S. Ramakrishna, J. Mater. Chem., 2012, 22, 12953-12971.

43 Z. M. Huang, Y. Z. Zhang, M. Kotaki and S. Ramakrishna, Compos. Sci. Technol., 2003, 63, 2223-2253.

44 P. S. Kumar, R. Sahay, V. Aravindan, J. Sundaramurthy, W. C. Ling, V. Thavasi, S. G. Mhaisalkar, S. Madhavi and S. Ramakrishna, J. Phys. D: Appl. Phys., 2012, 45, 265302.

45 R. Ramaseshan, S. Sundarrajan, R. Jose and S. Ramakrishna, J. Appl. Phys., 2007, 102, 111101.

46 W. E. Teo and S. Ramakrishna, Nanotechnology, 2006, 17, R89-R106.

47 V. J. Babu, A. S. Nair, Z. Peining and S. Ramakrishna, Mater. Lett., 2011, 65, 3064-3068.

48 X. Zhang, V. Aravindan, P. S. Kumar, H. Liu, J. Sundaramurthy, S. Ramakrishna and S. Madhavi, Nanoscale, 2013, 5, 5973-5980.

49 J. Sundaramurthy, V. Aravindan, P. S. Kumar, W. C. Ling, S. Ramakrishna and S. Madhavi, Chem. Commun., 2013, 49, 6677-6679.

50 S. Ramakrishna, K. Fujihara, W.-E. Teo, T.-C. Lim and Z. Ma, World Scientific, 2005, ISBN: 978-981-256-415-3.

51 D.-G. Yu, Y. Xu, Z. Li, L.-P. Du, B.-G. Zhao and X. Wang, J. Nanomater., 2014, 967295.

52 P. Raghavan, D.-H. Lim, J.-H. Ahn, C. Nah, D. C. Sherrington, H.-S. Ryu and H.-J. Ahn, React. Funct. Polym., 2012, 72, 915-930.

53 D. H. Reneker and A. L. Yarin, Polymer, 2008, 49, 2387-2425.

54 J. G. Hardy, L. M. Romer and T. R. Scheibel, Polymer, 2008, 49, 4309-4327.

55 B. Dong, O. Arnoult, M. E. Smith and G. E. Wnek, Macromol. Rapid Commun., 2009, 30, 539-542.

56 K. Ohkawa, D. I. Cha, H. Kim, A. Nishida and H. Yamamoto, Macromol. Rapid Commun., 2004, 25, 1600-1605.

57 S. Ramakrishna, R. Jose, P. S. Archana, A. S. Nair, R. Balamurugan, J. Venugopal and W. E. Teo, J. Mater. Sci., 2010, 45, 6283-6312.

58 P. V. Kamat, J. Phys. Chem. C, 2007, 111, 2834-2860.

59 K. W. J. Barnham, M. Mazzer and B. Clive, Nat. Mater., 2006, 5, 161-164.
60 B. O'Regan and M. Grätzel, Nature, 1991, 353, 737-740.

61 A. Yella, H.-W. Lee, H. N. Tsao, C. Yi, A. K. Chandiran, M. K. Nazeeruddin, E. W.-G. Diau, C.-Y. Yeh, S. M. Zakeeruddin and M. Grätzel, Science, 2011, 334, 629-634.

62 H. Sun, Y. Luo, Y. Zhang, D. Li, Z. Yu, K. Li and Q. Meng, J. Phys. Chem. C, 2010, 114, 11673-11679.

63 B. Lee, D. B. Buchholz, P. Guo, D.-K. Hwang and R. P. H. Chang, J. Phys. Chem. C, 2011, 115, 9787-9796.

64 R. D. McConnell, Renewable Sustainable Energy Rev., 2002, 6, 271-293.

65 L. M. Peter, Phys. Chem. Chem. Phys., 2007, 9, 2630-2642.

66 V. Thavasi, G. Singh and S. Ramakrishna, Energy Environ. Sci., 2008, 1, 205-221.

67 S.-J. Seo, S.-H. Yun, J.-J. Woo, D.-W. Park, M.-S. Kang, A. Hinsch and S.-H. Moon, Electrochem. Commun., 2011, 13, 1391-1394.

68 A. S. Nair, Z. Peining, V. J. Babu, Y. Shengyuan and S. Ramakrishna, Phys. Chem. Chem. Phys., 2011, 13, 21248-21261.

69 B. H. Lee, M. Y. Song, S.-Y. Jang, S. M. Jo, S.-Y. Kwak and D. Y. Kim, J. Phys. Chem. C, 2009, 113, 21453-21457.

70 Y. P. Lin, Y. Y. Chen, Y. C. Lee and Y. W. Chen-Yang, J. Phys. Chem. C, 2012, 116, 13003-13012.

71 K. Saha, S. S. Agasti, C. Kim, X. Li and V. M. Rotello, Chem. Rev., 2012, 112, 2739-2779.

72 M. Y. Song, Y. R. Ahn, S. M. Jo, D. Y. Kim and J.-P. Ahn, Appl. Phys. Lett., 2005, 87, 113113.

73 P. S. Kumar, S. A. S. Nizar, J. Sundaramurthy, P. Ragupathy, V. Thavasi, S. G. Mhaisalkar and S. Ramakrishna, J. Mater. Chem., 2011, 21, 9784-9790.

74 Z. Peining, A. S. Nair, Y. Shengyuan, P. Shengjied, N. K. Elumalai and S. Ramakrishna, J. Photochem. Photobiol., A, 2012, 231, 9-18.

75 G. S. Anjusree, A. Bhupathi, A. Balakrishnan, S. Vadukumpully, K. R. V. Subramanian, N. Sivakumar, S. Ramakrishna, S. V. Nair and A. S. Nair, RSC Adv., 2013, 3, 16720-16727.

76 L. Yang and W. W.-F. Leung, Adv. Mater., 2011, 23, 45594562.

77 A. S. Nair, R. Jose, Y. Shengyuan and S. Ramakrishna, J. Colloid Interface Sci., 2011, 353, 39-45.

78 A. S. Nair, P. Zhu, V. J. Babu, S. Yang, T. Krishnamoorthy, R. Murugan, S. Peng and S. Ramakrishna, Langmuir, 2012, 28, 6202-6206.

79 H. Krysova, J. Trckova-Barakova, J. Prochazka, A. Zukal, J. Maixner and L. Kavan, Catal. Today, 2014, 230, 234-239.

80 Z. Peining, A. S. Nair, P. Shengjie, Y. Shengyuan and S. Ramakrishna, ACS Appl. Mater. Interfaces, 2012, 4, 581-585.

81 Y. Li, D.-K. Lee, J. Y. Kim, B. S. Kim, N.-G. Park, K. Kim, J.-H. Shin, I.-S. Choi and M. J. Ko, Energy Environ. Sci., 2012, 5, 8950-8957.

82 X. Zhang, V. Thavasi, S. G. Mhaisalkar and S. Ramakrishna, Nanoscale, 2012, 4, 1707-1716.

83 E. M. Jin, J.-Y. Park, X. G. Zhao, I.-H. Lee, S. M. Jeong and H.-B. Gu, Mater. Lett., 2014, 126, 281-284. 
84 P. Du, L. Song, J. Xiong, N. Li, Z. Xi, L. Wang, D. Jin, S. Guo and Y. Yuan, Electrochim. Acta, 2012, 78, 392-397.

85 D. Hwang, S. M. Jo, D. Y. Kim, V. Armel, D. R. MacFarlane and S.-Y. Jang, ACS Appl. Mater. Interfaces, 2011, 3, 15211527.

86 S. K. Ahn, T. Ban, P. Sakthivel, J. W. Lee, Y.-S. Gal, J.-K. Lee, M.-R. Kim and S.-H. Jin, ACS Appl. Mater. Interfaces, 2012, 4, 2096-2100.

87 J.-U. Kim, S.-H. Park, H.-J. Choi, W.-K. Lee, J.-K. Lee and M.-R. Kim, Sol. Energy Mater. Sol. Cells, 2009, 93, 803-807.

88 M. Sethupathy, P. Pandey and P. Manisankar, Mater. Chem. Phys., 2014, 143, 1191-1198.

89 M. A. K. L. Dissanayake, H. K. D. W. M. N. R. Divarathne, C. A. Thotawatthage, C. B. Dissanayake, G. K. R. Senadeera and B. M. R. Bandara, Electrochim. Acta, 2014, 130, 76-81.

90 P. Joshi, L. Zhang, Q. Chen, D. Galipeau, H. Fong and Q. Qiao, ACS Appl. Mater. Interfaces, 2010, 2, 3572-3577.

91 L. Li, P. Zhu, S. Peng, M. Srinivasan, Q. Yan, A. S. Nair, B. Liu and S. Samakrishna, J. Phys. Chem. C, 2014, DOI: 10.1021/jp4117529.

92 P. Poudel, L. Zhang, P. Joshi, S. Venkatesan, H. Fong and Q. Qiao, Nanoscale, 2012, 4, 4726-4730.

93 S. Peng, P. Zhu, Y. Wu, S. G. Mhaisalkar and S. Ramakrishna, RSC Adv., 2012, 2, 652-657.

94 S.-H. Park, H.-R. Jung, B.-K. Kim and W.-J. Lee, J. Photochem. Photobiol., A, 2012, 246, 45-49.

95 S. S. Mali, P. S. Patil and C. K. Hong, ACS Appl. Mater. Interfaces, 2014, 6, 1688-1696.

96 J. Kim, J. Kang, U. Jeong, H. Kim and H. Lee, ACS Appl. Mater. Interfaces, 2013, 5, 3176-3181.

97 S.-H. Park, H.-R. Jung and W.-J. Lee, Electrochim. Acta, 2013, 102, 423-428.

98 G. Zhu, L. Pan, J. Yang, X. Liu, H. Sun and Z. Sun, J. Mater. Chem., 2012, 22, 24326-24329.

99 Y.-F. Wang, K.-N. Li, W.-Q. Wu, Y.-F. Xu, H.-Y. Chen, C.-Y. Su and D.-B. Kuang, RSC Adv., 2013, 3, 13804-13810.

100 H.-Y. Chen, T.-L. Zhang, J. Fan, D.-B. Kuang and C.-Y. Su, ACS Appl. Mater. Interfaces, 2013, 5, 9205-9211.

101 J.-H. Lee, K. Ahn, S. H. Kim, J. M. Kim, S.-Y. Jeong, J.-S. Jin, E. D. Jeong and C.-R. Cho, Curr. Appl. Phys., 2014, 14, 856861.

102 J.-J. Wu, Y.-R. Chen, W.-P. Liao, C.-T. Wu and C.-Y. Chen, ACS Nano, 2010, 4, 5679-5684.

103 P. Zhu, A. S. Nair, S. Yang, S. Peng and S. Ramakrishna, J. Mater. Chem., 2011, 21, 12210-12212.

104 P. Joshi, L. Zhang, D. Davoux, Z. Zhu, D. Galipeau, H. Fong and Q. Qiao, Energy Environ. Sci., 2010, 3, 1507-1510.

105 Y.-L. Chen, Y.-H. Chang, J.-L. Huang, I. Chen and C. Kuo, J. Phys. Chem. C, 2012, 116, 3857-3865.

106 J. Yang, L. Pan, G. Zhu, X. Liu, H. Sun and Z. Sun, J. Electroanal. Chem., 2012, 677-680, 101-104.

107 R. A. Naphade, M. Tathavadekar, J. P. Jog, S. Agarkar and S. Ogale, J. Mater. Chem. A, 2014, 2, 975-984.

108 Y. Horie, M. Deguchi, S. Guo, K. Aoki and T. Nomiyama, Jpn. J. Appl. Phys., 2014, 53, 05FB01.
109 Y. Horie, T. Watanabe, M. Deguchi, D. Asakura and T. Nomiyama, Electrochim. Acta, 2013, 105, 394-402.

110 A. M. Smith and S. Nie, Acc. Chem. Res., 2010, 43, 190-200. 111 W. A. Tisdale, K. J. Williams, B. A. Timp, D. J. Norris, E. S. Aydil and X.-Y. Zhu, Science, 2010, 328, 1543-1547.

112 M.-J. Jin, T. Ma, T. Ling, S.-Z. Qiao and X.-W. Du, J. Mater. Chem., 2012, 22, 13057-13063.

113 Y. Shengyuan, A. S. Nair, Z. Peining and S. Ramakrishna, Mater. Lett., 2012, 76, 43-46.

114 P. Sudhagar, J. H. Jung, S. Park, Y.-G. Lee, R. Sathyamoorthy, Y. S. Kang and H. Ahn, Electrochem. Commun., 2009, 11, 2220-2224.

115 P. Sudhagar, V. González-Pedro, I. Mora-Seró, F. FabregatSantiago, J. Bisquert and Y. S. Kang, J. Mater. Chem., 2012, 22, 14228-14235.

116 H. Han, P. Sudhagar, T. Song, Y. Jeon, I. Mora-Seró, F. Fabregat-Santiago, J. Bisquert, Y. S. Kang and U. Paik, Chem. Commun., 2013, 49, 2810-2812.

117 W. Zhang, R. Zhu, X. Liu, B. Liu and S. Ramakrishna, Appl. Phys. Lett., 2009, 95, 043304.

118 S. Yun and S. Lim, J. Solid State Chem., 2011, 184, 273-279.

119 I.-D. Kim, J.-M. Hong, B. H. Lee, D. Y. Kim, E.-K. Jeon, D.-K. Choi and D.-J. Yang, Appl. Phys. Lett., 2007, 91, 163109.

120 E. N. Kumar, R. Jose, P. S. Archana, C. Vijila, M. M. Yusoff and S. Ramakrishna, Energy Environ. Sci., 2012, 5, 5401-5407.

121 T. Krishnamoorthy, M. Z. Tang, A. Verma, A. S. Nair, D. Pliszka, S. G. Mhaisalkar and S. Ramakrishna, J. Mater. Chem., 2012, 22, 2166-2172.

122 C. Gao, X. Li, X. Zhu, L. Chen, Z. Zhang, Y. Wang, Z. Zhang, H. Duan and E. Xie, J. Power Sources, 2014, 264, 15-21.

123 N. K. Elumalai, T. M. Jin, V. Chellappan, R. Jose, S. K. Palaniswamy, S. Jayaraman, H. K. Raut and S. Ramakrishna, ACS Appl. Mater. Interfaces, 2013, 5, 9396-9404.

124 N. M. Bedford, M. B. Dickerson, L. F. Drummy, H. Koerner, K. M. Singh, M. C. Vasudev, M. F. Durstock, R. R. Naik and A. J. Steckl, Adv. Energy Mater., 2012, 2, 1136-1144.

125 J.-Y. Chen, H.-C. Wu, Y.-C. Chiu and W.-C. Chen, Adv. Energy Mater., 2014, 4, 1301665.

126 S. Wu, J. Li, S.-C. Lo, Q. Tai and F. Yan, Org. Electron., 2012, 13, 1569-1575.

127 P. S. Kumar, S. A. S. Nizar, J. Sundaramurthy, P. Ragupathy, V. Thavasi, S. G. Mhaisalkar and S. Ramakrishna, J. Mater. Chem., 2011, 21, 9784-9790.

128 X. Zhang, V. Thavasi, S. G. Mhaisalkar and S. Ramakrishna, Nanoscale, 2012, 4, 1707-1716.

129 P. Du, L. Song, J. Xiong, N. Li, Z. Xi, L. Wang, D. Jin, S. Guo and Y. Yuan, Electrochim. Acta, 2012, 78, 392-397.

130 D. Hwang, S. M. Jo, D. Y. Kim, V. Armel, D. R. MacFarlane and S.-Y. Jang, ACS Appl. Mater. Interfaces, 2011, 3, 15211527.

131 B. H. Lee, M. Y. Song, S.-Y. Jang, S. M. Jo, S.-Y. Kwak and D. Y. Kim, J. Phys. Chem. C, 2009, 113, 21453-21457.

132 A. A. Madhavan, S. Kalluri, D. K. Chacko, T. A. Arun, S. Nagarajan, K. R. V. Subramanian, A. S. Nair, S. V. Nair and A. Balakrishnan, RSC Adv., 2012, 2, 13032-13037. 
133 S. Yun and S. Lim, J. Solid State Chem., 2011, 184, 273279.

134 E. N. Kumar, R. Jose, P. S. Archana, C. Vijila, M. M. Yusoff and S. Ramakrishna, Energy Environ. Sci., 2012, 5, 54015407.

135 Y. P. Lin, S. Y. Lin, Y. C. Lee and Y. W. Chen-Yang, J. Mater. Chem. A, 2013, 1, 9875-9884.

136 P. Zhu, A. S. Nair, S. Yang, S. Peng and S. Ramakrishna, J. Mater. Chem., 2011, 21, 12210-12212.

137 P. Joshi, L. Zhang, D. Davoux, Z. Zhu, D. Galipeau, H. Fong and Q. Qiao, Energy Environ. Sci., 2010, 3, 1507-1510.

138 P. Joshi, L. Zhang, Q. Chen, D. Galipeau, H. Fong and Q. Qiao, ACS Appl. Mater. Interfaces, 2010, 2, 3572-3577.

139 S. Peng, P. Zhu, Y. Wu, S. G. Mhaisalkar and S. Ramakrishna, RSC Adv., 2012, 2, 652-657.

140 S.-H. Park, H.-R. Jung, B.-K. Kim and W.-J. Lee, J. Photochem. Photobiol., A, 2012, 246, 45-49.

141 X. Hu, G. Li and J. C. Yu, Langmuir, 2010, 26, 3031-3039.

142 A. D. Paola, E. García-López, G. Marci and L. Palmisano, J. Hazard. Mater., 2012, 211-212, 3-29.

143 D. S. Bhatkhande, V. G. Pangarkar and A. A. C. M. Beenackers, J. Chem. Technol. Biotechnol., 2002, 77, 102-116.

144 M. R. Hoffmann, S. T. Martin, W. Choi and D. W. Bahnemann, Chem. Rev., 1995, 95, 69-96.

145 A. L. Linsebigler, G. Lu and J. T. Yates, Chem. Rev., 1995, 95, 735-758.

146 A. Fujishima and X. Zhang, C. R. Chim., 2006, 9, 750-760.

147 A. Kubacka, M. Fernández-García and G. Colón, Chem. Rev., 2011, 112, 1555-1614.

148 Y. N. Tan, C. L. Wong and A. R. Mohamed, ISRN Materials Science, 2011, 2011, 18.

149 V. A. Ganesh, A. S. Nair, H. K. Raut, T. M. Walsh and S. Ramakrishna, RSC Adv., 2012, 2, 2067-2072.

150 H. Liu, J. Yang, J. Liang, Y. Huang and C. Tang, J. Am. Ceram. Soc., 2008, 91, 1287-1291.

151 J. Sundaramurthy, P. S. Kumar, M. Kalaivani, V. Thavasi, S. G. Mhaisalkar and S. Ramakrishna, RSC Adv., 2012, 2, 8201-8208.

152 G. Zhao, S. Liu, Q. Lu and L. Song, Ind. Eng. Chem. Res., 2012, 51, 10307-10312.

153 V. J. Babu, R. S. R. Bhavatharini and S. Ramakrishna, RSC Adv., 2014, 4, 19251-19256.

154 V. J. Babu, R. S. R. Bhavatharini and S. Ramakrishna, RSC Adv., 2014, 4, 29957-29963.

155 V. J. Babu, S. Vempati and S. Ramakrishna, RSC Adv., 2014, 4, 27979-27987.

156 J. Mu, B. Chen, M. Zhang, Z. Guo, P. Zhang, Z. Zhang, Y. Sun, C. Shao and Y. Liu, ACS Appl. Mater. Interfaces, 2011, 4, 424-430.

157 D. Mitoraj and H. Kisch, Angew. Chem., Int. Ed., 2008, 47, 9975-9978.

158 D. Zhang, G. Li and J. C. Yu, Advanced Photocatalytic Nanomaterials for Degrading Pollutants and Generating Fuels by Sunlight, in Energy Efficiency and Renewable Energy Through Nanotechnology, ed. L. Zang, Springer London, 2011, pp. 679-716.
159 J.-Y. Park, K.-J. Hwang, J.-W. Lee and I.-H. Lee, J. Mater. Sci., 2011, 46, 7240-7246.

160 E. Formo, M. S. Yavuz, E. P. Lee, L. Lane and Y. Xia, J. Mater. Chem., 2009, 19, 3878-3882.

161 Z. Zhang, C. Shao, L. Zhang, X. Li and Y. Liu, J. Colloid Interface Sci., 2010, 351, 57-62.

162 J. Xu, W. Wang, M. Shang, E. Gao, Z. Zhang and J. Ren, J. Hazard. Mater., 2011, 196, 426-430.

163 D. Lin, H. Wu, R. Zhang and W. Pan, Chem. Mater., 2009, 21, 3479-3484.

164 C. H. Kim, B.-H. Kim and K. S. Yang, Carbon, 2012, 50, 2472-2481.

165 L. Li, P. Zhang, R. Liu and S. M. Guo, J. Power Sources, 2011, 196, 1242-1247.

166 P. Zhang, C. Shao, Z. Zhang, M. Zhang, J. Mu, Z. Guo, Y. Sun and Y. Liu, J. Mater. Chem., 2011, 21, 1774617753.

167 R. Asahi, T. Morikawa, T. Ohwaki, K. Aoki and Y. Taga, Science, 2001, 293, 269-271.

168 Y. Zhang, L. Fei, X. Jiang, C. Pan and Y. Wang, J. Am. Ceram. Soc., 2011, 94, 4157-4161.

169 Y. Wang, J. Zhang, L. Liu, C. Zhu, X. Liu and Q. Su, Mater. Lett., 2012, 75, 95-98.

170 R. Liu, H. Ye, X. Xiong and H. Liu, Mater. Chem. Phys., 2010, 121, 432-439.

171 M. Shang, W. Wang, L. Zhang, S. Sun, L. Wang and L. Zhou, J. Phys. Chem. C, 2009, 113, 14727-14731.

172 Z. Zhang, C. Shao, X. Li, C. Wang, M. Zhang and Y. Liu, ACS Appl. Mater. Interfaces, 2010, 2, 2915-2923.

173 Z. Liu, D. D. Sun, P. Guo and J. O. Leckie, Nano Lett., 2006, 7, 1081-1085.

174 H. Li, W. Zhang, B. Li and W. Pan, J. Am. Ceram. Soc., 2010, 93, 2503-2506.

175 D. Ma, Y. Xin, M. Gao and J. Wu, Appl. Catal., B, 2014, 147, 49-57.

176 C.-J. Li, J.-N. Wang, B. Wang, J. R. Gong and Z. Lin, J. Nanosci. Nanotechnol., 2012, 12, 2496-2502.

177 S. S. Lee, H. Bai, Z. Liu and D. D. Sun, Water Res., 2013, 47, 4059-4073.

178 G. Yang, Q. Zhang, W. Chang and W. Yan, J. Alloys Compd., 2013, 580, 29-36.

179 X. Peng, A. C. Santulli, E. Sutter and S. S. Wong, Chem. Sci., 2012, 3, 1262-1272.

180 I. M. Szilágyi, E. Santala, M. Heikkilä, V. Pore, M. Kemell, T. Nikitin, G. Teucher, T. Firkala, L. Khriachtchev, M. Räsänen, M. Ritala and M. Leskelä, Chem. Vap. Deposition, 2013, 19, 149-155.

181 P. Zhang, C. Shao, X. Li, M. Zhang, X. Zhang, Y. Sun and Y. Liu, J. Hazard. Mater., 2012, 237-238, 331-338.

182 P. F. Du, L. X. Song, J. Xiong, Z. Q. Xi, J. J. Chen, L. H. Gao and N. Y. Wang, J. Nanosci. Nanotechnol., 2011, 11, 77237728.

183 P. Ren, H. Fan and X. Wang, Catal. Commun., 2012, 25, 3235.

184 J. Mu, C. Shao, Z. Guo, Z. Zhang, M. Zhang, P. Zhang, B. Chen and Y. Liu, ACS Appl. Mater. Interfaces, 2011, 3, 590-596. 
185 Z. Wang, Z. Li, H. Zhang and C. Wang, Catal. Commun., 2009, 11, 257-260.

186 J. S. Lee, O. S. Kwon and J. Jang, J. Mater. Chem., 2012, 22, 14565-14572.

187 M. Samadi, H. A. Shivaee, M. Zanetti, A. Pourjavadi and A. Moshfegh, J. Mol. Catal. A: Chem., 2012, 359, 42-48.

188 C. Li, R. Chen, X. Zhang, S. Shu, J. Xiong, Y. Zheng and W. Dong, Mater. Lett., 2011, 65, 1327-1330.

189 Y. Liu, H. Yu, S. Zhan, Y. Li, Z. Lv, X. Yang and Y. Yu, J. SolGel Sci. Technol., 2011, 58, 716-723.

190 S. Zhan, J. Yang, Y. Liu, N. Wang, J. Dai, H. Yu, X. Gao and Y. Li, J. Colloid Interface Sci., 2011, 355, 328-333.

191 D. Hou, W. Luo, Y. Huang, J. C. Yu and X. Hu, Nanoscale, 2013, 5, 2028-2035.

192 G. Zhao, S. Liu, Q. Lu, M. Shi and L. Song, J. Cluster Sci., 2011, 22, 621-631.

193 B. Dong, Z. Li, Z. Li, X. Xu, M. Song, W. Zheng, C. Wang, S. S. Al-Deyab and M. El-Newehy, J. Am. Ceram. Soc., 2010, 93, 3587-3590.

194 X. Wang, H. Fan and P. Ren, Catal. Commun., 2013, 31, 3741.

195 V. Štengl, J. Velická, M. Maříková and T. M. Grygar, ACS Appl. Mater. Interfaces, 2011, 3, 4014-4023.

196 M. Kanjwal, N. Barakat, F. Sheikh and H. Kim, J. Mater. Sci., 2010, 45, 1272-1279.

197 Z. Zhang, C. Shao, X. Li, L. Zhang, H. Xue, C. Wang and Y. Liu, J. Phys. Chem. C, 2010, 114, 7920-7925.

198 T. Cao, Y. Li, C. Wang, L. Wei, C. Shao and Y. Liu, Mater. Res. Bull., 2010, 45, 1406-1412.

199 M. Jin, X. Zhang, A. V. Emeline, Z. Liu, D. A. Tryk, T. Murakami and A. Fujishima, Chem. Commun., 2006, 4483-4485.

200 A. Ma, Y. Wei, Z. Zhou, W. Xu, F. Ren, H. Ma and J. Wang, Polym. Degrad. Stab., 2012, 97, 125-131.

201 A. Yousef, N. A. M. Barakat, T. Amna, A. R. Unnithan, S. S. Al-Deyab and H. Yong Kim, J. Lumin., 2012, 132, 1668-1677.

202 P. V. Kamat, J. Phys. Chem. C, 2008, 112, 18737-18753.

203 N. Han, F. Wang and J. C. Ho, Nanomater. Energy, 2012, 1(1), 4-17.

204 E. C. Garnett and P. Yang, J. Am. Chem. Soc., 2008, 130, 9224-9225.

205 L. Tsakalakos, J. Balch, J. Fronheiser, B. A. Korevaar, O. Sulima and J. Rand, Appl. Phys. Lett., 2007, 91, 233117.

206 A. C. Ford, J. C. Ho, Y.-L. Chueh, Y.-C. Tseng, Z. Fan, J. Guo, J. Bokor and A. Javey, Nano Lett., 2009, 9, 360-365.

207 K. Takei, T. Takahashi, J. C. Ho, H. Ko, A. G. Gillies, P. W. Leu, R. S. Fearing and A. Javey, Nat. Mater., 2010, 9, 821-826.

208 H. Yan, H. S. Choe, S. W. Nam, Y. Hu, S. Das, J. F. Klemic, J. C. Ellenbogen and C. M. Lieber, Nature, 2011, 470, 240244.

209 R. Yan, D. Gargas and P. Yang, Nat. Photonics, 2009, 3, 569576.

210 N. S. Lewis, Science, 2007, 315, 798-801.
211 Y.-Z. Long, M. Yu, B. Sun, C.-Z. Gu and Z. Fan, Chem. Soc. Rev., 2012, 41, 4560-4580.

212 G. Dong, X. Xiao, L. Zhang, Z. Ma, X. Bao, M. Peng, Q. Zhang and J. Qiu, J. Mater. Chem., 2011, 21, 2194-2203.

213 A. Babel, D. Li, Y. Xia and S. A. Jenekhe, Macromolecules, 2005, 38, 4705-4711.

214 P. Ahmadpoor, A. S. Nateri and V. Motaghitalab, J. Appl. Polym. Sci., 2013, 130, 78-85.

215 L. Gao and C. Li, J. Lumin., 2010, 130, 236-239.

216 M. M. Munir, F. Iskandar, K. M. Yun, K. Okuyama and M. Abdullah, Nanotechnology, 2008, 19, 145603.

217 J.-Y. Chen, C.-C. Kuo, C.-S. Lai, W.-C. Chen and H.-L. Chen, Macromolecules, 2011, 44, 2883-2892.

218 Y. Shmueli, G. E. Shter, O. Assad, H. Haick, P. Sonntag, P. Ricoux and G. S. Grader, J. Mater. Res., 2012, 27, 16721679.

219 A. Kumar, R. Jose, K. Fujihara, J. Wang and S. Ramakrishna, Chem. Mater., 2007, 19, 6536-6542.

220 D. Hou, X. Hu, Y. Wen, B. Shan, P. Hu, X. Xiong, Y. Qiao and Y. Huang, Phys. Chem. Chem. Phys., 2013, 15, 20698-20705.

221 S. Chuangchote, J. Jitputti, T. Sagawa and S. Yoshikawa, ACS Appl. Mater. Interfaces, 2009, 1, 1140-1143.

222 E. C. Garnett, M. L. Brongersma, Y. Cui and M. D. McGehee, Annu. Rev. Mater. Res., 2011, 41, 269-295.

223 A. I. Hochbaum and P. Yang, Chem. Rev., 2010, 110, 527546.

224 B. Tan and Y. Wu, J. Phys. Chem. B, 2006, 110, 15932-15938.

225 Z.-S. Wang, H. Kawauchi, T. Kashima and H. Arakawa, Coord. Chem. Rev., 2004, 248, 1381-1389.

226 Y.-J. Lee, D. S. Ruby, D. W. Peters, B. B. McKenzie and J. W. P. Hsu, Nano Lett., 2008, 8, 1501-1505.

227 A. Fujishima and K. Honda, Nature, 1972, 238, 37-38.

228 M. Ni, M. K. H. Leung, D. Y. C. Leung and K. Sumathy, Renewable Sustainable Energy Rev., 2007, 11, 401-425.

229 M. Ashokkumar, Int. J. Hydrogen Energy, 1998, 23, 427-438. 230 A. Kudo and Y. Miseki, Chem. Soc. Rev., 2009, 38, 253-278.

231 O. Diwald, T. L. Thompson, T. Zubkov, E. G. Goralski, S. D. Walck and J. T. Yates Jr, J. Phys. Chem. B, 2004, 108, 6004-6008.

232 X. Chen and C. Burda, J. Phys. Chem. B, 2004, 108, 1544615449.

233 R. Asahi and T. Morikawa, Chem. Phys., 2007, 339, 57-63.

234 T. Ohsawa, I. Lyubinetsky, Y. Du, M. A. Henderson, V. Shutthanandan and a. S. A. Chambers, Phys. Rev. B: Condens. Matter Mater. Phys., 2009, 79, 085401.

235 J. H. Ming-Chung Wu, A. Sápi, A. Avila, W. Larsson, H.-C. Liao, M. Huuhtanen, G. Tóth, A. Shchukarev, N. Laufer, Á. Kukovecz, Z. Kónya, J.-P. Mikkola, R. Keiski, W.-F. Su, H. J. Yang-Fang Chen, P. M. Ajayan, R. Vajtai and K. Kordás, ACS Nano, 2011, 5, 5025-5030.

236 J. B. Varley, A. Janotti and C. G. V. d. Walle, Adv. Mater., 2011, 23, 2343-2347.

237 X. Sun, H. Liu, J. Dong, J. Wei and Y. Zhang, Catal. Lett., 2010, 135, 219-225.

238 A. Chinnappan and H. Kim, Int. J. Hydrogen Energy, 2012, 37, 18851-18859. 
239 S. S. Lee, H. Bai, Z. Liu and D. D. Sun, Appl. Catal., B, 2013, 140, 68-81.

240 J. Jitputti, Y. Suzuki and S. Yoshikawa, Catal. Commun., 2008, 9, 1265-1271.

241 X. Chen, S. Shen, L. Guo and a. S. S. Mao, Chem. Rev., 2010, 110, 6503-6570.

242 H. Bai, Z. Liu and D. D. Sun, J. Am. Ceram. Soc., 2013, 96, 942-949.

243 S. S. Lee, H. Bai, Z. Liu and D. D. Sun, Int. J. Hydrogen Energy, 2012, 37, 10575-10584.

244 Y. Tong, X. Lu, W. Sun, G. Nie, L. Yang and C. Wang, J. Power Sources, 2014, 261, 221-226.

245 K. Maeda, K. Teramura, D. Lu, T. Takata, N. Saito, Y. Inoue and K. Domen, Nature, 2006, 440, 295.

246 X. Chen, C. Li, M. Gratzel, R. Kostecki and S. S. Mao, Chem. Soc. Rev., 2012, 41, 7909-7937.

247 V. J. Babu, M. K. Kumar, R. Murugan, M. M. Khin, R. P. Rao, A. S. Nair and S. Ramakrishna, Int. J. Hydrogen Energy, 2013, 38, 4324-4333.

248 S. K. Choi, S. Kim, J. Ryu, S. K. Limb and H. Park, Photochem. Photobiol. Sci., 2012, 11, 1437-1444.

249 V. J. Babu, M. K. Kumar, A. S. Nair, T. K. Lee, I. A. Suleyman and S. Ramakrishna, Int. J. Hydrogen Energy, 2012, 37, 88978904.

250 L. Macaraig, S. Chuangchote and T. Sagawa, J. Mater. Res., 2014, 29, 123-130.

251 L. Zhang, J. Kim, E. Dy, S. Ban, K.-c. Tsay, H. Kawai and Z. Shi, Electrochim. Acta, 2013, 108, 480-485.

252 J.-Y. Jhan, Y.-W. Huang, C.-H. Hsu, H. Teng, D. Kuo and P.-L. Kuo, Energy, 2013, 53, 282-287.

253 N. Jha, P. Ramesh, E. Bekyarova, X. Tian, F. Wang, M. E. Itkis and R. C. Haddon, Sci. Rep., 2013, 3, 1-7.

254 S. H. Hur and J.-N. Park, Asia-Pac. J. Chem. Eng., 2013, 8, 218-233.

255 R. Kumar, C. Xu and K. Scott, RSC Adv., 2012, 2, 8777-8782. 256 X. Li, W. Cai, J. An, S. Kim, J. Nah, D. Yang, R. Piner, A. Velamakanni, I. Jung, E. Tutuc, S. K. Banerjee, L. Colombo and R. S. Ruoff, Science, 2009, 324, 13121314.

257 J. B. Ballengee and P. N. Pintauro, Macromolecules, 2011, 44, 7307-7314.

258 T. Tamura and H. Kawakami, Nano Lett., 2010, 10, 13241328.

259 W. Li, X. Wang, Z. Chen, M. Waje and Y. Yushan, Langmuir, 2005, 21, 9386-9389.

260 J. M. Kim, H.-I. Joh, S. M. Jo, D. J. Ahn, H. Y. Ha, S.-A. Hong and S.-K. Kim, Electrochim. Acta, 2010, 55, 4827-4835.

261 L. Su, W. Jia, A. Schempf, Y. Ding and Y. Lei, J. Phys. Chem. C, 2009, 113, 16174-16180.

262 D. Chen, Y.-E. Miao and T. Liu, ACS Appl. Mater. Interfaces, 2013, 5, 1206-1212.

263 W. J. Kim and J. Y. Chang, Mater. Lett., 2011, 65, 13881391.

264 N. T. Xuyen, E. J. Ra, H.-Z. Geng, K. K. Kim, K. H. An and Y. H. Lee, J. Phys. Chem. B, 2007, 111, 11350-11353.

265 J.-H. Park, Y.-W. Ju, S.-H. Park, H.-R. Jung, K.-S. Yang and W.-J. Lee, J. Appl. Electrochem., 2009, 39, 1229-1236.
266 M. Li, S. Zhao, G. Han and B. Yang, J. Power Sources, 2009, 191, 351-356.

267 M. Li, G. Han and B. Yang, Electrochem. Commun., 2008, 10, $880-883$.

268 Z. Lin, L. Ji and X. Zhang, Electrochim. Acta, 2009, 54, 70427047.

269 B. Guo, S. Zhao, G. Han and L. Zhang, Electrochim. Acta, 2008, 53, 5174-5179.

270 N. T. Xuyen, H. K. Jeong, G. Kim, K. P. So, K. H. An and Y. H. Lee, J. Mater. Chem., 2009, 19, 1283-1288.

271 Z. Lin, L. Ji, M. D. Woodroof, Y. Yao, W. Krause and X. Zhang, J. Phys. Chem. C, 2010, 114, 3791-3797.

272 D. Wang, Y. Liu, J. Huang and T. You, J. Colloid Interface Sci., 2012, 367, 199-203.

273 L. Su, W. Jia, A. Schempf and Y. Lei, Electrochem. Commun., 2009, 11, 2199-2202.

274 Z.-G. Zhao, Z.-J. Yao, J. Zhang, R. Zhu, Y. Jin and Q.-W. Li, J. Mater. Chem., 2012, 22, 16514-16519.

275 E. Formo, Z. Peng, E. Lee, X. Lu, H. Yang and Y. Xia, J. Phys. Chem. C, 2008, 112, 9970-9975.

276 Z. Lin, L. Ji, O. Toprakci, W. Krause and X. Zhang, J. Mater. Res., 2010, 25, 1329-1335.

277 S. K. Nataraj, B. H. Kim, J. H. Yun, D. H. Lee, T. M. Aminabhavi and K. S. Yang, Synth. Met., 2009, 159, 1496-1504.

278 C. Tekmen, Y. Tsunekawa and H. Nakanishi, J. Mater. Process. Technol., 2010, 210, 451-455.

279 N. Seki, T. Arai, Y. Suzuki and H. Kawakami, Polymer, 2012, 53, 2062-2067.

280 Y. Chang, G. Han, M. Li and F. Gao, Carbon, 2011, 49, 51585165.

281 S. Chen, G. He, A. A. Carmona-Martinez, S. Agarwal, A. Greiner, H. Hou and U. Schröder, Electrochem. Commun., 2011, 13, 1026-1029.

282 S. Chen, H. Hou, F. Harnisch, S. A. Patil, A. A. CarmonaMartinez, S. Agarwal, Y. Zhang, S. Sinha-Ray, A. L. Yarin, A. Greiner and U. Schröder, Energy Environ. Sci., 2011, 4, 1417-1421.

283 M. Ghasemi, S. Shahgaldi, M. Ismail, B. H. Kim, Z. Yaakob and W. R. W. Daud, Int. J. Hydrogen Energy, 2011, 36, 1374613752.

284 Y. Zhang and A. L. Yarin, Langmuir, 2011, 27, 1462714631.

285 Y. Ding, W. Jia, H. Zhang, B. Li, Z. Gu and Y. Lei, Electroanalysis, 2010, 22, 1911-1917.

286 P. Schechner, E. Kroll, E. Bubis, S. Chervinsky and E. Zussman, J. Electrochem. Soc., 2007, 154, B942-B948.

287 J. Choi, K. M. Lee, R. Wycisk, P. N. Pintauro and P. T. Mather, J. Electrochem. Soc., 2010, 157, B914-B919.

288 M. Zhi, S. Lee, N. Miller, N. H. Menzler and N. Wu, Energy Environ. Sci., 2012, 5, 7066-7071.

289 N. T. Hieu, J. Park and B. Tae, Mater. Sci. Eng., B, 2012, 177, 205-209.

290 A. M. Al-Enizi, A. A. Elzatahry, A.-R. I. Soliman and S. S. AlTheyab, Int. J. Electrochem. Sci., 2012, 7, 12646-12655.

291 S. Martwiset and K. Jaroensuk, J. Appl. Polym. Sci., 2012, 124, 2594-2600. 
292 J. Choi, K. M. Lee, R. Wycisk, P. N. Pintauro and P. T. Mather, J. Mater. Chem., 2010, 20, 6282-6290.

293 C. Alessandra, S. Ada, B. Concetta, F. Patrizia, A. P. Luigi and P. Enza, J. Nanosci. Nanotechnol., 2011, 11, 8768-8774.

294 R. Bajon, S. Balaji and S. M. Guo, J. Fuel Cell Sci. Technol., 2009, 6, 031004.

295 J. B. Ballengee and P. N. Pintauro, J. Electrochem. Soc., 2011, 158, B568-B572.

296 I. Shabani, M. M. Hasani-Sadrabadi, V. Haddadi-Asl and M. Soleimani, J. Membr. Sci., 2011, 368, 233-240.

297 M. M. Hasani-Sadrabadi, I. Shabani, M. Soleimani and H. Moaddel, J. Power Sources, 2011, 196, 4599-4603.
298 S. W. Choi, Y. Z. Fu, Y. R. Ahn, S. M. Jo and A. Manthiram, J. Power Sources, 2008, 180, 167-171.

299 T. Tamura, R. Takemori and H. Kawakami, J. Power Sources, 2012, 217, 135-141.

300 S. Subianto, S. Cavaliere, D. J. Jones and J. Rozière, J. Polym. Sci., Part A: Polym. Chem., 2013, 51, 118-128.

301 W. Liu, S. Wang, M. Xiao, D. Han and Y. Meng, Chem. Commun., 2012, 48, 3415-3417.

302 Y. Yao, Z. Lin, Y. Li, M. Alcoutlabi, H. Hamouda and X. Zhang, Adv. Energy Mater., 2011, 1, 1133-1140.

303 Y. Yao, L. Ji, Z. Lin, Y. Li, M. Alcoutlabi, H. Hamouda and X. Zhang, ACS Appl. Mater. Interfaces, 2011, 3, 3732-3737. 